Article

\title{
An Assessment of Onshore and Offshore Wind Energy Potential in India Using Moth Flame Optimization
}

\author{
Krishnamoorthy $\mathbf{R}^{1}$,*, Udhayakumar $\mathbf{K}^{1}$, Kannadasan Raju ${ }^{2}$, \\ Rajvikram Madurai Elavarasan $2, *$ (D) and Lucian Mihet-Popa $3, *$ (D) \\ 1 Department of Electrical and Electronics Engineering, College of Engineering Guindy, Anna University, \\ Chennai 600025, India; k_udhayakumar@annauniv.edu \\ 2 Department of Electrical and Electronics Engineering, Sri Venkateswara College of Engineering, \\ Tamil Nadu 602117, India; kannadasanr@svce.ac.in \\ 3 Faculty of Electrical Engineering, Ostfold University College, No-1757 Halden, Norway \\ * Correspondence: krimoindia@gmail.com (K.R.); rajvikram787@gmail.com (R.M.E.); \\ lucian.mihet@hiof.no (L.M.-P.)
}

Received: 24 May 2020; Accepted: 11 June 2020; Published: 13 June 2020

\begin{abstract}
Wind energy is one of the supremely renewable energy sources and has been widely established worldwide. Due to strong seasonal variations in the wind resource, accurate predictions of wind resource assessment and appropriate wind speed distribution models (for any location) are the significant facets for planning and commissioning wind farms. In this work, the wind characteristics and wind potential assessment of onshore, offshore, and nearshore locations of India-particularly Kayathar in Tamilnadu, the Gulf of Khambhat, and Jafrabad in Gujarat-are statistically analyzed with wind distribution methods. Further, the resource assessments are carried out using Weibull, Rayleigh, gamma, Nakagami, generalized extreme value (GEV), lognormal, inverse Gaussian, Rician, Birnbaum-Sandras, and Bimodal-Weibull distribution methods. Additionally, the advent of artificial intelligence and soft computing techniques with the moth flame optimization (MFO) method leads to superior results in solving complex problems and parameter estimations. The data analytics are carried out in the MATLAB platform, with in-house coding developed for MFO parameters estimated through optimization and other wind distribution parameters using the maximum likelihood method. The observed outcomes show that the MFO method performed well on parameter estimation. Correspondingly, wind power generation was shown to peak at the South West Monsoon periods from June to September, with mean wind speeds ranging from 9 to $12 \mathrm{~m} / \mathrm{s}$. Furthermore, the wind speed distribution method of mixed Weibull, Nakagami, and Rician methods performed well in calculating potential assessments for the targeted locations. Likewise, the Gulf of Khambhat (offshore) area has steady wind speeds ranging from 7 to $10 \mathrm{~m} / \mathrm{s}$ with less turbulence intensity and the highest wind power density of 431 watts $/ \mathrm{m}^{2}$. The proposed optimization method proves its potential for accurate assessment of Indian wind conditions in selected locations.
\end{abstract}

Keywords: bimodal; India; mixed; offshore; statistical analysis; Weibull; wind speed distribution

\section{Introduction}

As populations and technological developments grow, the need for electricity consumption also increases, which impacts the environmental pollution conditions based on the type of fuels used for power generation. Remarkably, the fossil fuel-based generation from coal and oil threatens the climatic conditions due to its pollution particles (suspended in the air) which increase carbon emission greatly. As per the Paris Agreement commitments, the rising magnitude of average global temperature should be maintained at about $1.5^{\circ} \mathrm{C}$. Therefore, the Indian government has set an ambitious target to achieve 
$60 \mathrm{GW}$ of wind capacity with a total of $175 \mathrm{GW}$ of renewable energy capacity by 2022 [1], because it has always been a prominent country in terms of renewable energy aspects-especially wind and solar [2,3]. Presently, onshore wind energy extends its contribution about 37.69 GW as of March 2020 [4]. Moreover, India has a long coastline of nearly $7600 \mathrm{~km}$ with relatively shallow waters near shore. There are also some significant states in India, where wind energy resource was a vital source and whose wind potential is also high $[5,6]$. It displays the great potential of offshore wind energy specifically on the coast of Gujarat and Tamil Nadu. Recently, the Indian government has announced its target of installing $5 \mathrm{GW}$ and $30 \mathrm{GW}$ of offshore wind installations by 2022 and 2030 respectively [7]. Globally, the offshore and onshore wind power capacity of $23.14 \mathrm{GW}$ and $568.409 \mathrm{GW}$ is achieved respectively (as on 2018) [8]. The main drive force to install the wind turbines in onshore and offshore areas is the profound analysis of wind characteristics and its potential in the target locations. Generally, the study of wind characteristics is made through local site surveys by installing anemometers, pressure sensors, temperature sensors, humidity sensors, and LiDAR (Light detection and ranging) wind measurements (for coastal and mast areas) for minimum of one year. Moreover, the ground level measurements are taken as primary data for accuracy over satellite data. For additional wind potential history for elongated years, neighboring stations like airports and nearby wind stations are taken for reference [9].

Several research studies on wind resource assessment are carried out by relating numerous probability density functions (PDF) to identify the most effectual fitting measurement. Predominantly, Weibull and Rayleigh are the top distributions methods used in most research works. Notably, the Weibull method is incorporated in the commercially available wind analysis software. Don et al. [10] related various approaches of Weibull parameters estimation in fitting with Jeju Island, South Korea using moment and energy pattern method. Moreover, Pobočíková et al. [11] have assessed the appropriateness of distributions of two and three parameter Weibull, gamma, and lognormal in fitting the wind speed distribution in Slovakia and described the usefulness of three-parameter Weibull (best distribution method). Additionally, Yilmaz and Heçeli [12] compared the effectiveness of ten PDFs namely, Erlang, beta, exponential, log-logistic, lognormal, gamma, Pearson V, Pearson VI, Weibull, and uniform. Wherein, Weibull claimed its potential to be the best one to fit the wind speed distribution in the Aegean region in Turkey. Moreover, Paula-Andrea et al. [13] performed the analysis with Weibull, Rayleigh, gamma, and lognormal and goodness of fitness with $\mathrm{R}^{2}$ (correlation coefficient), RMSE (root mean square error), KS (Kolmogorov-Smirnov), index of agreements (Index-A) and wind power density (WPD) fit error methods to attain the best fit. Additionally, Hayriye et al. analyzed the performance of Weibull, lognormal, and gamma using five-year data and concluded that gamma was a good fit. Further, Mohammad at el. [14] evaluated ten wind speed distributions in eight selected locations with vertical axis turbines in low wind speed area in Cyprus and determined that the GEV (generalized extreme value) performed better compared with other distribution methods.

In contradiction to the existing report that supports the Weibull method (as best fit), Fatma et al. [15] examined the usefulness of inverse Weibull (IW), Burr-III extreme value (EV), gamma, inverse gamma (IG), GEV, exponentiated Weibull (EW) and Rayleigh distributions to find the alternative method over Weibull. Further, Morgan et al. [15] assessed the wind speed distribution method at 178 stations in the United States and established that the bimodal Weibull stretches the best results. Additionally, Emilo et al. [16] examined the bimodality method by selecting the number of components in the mixture through two well-known criteria likely Akaike information criterion (AIC) and the Bayesian information criterion (BIC). Finally, the optimal number of Weibull components for maximum likelihood is discovered for the defined patterns with the estimated weight, scale, and shape parameters. The observed outcome displayed that the multi-Weibull models are more suitable. Tian et al. [17] assessed the parameters using bimodal Weibull function (BW), truncated normal Weibull function $(\mathrm{NW})$, gamma-Weibull function (GW), mixture truncated normal function (NN), two parameter Weibull and maximum entropy principle (MEP) method-in which, the MEP and GW methods performed well among others. Ravindra et al. [18] evaluated the Weibull-extreme value distribution, Weibull-lognormal, and GEV-lognormal and stated that the Weibull-GEV model performed fine in 
unimodal and bimodal wind distributions. Ijjou et al. [19] evaluated Weibull, Rayleigh, gamma, and lognormal method and reported that the Weibull is the best fit.

Consolidating the literature studies on different wind distributions discussed above, the accuracy of the wind distribution histograms is not satisfactory. It is known fact that the accurate parameter estimation using wind distribution methods is the key factor for wind potential analysis. The recent developments of artificial intelligence with soft computing techniques offer better optimization of resources and parameter estimation for complex tasks through optimization methods. Generally, the optimization methods are based on the inspiration activities of humans, birds, and animals. Consequently, this work targets on estimating the parameters of bimodal Weibull-Weibull distribution for matching the wind distribution profile using moth flame optimization (MFO). The MFO is a population-based optimization method with the combination of moths and flames modelling. The main task for using optimization techniques is to overcome the shortfalls of conventional parameter estimation through the maximum likelihood method for accurate wind resource assessment. Considering all these reports, this work focuses on wind characteristics and wind distribution methodologies using the wind data observed from onshore location (Kayathar, TamilNadu, India) and offshore location (Gulf of Khambhat, Gujarat, India) along with the nearshore location (Jafrabad, Gujarat, India) for analysis. Several research activities had been carried out on onshore and offshore locations, but not many on the nearshore landscape. Hence, this work chiefly focuses on the analysis of wind behaviors in onshore, nearshore, and offshore areas [20] by comparing the obtained results. Ten numbers of wind speed distributions methods are considered for analysis along with unimodal conventional distributions from Weibull [21], Rayleigh, gamma, Nakagami, generalized extreme value, lognormal, inverse Gaussian, Rician and Birnbaum-Sandras [22] and bimodal-WW for wind resource assessment. The presentation of each method is estimated by the RMSE and $\mathrm{R}^{2}$ tests [23]. The bimodal Weibull and Weibull (WW) probability distribution function (PDF) has been adopted to analyze the wind speed distribution in targeted locations [24]. Moreover, the influences of bimodality [25] in the targeted locations are analyzed. Likewise, the mixed Weibull method is also used because their relative percentage error of wind potential energy is not exceeding $0.1 \%$ compared to theoretical values [26]. The outcome of this method and procedure support the effective deployment of onshore and offshore wind farms.

This paper is organized as follows: Section 2 describes the wind characteristics parameters, and wind speed distribution methods used for the analysis and goodness of fitness methods to evaluate the best wind distribution. Subsequently, Section 3 defines the wind site location information for the analysis and optimization method. Further, Section 4 labels the detailed results of wind characteristics analysis and complete examination of ten wind distribution methods with parameters estimated through maximum likelihood (MLM) and goodness of probability density wind. Further, it describes the application of moth flame optimization analysis results with wind power density analysis of selected locations along with detailed research findings of each location.

\section{Wind Data Analysis Methods}

Wind speeds in specific locations are subject to variation by the time of day, seasonal, and weather events due to the uneven heating of the earth's surface. As well, the wind resource is varying (increase or decrease or made turbulent) by factors such as hilly area, bodies of water, buildings, and vegetative lands. The wind data analysis of different landscapes such as onshore, nearshore, and offshore is carried out in the subsequent sections. Later, wind characteristics, wind distribution fitting, and wind power densities are presented for the selected locations.

\subsection{Wind Characteristics Parameters}

Ground-level wind parameters are measured by meteorological instruments mounted on tall towers and other modern instruments like LiDAR and SODAR (Sonic detection and ranging) [27]. They act as a primary-data collection sensors for most wind resource assessment. The key parameters 
for any wind monitoring program are wind speed, wind direction, and air temperature. The parameters normally measured in a wind location are as follows:

- Average, standard deviation, minimum and maximum wind speed $(\mathrm{m} / \mathrm{s})$ are measured for wind generation suitability assessment, and turbine selection.

- Average, standard deviation and maximum gust direction (degrees) are estimated for optimizing wind turbines and understand the spatial distribution of wind

- Temperature $\left({ }^{\circ} \mathrm{C}\right)$ and vertical wind speed $(\mathrm{m} / \mathrm{s})$ are used for the air density and turbulence application respectively to measure the average and minimum/maximum value.

- Average, standard deviation and minimum/maximum value of barometric pressure ( $\mathrm{kPa})$ are measured for air density applications

- Relative humidity (\%) and solar radiation $\left(\mathrm{W} / \mathrm{m}^{2}\right.$ ) (average, minimum/maximum value) are measured for the icing and atmospheric analysis respectively.

\subsection{Wind Speed Distribution Methods}

The wind speed and its frequency of occurrence to form a wind distribution pattern is a critical piece of information. They are used to evaluate the power output of the wind turbine directly. The frequency of wind distribution denotes the number of intervals during period of data collected when the perceived wind speed falls within specific bins. They are normally occurred about 0.5 or $1 \mathrm{~m} / \mathrm{s}$ space. They cover a minimum range of speeds described for the turbine power curve, i.e., 0 to $25 \mathrm{~m} / \mathrm{s}$ and even more. The usual reports are presented in the bar chart/histogram and input as a table for software analysis. The probability density function is a mathematical one that visualizes the probable pattern of wind speed, which is random by nature in a continuous period. The detailed wind distribution models for the calculation of probability density function and cumulative distribution function [14] are presented in Appendix B.

\subsection{Goodness of Fit}

The goodness of fit is a statistical analysis method for qualifying the ten wind probability distributions considered for evaluation to match with actual data measured. The best scored root mean square error (RMSE) and correlation coefficient $\left(R^{2}\right)$ [11] finds the best fit wind distribution method for the defined location. They are used to determine the fitness of ten distributions. These can be calculated as follows:

\subsubsection{Root Mean Square Value (RMSE)}

RMSE estimate the residuals of the frequency of examined PDF (Probability density function) and the measured data.

$$
\text { RMSE }=\left[\frac{1}{n} \sum_{i=1}^{n}\left(y_{i}-x_{i}\right)^{2}\right]^{0.5}
$$

where $y_{i}$ is the observed data plotted in a histogram, $n$ stands for the number of bins and $x_{i}$ is an estimated PDF of wind distribution considered for evaluation. The evaluated RMSE value should be close to zero to form a best fit.

\subsubsection{The Coefficient of Determination $\left(R^{2}\right)$}

The $\mathrm{R}^{2}$ evaluates the linear correlation between predicted values from PDF functions and measured data.

$$
R^{2}=1-\frac{\sum_{i=1}^{n}\left(y_{i}-x_{i}\right)^{2}}{\sum_{i=1}^{n}\left(y_{i}-\bar{y}\right)^{2}}
$$

where $\bar{y}$ defines the mean of the total observed value and the value of $R^{2}$ lies between 0 to 1 (closer to 1 is the best fit). 


\section{Wind Site and Measurement Details}

The wind data collected from two Indian states namely Gujarat and Tamilnadu are considered for analysis. These two states are pioneers in wind energy generation contributing to the Indian power grid in a higher stake. The wind data segregated into three categories such as onshore from Kayathar (Tamilnadu, India), offshore from Gulf of Khambhat (Gujarat, India), and nearshore from Jafrabad (Gujarat, India). The statistics of each location are presented in Table 1.

Table 1. Measurement sensor data from wind stations.

\begin{tabular}{|c|c|c|c|c|c|}
\hline Location & $\begin{array}{l}\text { Landmass } \\
\text { Meas. Sensor }\end{array}$ & Latitude and Longitude & Dataset Period & Interval & Recovery Rate \\
\hline $\begin{array}{l}\text { Kayathar } \\
\text { (Tamilnadu) }\end{array}$ & Onshore (Mast) & $\begin{array}{l}8^{\circ} 56^{\prime} 42.50^{\prime \prime} \mathrm{N} \\
77^{\circ} 43^{\prime} 24.12^{\prime \prime} \mathrm{E}\end{array}$ & $\begin{array}{l}\text { 2014, 2015, } 2016 \\
\text { (3 years) }\end{array}$ & $10 \mathrm{~min}$ & $100 \%$ \\
\hline $\begin{array}{c}\text { Gulf of Khambhat } \\
\text { (Gujarat) }\end{array}$ & $\begin{array}{l}\text { Offshore } \\
\text { (LiDAR) }\end{array}$ & $\begin{array}{l}20^{\circ} 45^{\prime} 19.10^{\prime \prime} \mathrm{N}, \\
71^{\circ} 41^{\prime} 10.93^{\prime \prime} \mathrm{E}\end{array}$ & $\begin{array}{c}12 / 2018 \text { to } \\
11 / 2019 \text { (1 year) }\end{array}$ & $10 \mathrm{~min}$ & $75.85 \%$ \\
\hline Jafrabad (Gujarat) & $\begin{array}{l}\text { Nearshore } \\
\text { (Mast) }\end{array}$ & $\begin{array}{l}20^{\circ} 53^{\prime} 29.81^{\prime \prime} \mathrm{N}, \\
71^{\circ} 27^{\prime} 35.68^{\prime \prime} \mathrm{E}\end{array}$ & $\begin{array}{c}12 / 2018 \text { to } \\
11 / 2019 \text { ( } 1 \text { year) }\end{array}$ & $10 \mathrm{~min}$ & $99.89 \%$ \\
\hline
\end{tabular}

\subsection{Kayathar (Tamilnadu)—Onshore Location}

The Tamilnadu State, situated at the southeastern end of the Indian peninsula, comprises of a higher rate of humidity and temperature throughout the year. The annual rainfall received from the South-West monsoon (June to September) and the North-East monsoon (October to December) is $911.6 \mathrm{~mm}$ and temperature ranges between $20^{\circ} \mathrm{C}$ and $38^{\circ} \mathrm{C}$ in the plains [28]. Kayathar is a small town located in the southern part of the Tamilnadu. The mapping coordinates of Kayathar are $08^{\circ} 57^{\prime} \mathrm{N}$ $77^{\circ} 48^{\prime} \mathrm{E}$ and it is situated at $78 \mathrm{~m}$ elevation (altitude) above sea level. The geolocation of the targeted site is shown in Figure 1a. The wind data collected from the mast installed at a height of $120 \mathrm{~m}$ by the National Institute of Wind Energy (NIWE) (the central agency for wind energy developments in India). Wind data measured at Kayathar were recorded with an average of $10 \mathrm{~min}$ along with different altitudes, directions of wind flow, temperature, and pressure for three years between the years 2014 and 2016. This region experiences a template of monsoon variations from South-West and North-East monsoons. Therefore, the summer season is very hot with high humidity, and hence this site is prone to high windy during monsoons. The wind data collected from this site is classified into three categories likely seasonal, yearly, and monthly to evaluate the wind characteristics [29].

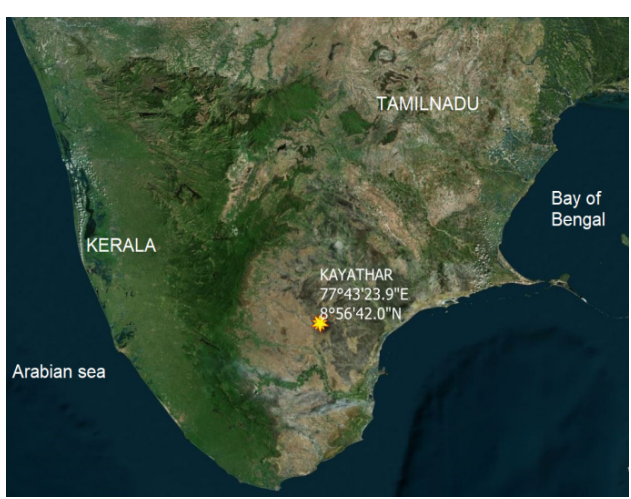

(a)

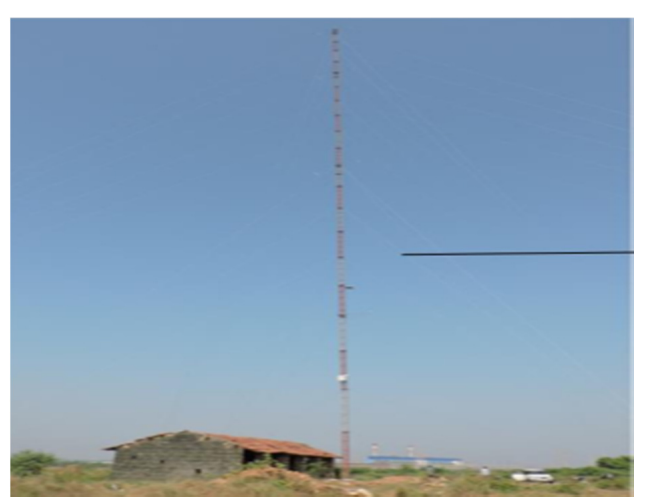

(b)

Figure 1. (a) Kayathar, Tamilnadu-Metmast location (Source: google maps); (b) Jafrabad, Gujarat coastal mast.

\subsection{Gulf of Khambhat (Gujarat)—Offshore Location}

Gujarat state has an international boundary with common border at the North-Western (NW) fringe [30]. It has a long coastline of about $1600 \mathrm{~km}$, which is the longest among all states of the country 
with a geographical area of 1.96 lakh sq. $\mathrm{km}$. It is situated between $20^{\circ} 1^{\prime}$ and $24^{\circ} 7^{\prime}$ North latitudes and $68^{\circ} 4^{\prime}$ and $74^{\circ} 4^{\prime}$ East longitudes with an elevation of about $9 \mathrm{~m}$ [30]. India earmarked the states Gujarat and Tamilnadu for pacing up rapidly towards offshore wind energy development through the supervision of the nodal ministry MNRE-Ministry of New and Renewable Energy and nodal agency NIWE-National Institute of Wind Energy). The offshore development activities are started with preliminary site assessments in Gujarat coastal area. The proposed location of the offshore wind farm is about 23 to $40 \mathrm{~km}$ off the coast from the Pipavav port, Gulf of Khambhat, Gujarat. It covers about $400 \mathrm{~km}^{2}$ and the wind measurements and other data collections are through LiDAR.

Figure 2 displays the placement of the LiDAR instruments, showing a monopole structure erected in the Gulf of Khambhat at $20^{\circ} 45^{\prime} 19.10^{\prime \prime} \mathrm{N}, 71^{\circ} 41^{\prime} 10.93^{\prime \prime} \mathrm{E}$ with $25 \mathrm{~km}$ distance from the coast and $15 \mathrm{~m}$ water depth. The nearest port is Pipavav located at approximately $23 \mathrm{~km}$ from the Gujarat coast in the South-East direction. The monopole structure with a platform comprises of an anemometer, wind vane, temperature monitor, and pressure instruments are also commissioned. The LiDAR instrument is a wind cube configured for 12 various heights with a minimum height of $40 \mathrm{~m}$ and maximum height of $200 \mathrm{~m}$. The overall data collected from LiDAR for the period from December 2018 to November 2019 is about $75.85 \%$ of the total, and the remaining $24 \%$ of data are not successful due to technical issues.
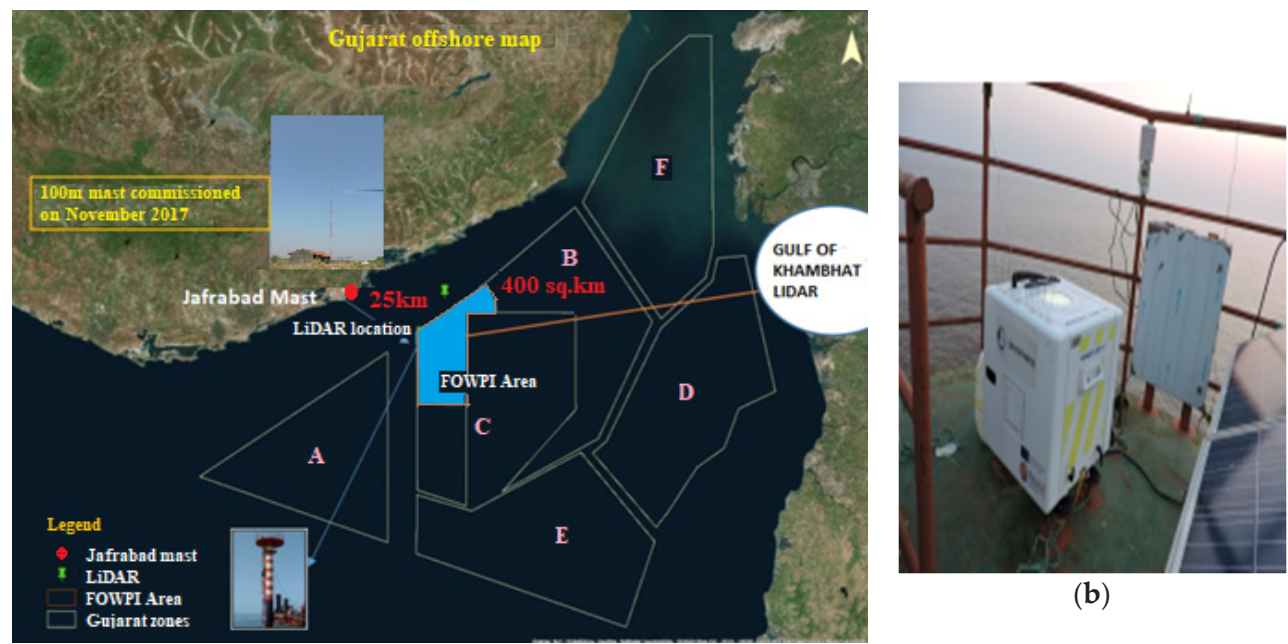

(b)

(a)

Figure 2. (a) Onshore Mast and offshore LiDAR locations, Gulf of Khambhat; (b) LiDAR Instrument (offshore).

\subsection{Jafrabad (Gujarat) Nearshore Location}

The meteorological mast tower is installed with $100 \mathrm{~m}$ height at the Jafrabad coast in line of sight with the LiDAR location, at the distance of $25 \mathrm{~km}$ (Figure 1b). The main purpose of this installation is to correlate and validate with the LiDAR measurement for assessing offshore Gulf of Khambhat wind potential. The wind speed is measured from anemometers and temperature sensors placed at various levels such as 100, 80,50, and $20 \mathrm{~m}$ above ground level. The wind direction sensors are positioned at 98,78 , and $48 \mathrm{~m}$. This mast is installed at $2053^{\prime} 29.81^{\prime \prime} \mathrm{N}, 7127^{\prime} 35.68^{\prime \prime} \mathrm{E}$ with an altitude of $9 \mathrm{~m}$ above the ground level, with a mast height of $100 \mathrm{~m}$. The wind data was collected with a $99.89 \%$ recovery rate for the period from December 2018 to November 2019.

\subsection{Seasonal Wind Periods}

The highest wind power potential in India concentrated on two major states, namely Tamilnadu [28] and Gujarat [29]. Concerning the classification of seasons for Gujarat and Tamilnadu states, the influence of seasonal winds from North-East monsoon (NEM) and South-West monsoon (SWM) are taken into consideration for analysis [30]. These seasons are grouped based on seasonal months, as follows:

Winter: January and February (2 months) 
Summer: March, April, and May (3 months)

SWM: June, July, August, and September (4 months)

NEM: October, November, and December (3 months)

\subsection{Moth Flame Optimization (MFO) Method}

The application of artificial intelligence and soft computing techniques along with optimization is adopted in various activities. In this work, this method is implemented for estimating the parameters of the bimodal Weibull-Weibull method. The MFO algorithm [31] is a naturally inspired algorithm where moths are fancy insects, which are highly similar to the family of butterflies. The main inspiration of MFO is the navigation method of moths in nature, called transverse orientation. Moths navigate at night by maintaining a fixed angle to the moon. This is an effective mechanism for traveling long distances in a straight line [32]. It is considered as one of the promising metaheuristic algorithms and successfully applied in various optimization problems in a wide range of fields, such as power and energy systems, economic dispatch, engineering design, image processing, and medical applications. The working principle of MFO is based on the individuals/set of moths (M) called population and flame (F) is said to be the best solution for each moth. The moth-flame combination contains one flame per moth, which is considered to be as its best position. During the iteration, this flame will get updated if any better solution found. The matrix $O M$ stores the corresponding fitness (objective) value, which can be written as follows:

$$
M=\left[\begin{array}{cccc}
m_{11} & m_{12} & \cdots & m_{1 d} \\
m_{21} & m_{22} & \cdots & m_{2 d} \\
\vdots & \vdots & \vdots & \vdots \\
m_{n 1} & m_{n 2} & \cdots & m_{n d}
\end{array}\right] \text { and } O M=\left[\begin{array}{c}
I\left(m_{11}, m_{12}, \cdots, m_{1 d}\right) \\
I\left(m_{21}, m_{22}, \cdots, m_{2 d}\right) \\
\vdots \\
I\left(m_{n 1}, m_{n 2}, \cdots, m_{n d}\right)
\end{array}\right]=\left[\begin{array}{c}
O M_{1} \\
O M_{2} \\
\vdots \\
O M_{n}
\end{array}\right]
$$

where $n$ is the number of moths, $I$ is the objective function, and $d$ is the number of variables. Notably, each moth flies around its corresponding flame. Therefore, the flames matrix is the same size as the moths matrix [30]. The set of flames can be represented in the matrix F, while the matrix OF indicates the corresponding fitness value and can be written as follows.

$$
F=\left[\begin{array}{cccc}
F_{11} & F_{12} & \cdots & F_{1 d} \\
F_{21} & F_{22} & \cdots & F_{2 d} \\
\vdots & \vdots & \vdots & \vdots \\
F_{n 1} & F_{n 2} & \cdots & F_{n d}
\end{array}\right] \text { and } O F=\left[\begin{array}{c}
I\left(F_{11}, F_{12}, \cdots, F_{1 d}\right) \\
I\left(F_{21}, F_{22}, \cdots, F_{2 d}\right) \\
\vdots \\
I\left(F_{n 1}, F_{n 2}, \cdots, F_{n d}\right)
\end{array}\right]=\left[\begin{array}{c}
O F_{1} \\
O F_{2} \\
\vdots \\
O F_{n}
\end{array}\right]
$$

The main difference between moths and flames is the way they are treated and updated in each iteration. The moths are search agents moving around the search space, while flames are the best position of moths obtained by the current iteration [30]. The equation to find the best optimal value is given as:

$$
M i=S\left(M_{i}, F_{j}\right)
$$

where $M_{i}$ indicates the $i$-th moth, $F j$ indicates the $j$-th flame, and $S$ is the spiral function. The spiral function of the moth is given as:

$$
S\left(M_{i}, F_{j}\right)=D_{i} \cdot e^{b t} \cdot \cos (2 \pi t)+F_{j}
$$

where $D_{i}$ indicates the distance of the $i$-th moth for the $j$-th flame, $b$ is a constant for defining the shape of the logarithmic spiral, and $t$ is a random number. $D_{i}$ is calculated as follows:

$$
S D_{i}=\left|F_{i}-M_{i}\right|
$$


where $F_{i}$ indicates the $i$-th flame. The moth can converge or exploit in the given search space by changing the value ' $t$ ' when the position of a moth gets changed. A mechanism to solve the number of flames during each iteration is mathematically defined as follows:

$$
\text { flame no }=\operatorname{round}\left(N-l * \frac{N-1}{\mathrm{~T}}\right)
$$

where $N$ is the maximum number of flames, $l$ is the number of current iteration and $T$ is the maximum number of iterations. The objective function to be considered for minimization of estimated Bimodal Weibull distribution parameters by MFO and observed actual wind speed distribution is derived as:

$$
\xi^{2}=\sum(f e s t-f o)^{2}
$$

where fest is the estimated value from bimodal-MFO and $f o$ is the observed data from the histogram:

$$
f e s t=w 1\left(\frac{k 1}{c 1}\right)\left(\frac{v}{c 1}\right)^{k 1-1} \exp \left(-\left(\frac{v}{c 1}\right)^{k 1}\right)+w 2\left(\frac{k 2}{c 2}\right)\left(\frac{v}{c 2}\right)^{k 2-1} \exp \left(-\left(\frac{v}{c 2}\right)^{k 2}\right)
$$

where, the parameters $k 1$ and $k 2$ are shapes, $c 1$ and $c 2$ stand for scales, $w 1$ and $w 2$ define weights and $v$ terms the wind speed. The MFO pseudocode algorithm with program logic is derived in Appendix A and the flow chart for the MFO algorithm is described in Figure 3.

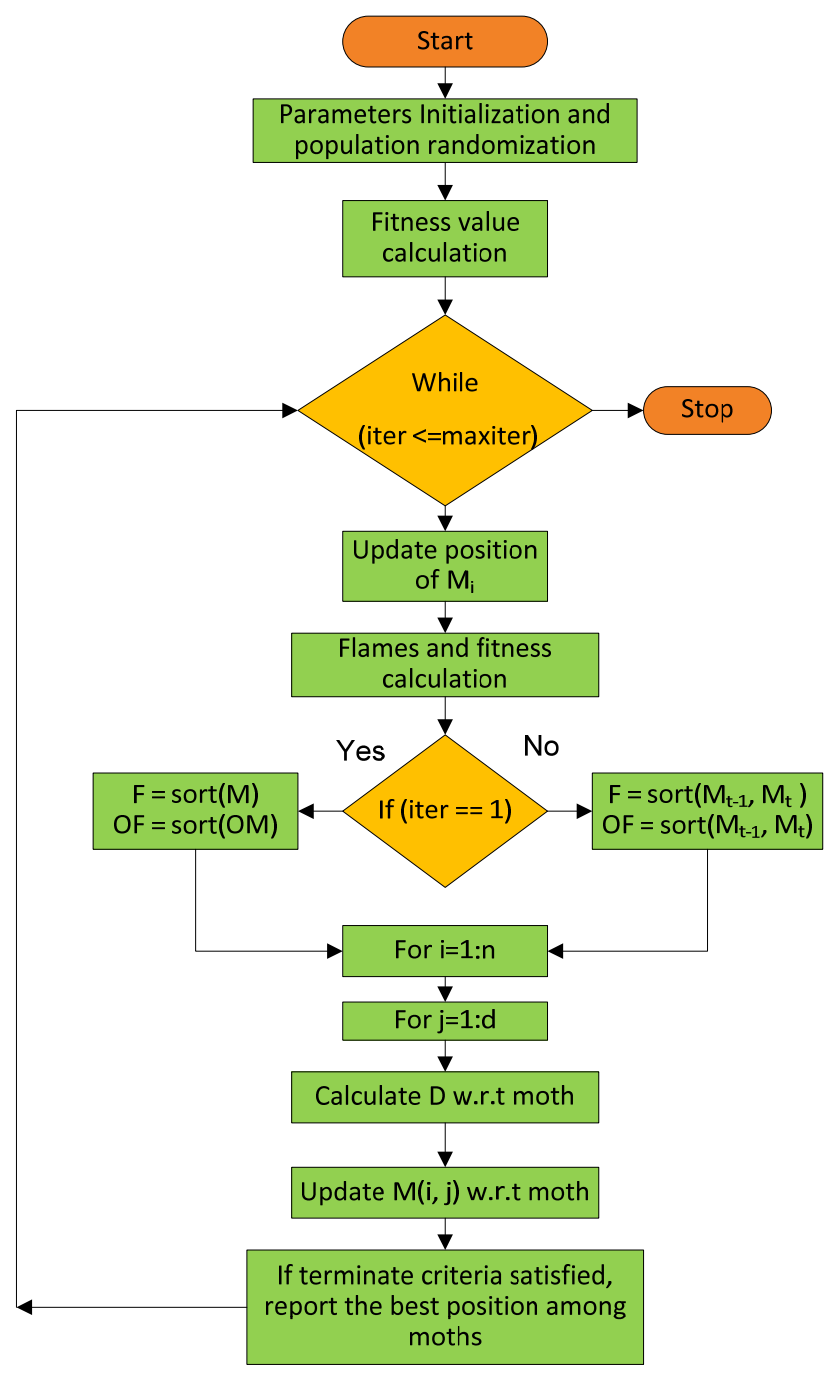

Figure 3. Flow chart of the MFO Algorithm. 


\section{Results and Discussions}

This segment outlines the statistical investigation of the wind data measured in the three different landscapes. A total of ten wind distribution functions are adopted to estimate the correctness of the distribution that best fits the wind speeds of the targeted location. Later, the optimization method, i.e., the MFO method is applied for parameter estimation and compared with ten wind distribution parameters. The MATLAB R2018b software with in-house developed code is used for estimating the parameters of ten wind distribution functions along with the MLM. Then, it is compared with the estimated parameters through MFO method using bimodal (Weibull-Weibull) distribution. As stated earlier, the goodness of fit is to evaluate the best wind distribution method with a lower rate of RMSE value nearer to zero. Additionally, the higher rate of $\mathrm{R}^{2}$ should be nearer to one with reduced error fitting for evaluating the wind power density. Further, the results are grouped for the best wind power density with the selected distribution. Later, the annual mean wind speed along with mean turbulence intensity $(15 \mathrm{~m} / \mathrm{s})$ are considered for categorizing the turbulence class for the turbine selection to form a standalone wind turbine/wind farm. The complete steps/procedures for the assessment of wind resources are given in Figure 4.

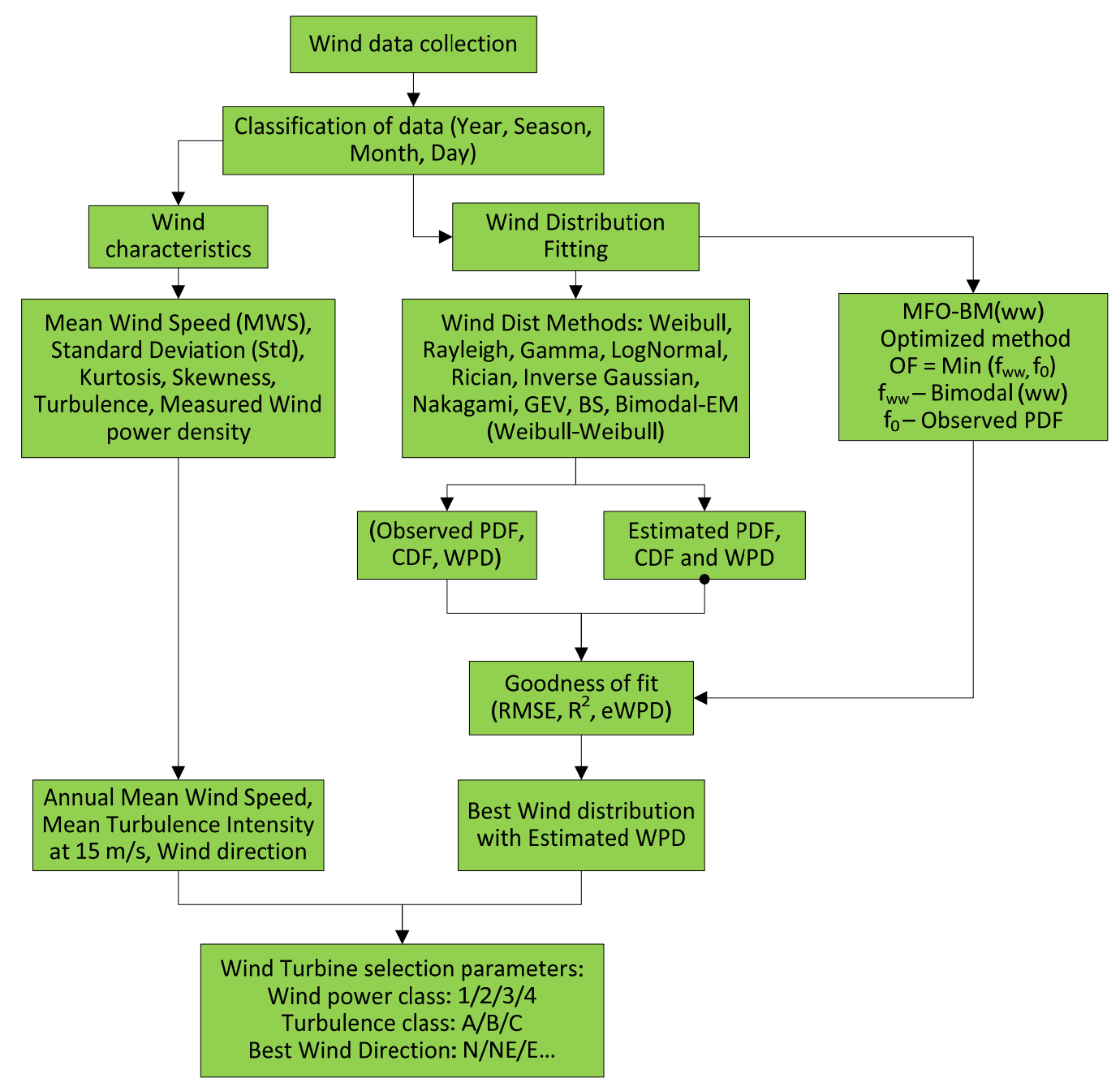

Figure 4. Flow chart of wind resource assessment.

\subsection{Wind Characteristics}

The detailed wind statistical analysis for the Kayathar station (onshore), Jafrabad station (Mast-nearshore), and Gulf of Khambhat station (offshore) are presented in this section. The key characteristics of any wind assessment are to ascertain the wind resource feasibility such as mean 
wind speed, standard deviations of wind, turbulence intensity, and wind directions. The collected statistical analysis is used to determine the site eligibility for wind turbines, selection and energy yield to make the wind project technically viable. The statistical analysis of wind speed, wind direction, and its relation is represented by the wind rose plot. The mean wind speed over the periods for seasonal, monthly, and annual analysis represent the energy contained in the wind, and for the analysis of turbulence intensity to classify turbines. The PDF for fitting the wind speed distribution, wind power potential analysis, and statistical characteristics are presented in the following sections.

\subsubsection{Kayathar Station (Onshore)}

The annual mean wind speed (MWS), standard deviation, maximum wind speed, skew, and kurtosis in the Kayathar region between the years 2014 and 2016 are presented in Table 2 and Figure 5a. The highest mean wind speed of about $6.62 \mathrm{~m} / \mathrm{s}$ is recorded in the year 2014 with a maximum wind speed of $20.92 \mathrm{~m} / \mathrm{s}$ for the same year. Further, the skewness factors of the wind speed are observed as a maximum of $0.8086 \mathrm{~m} / \mathrm{s}$ in the year 2014 and a minimum of $0.5589 \mathrm{~m} / \mathrm{s}$ in the year 2015. This skewness rate indicates the positive wind distribution with a moderate skew range between 0.5 to 1 [32]. The annual average kurtosis is recorded as -0.3190 and -0.7038 in the year 2014 and 2016 respectively. It specifies the shorter wind distribution and thinner tails than the normal distribution. The wind speed at various altitudes are measured and shown in Figure $5 \mathrm{~b}$. It is observed for different ranges such as 10, 30, 60, and $100 \mathrm{mWS}$. Additionally, the shear analysis power-law coefficient is evaluated and observed as 0.170 .

Table 2. Annual wind speed $(100 \mathrm{~m})$ statistics.

\begin{tabular}{cccccccccc}
\hline Year & $\begin{array}{c}\mathbf{V}_{\text {mean }} \\
(\mathbf{m} / \mathbf{s})\end{array}$ & $\begin{array}{c}\mathbf{V}_{\text {rmc }} \\
(\mathbf{m} / \mathbf{s})\end{array}$ & $\begin{array}{c}\mathbf{V}_{\text {std }} \\
(\mathbf{m} / \mathbf{s})\end{array}$ & $\begin{array}{c}\mathbf{V}_{\text {max }} \\
(\mathbf{m} / \mathbf{s})\end{array}$ & $\begin{array}{c}\mathbf{V}_{\text {min }} \\
(\mathbf{m} / \mathbf{s})\end{array}$ & $\begin{array}{c}\mathbf{V}_{\text {skew }} \\
(\mathbf{m} / \mathbf{s})\end{array}$ & $\mathbf{V}_{\text {kurt }}$ & $\mathbf{V}_{\text {median }}$ & $\begin{array}{c}\text { MTI } \\
(\mathbf{m} / \mathbf{s})\end{array}$ \\
\hline 2014 & 6.62 & 8.84 & 4.14 & 20.92 & 0.28 & 0.80 & -0.31 & 5.34 & 0.17 \\
2015 & 5.98 & 7.81 & 3.56 & 19.27 & 0.41 & 0.77 & -0.32 & 4.96 & 0.18 \\
2016 & 6.38 & 8.16 & 3.65 & 18.84 & 0.19 & 0.55 & -0.70 & 5.51 & 0.17 \\
\hline
\end{tabular}

Table 3 illustrates the seasonal wind speed peaks on the South-West monsoon period (SWM) of about $10.03 \mathrm{~m} / \mathrm{s}$ and maximum seasonal wind speed observed as $18.52 \mathrm{~m} / \mathrm{s}$. Comparing the monsoon periods, the North-East monsoon (NEM) fetches a low wind mean speed of $4.5 \mathrm{~m} / \mathrm{s}$. The monthly mean wind speed is observed as having a maximum during June of $10.29 \mathrm{~m} / \mathrm{s}$ and the maximum wind speed during July is $19.81 \mathrm{~m} / \mathrm{s}$. The monthly standard deviation is stable from January to March with an average value of $1.8 \mathrm{~m} / \mathrm{s}$. Further, it is observed as 3.99, 3.5, and $3.01 \mathrm{~m} / \mathrm{s}$ for May, July, and October respectively during the peaks in monsoon periods due to seasonal winds. The mean turbulence intensity (MTI) is estimated as a ratio between the standard deviation of the experiential wind speed every $10 \mathrm{~min}$ and the mean observed wind speed for the same period. Additionally, the turbulence is higher at a low wind speed as shown in Figure 5c. The defined location, namely the Kayathar wind station, falls on turbulence category ' $\mathrm{B}$ ' (as per International Electrotechnical Commission (IEC) standard) with MTI at $15 \mathrm{~m} / \mathrm{s}$ of 0.132 , i.e., $13.2 \%$ (Table 3). 


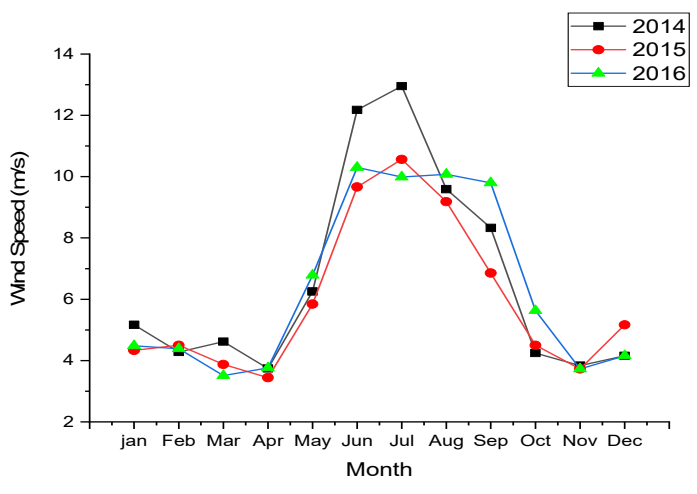

(a)

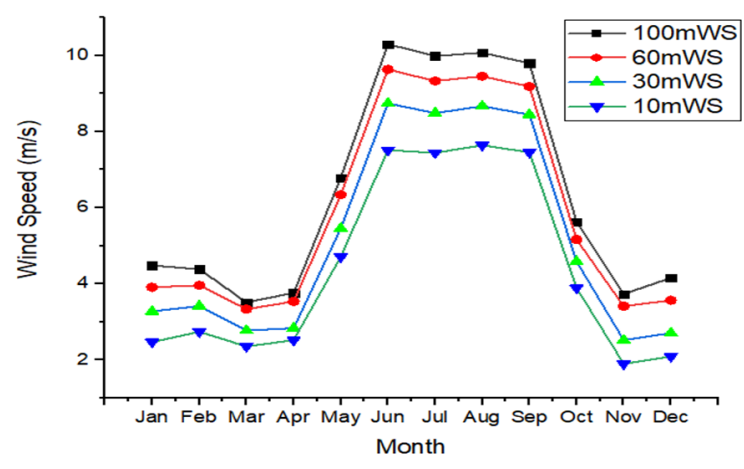

(b)

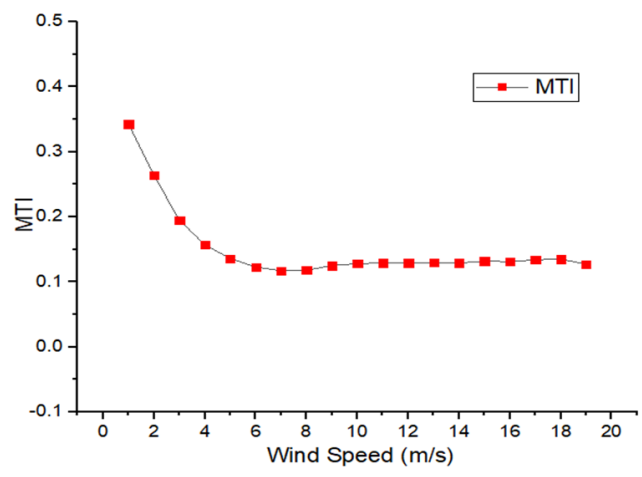

(c)

Figure 5. (a) Annual wind statistics (100 m); (b) wind speed at different altitude; (c) turbulence intensity.

Table 3. Kayathar wind characteristics-month wise.

\begin{tabular}{ccccccc}
\hline Season & $\mathbf{V}_{\text {mean }}(\mathbf{m} / \mathbf{s})$ & $\mathbf{V}_{\text {std }}(\mathbf{m} / \mathbf{s})$ & $\mathbf{V}_{\text {max }}(\mathbf{m} / \mathbf{s})$ & $\mathbf{V}_{\text {Skew }}$ & $\mathbf{V}_{\text {Kurt }}$ & MTI (m/s) \\
\hline Winter & 4.43 & 1.69 & 10.36 & 0.50 & -0.01 & 0.25 \\
Summer & 4.68 & 2.65 & 14.30 & 0.57 & -0.39 & 0.16 \\
SWM & 10.03 & 2.74 & 18.52 & -0.13 & 0.006 & 0.13 \\
NEM & 4.50 & 2.21 & 13.83 & 0.67 & 0.34 & 0.19 \\
Annual & 6.38 & 3.65 & 18.84 & 0.55 & -0.70 & 0.17 \\
January & 4.48 & 1.49 & 9.66 & 0.45 & -0.06 & 0.18 \\
February & 4.38 & 1.88 & 11.07 & 0.56 & 0.03 & 0.33 \\
March & 3.51 & 1.72 & 13.3 & 0.68 & 0.41 & 0.17 \\
April & 3.76 & 2.23 & 11.18 & 0.74 & -0.46 & 0.17 \\
May & 6.78 & 3.99 & 18.44 & 0.27 & -1.12 & 0.14 \\
June & 10.29 & 2.67 & 19.63 & -0.09 & 0.18 & 0.13 \\
July & 9.98 & 3.53 & 19.81 & -0.29 & 0.0004 & 0.14 \\
August & 10.07 & 2.48 & 17.05 & -0.05 & -0.15 & 0.13 \\
September & 9.79 & 2.29 & 17.6 & -0.10 & -0.009 & 0.13 \\
October & 5.62 & 3.01 & 16.54 & 0.60 & -0.37 & 0.18 \\
November & 3.73 & 1.93 & 12.85 & 0.83 & 0.98 & 0.22 \\
December & 4.15 & 1.68 & 12.1 & 0.57 & 0.41 & 0.18 \\
\hline
\end{tabular}

Figure 5 shows the annual wind statistics at $100 \mathrm{~m}$ height, wind speed at different altitude and intensity of turbulence. It is observed that the wind speed increases on higher altitudes. When considering the $10 \mathrm{~m}$, the wind speed attained a scale of $2 \mathrm{~m} / \mathrm{s}$ and further reaches about $4 \mathrm{~m} / \mathrm{s}(100 \mathrm{~m})$. It is known fact that the wind power is the cubic of wind speed; it is suggested to erect the turbines at 
higher altitude and hub height to obtain higher wind energy extraction. The wind speed observed in the year 2016 was not great, and particularly relatively lower than 2015 and 2014 due to climatic changes. Table 3 shows the observed wind speed of the Kayathar station for seasonal case and it recorded better characteristics. It is situated in the southern part of Tamilnadu and produces more wind power during the SWM, which stakes the major portion of state demand.

Furthermore, the annual maximum wind speeds hinge on wind direction; the West direction observed a maximum wind speed of $10.26 \mathrm{~m} / \mathrm{s}$ (38.66\%) followed by WSW and WNW, i.e., $11.27 \%$ and $7.57 \%$ respectively, as shown in Table 4 . The second maximum wind generation of NEM in NE wind direction is observed as $6.51 \%$, with a mean wind speed of $4.766 \mathrm{~m} / \mathrm{s}$ followed by NNE (North-Northern east) of $6.50 \%$. The wind rose plots exposed in Figure 6 indicate the influence of South-West and North-East monsoons. The North-East monsoon influenced the wind direction during October to December, and the West direction shifts to N-NNE (Northern NNE). During SWM periods, (i.e., June-September) wind directions are found to be West and WSW (West southern west). It also represents the main wind direction from the West and ranges between $258.75^{\circ}-281.25^{\circ}$ during the South-West. The winter season experiences NEM winds and influences at the end of the South-West monsoon period. The summer wind rose plot experiences wind from SWM and the wind direction from SE-SSE (Southeast-South Southeast) and Western direction. It indicates that the Kayathar region experiences maximum wind power from the Southwest direction. During low-wind periods from NEM and winter seasons, the wind speed reduced relatively which deteriorate to low wind generation.

Table 4. Kayathar wind directions-annual occurrence.

\begin{tabular}{cccccc}
\hline Direction Sector & Direction Name & Mean $(\mathbf{m} / \mathbf{s})$ & Max $(\mathrm{m} / \mathbf{s})$ & Std. Dev. (m/s) & Wind Occ. (\%) \\
\hline $348.75^{\circ}-11.25^{\circ}$ & N & 3.14 & 13.46 & 1.25 & 1.73 \\
$11.25^{\circ}-33.75^{\circ}$ & NNE & 4.25 & 15.05 & 1.68 & 6.50 \\
$33.75^{\circ}-56.25^{\circ}$ & NE & 4.76 & 20.63 & 1.82 & 6.51 \\
$56.25^{\circ}-78.75^{\circ}$ & ENE & 4.82 & 14.03 & 2.03 & 4.67 \\
$78.75^{\circ}-101.25^{\circ}$ & E & 4.62 & 13.38 & 2.24 & 2.84 \\
$101.25^{\circ}-123.75^{\circ}$ & ESE & 3.73 & 16.54 & 1.68 & 4.16 \\
$123.75^{\circ}-146.25^{\circ}$ & SE & 4.20 & 11.82 & 1.98 & 3.51 \\
$146.25^{\circ}-168.75^{\circ}$ & SSE & 4.82 & 11.18 & 2.29 & 3.58 \\
$168.75^{\circ}-191.25^{\circ}$ & S & 3.48 & 11.77 & 1.85 & 2.37 \\
$191.25^{\circ}-213.75^{\circ}$ & SSW & 2.75 & 12.12 & 1.39 & 1.60 \\
$213.75^{\circ}-236.25^{\circ}$ & SW & 2.97 & 10.11 & 1.53 & 1.86 \\
$236.25^{\circ}-258.75^{\circ}$ & WSW & 5.44 & 19.87 & 3.50 & 11.27 \\
$258.75^{\circ}-281.25^{\circ}$ & W & 10.26 & 22.86 & 3.30 & 38.66 \\
$281.25^{\circ}-303.75^{\circ}$ & WNW & 6.06 & 18.82 & 3.00 & 7.57 \\
$303.75^{\circ}-326.25^{\circ}$ & NW & 3.11 & 13.48 & 1.35 & 1.88 \\
$326.25^{\circ}-348.75^{\circ}$ & NNW & 3.07 & 11.94 & 1.30 & 1.21 \\
\hline
\end{tabular}




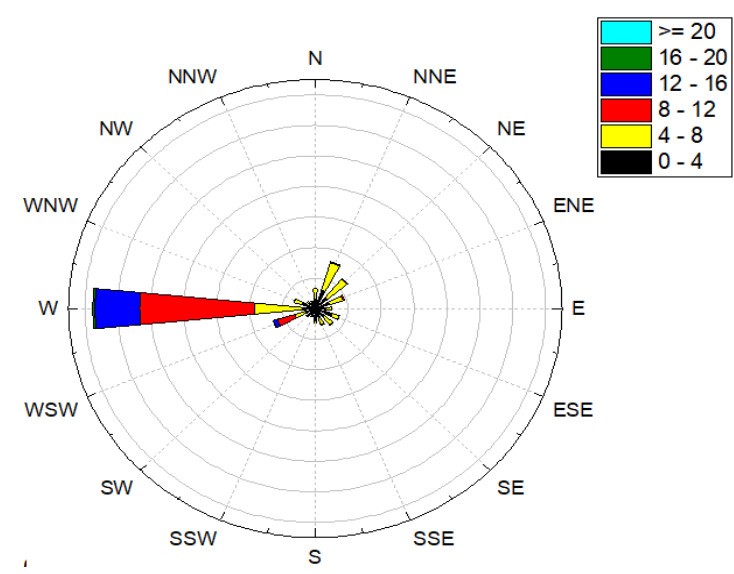

(a)

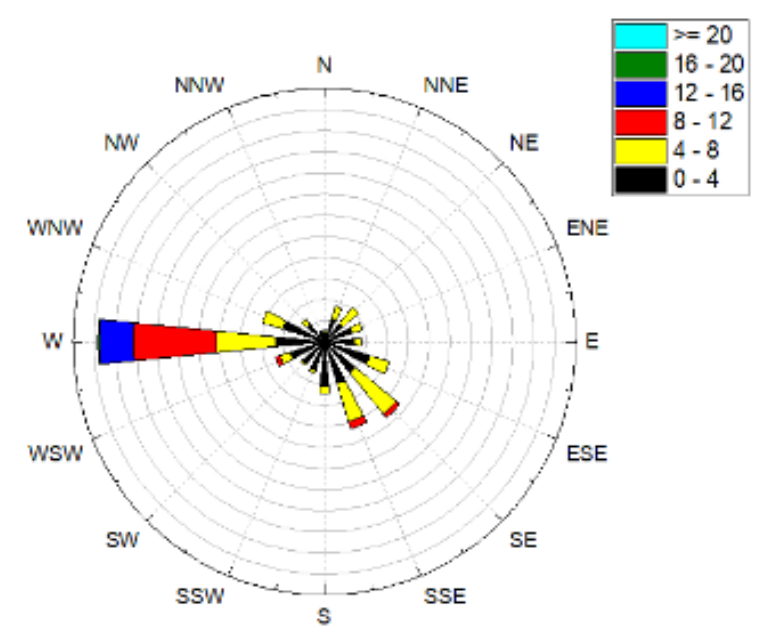

(c)

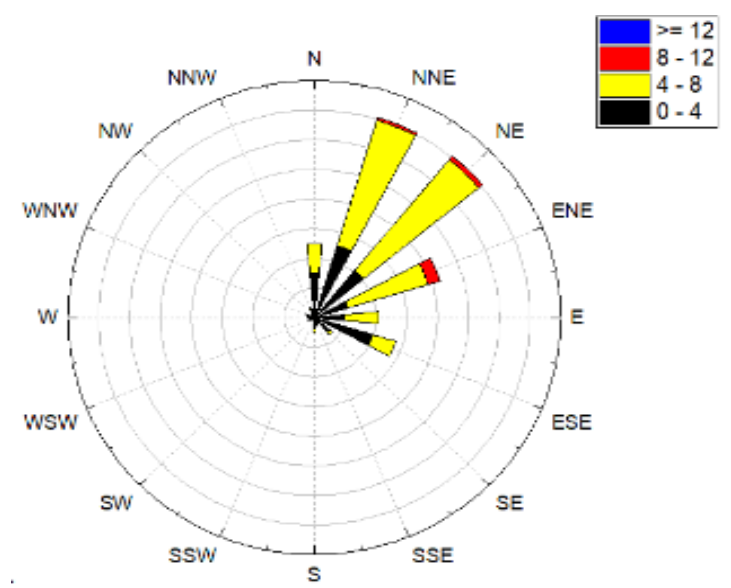

(b)

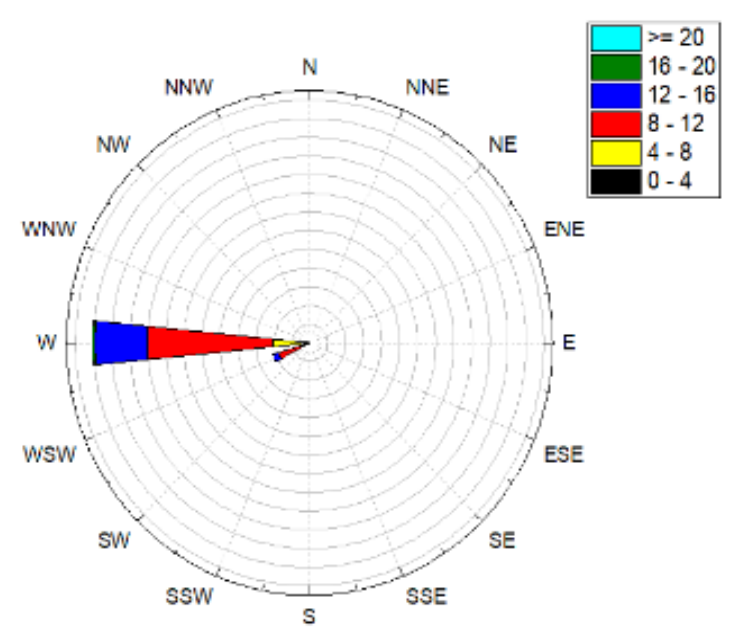

(d)

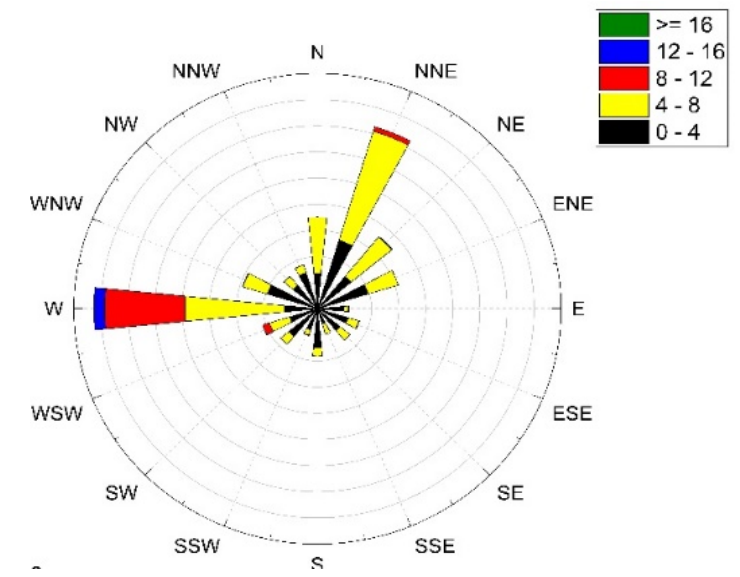

(e)

Figure 6. Wind rose plot: (a) annual plot; (b) winter; (c) summer; (d) SWM; (e) NEM.

\subsubsection{Gulf of Khambhat (Gujarat Offshore) Station}

The mean wind speed (MWS) collected from LiDAR measurements at various heights (40 to $200 \mathrm{~m}$ ) are presented in Figure 7 for the period of December 2018 to November 2019. It is observed that the wind speed attained an increased rate for higher altitudes with higher hub height (100 to $160 \mathrm{~m}$ ) which fetches more wind power. The wind speed of the Gulf of Khambhat during prevailing months 
is high compared with the Kayathar region, particularly during winter and NEM periods, which are suitable for sustained wind generation.

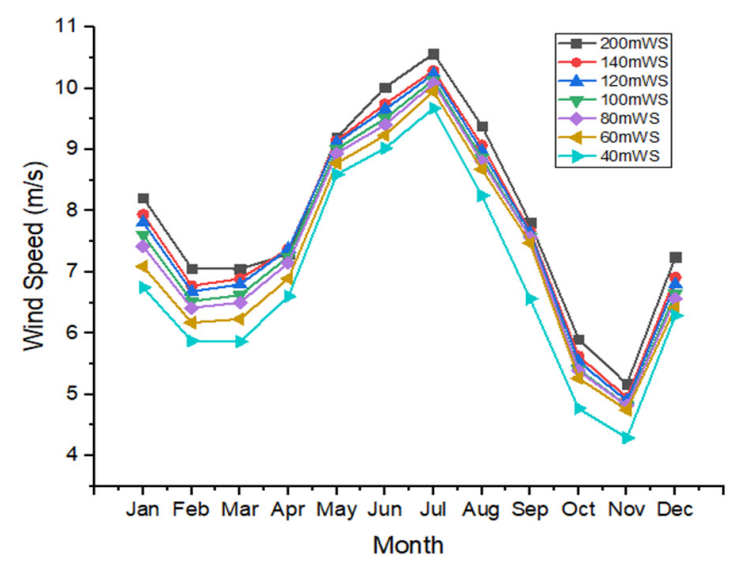

(a)

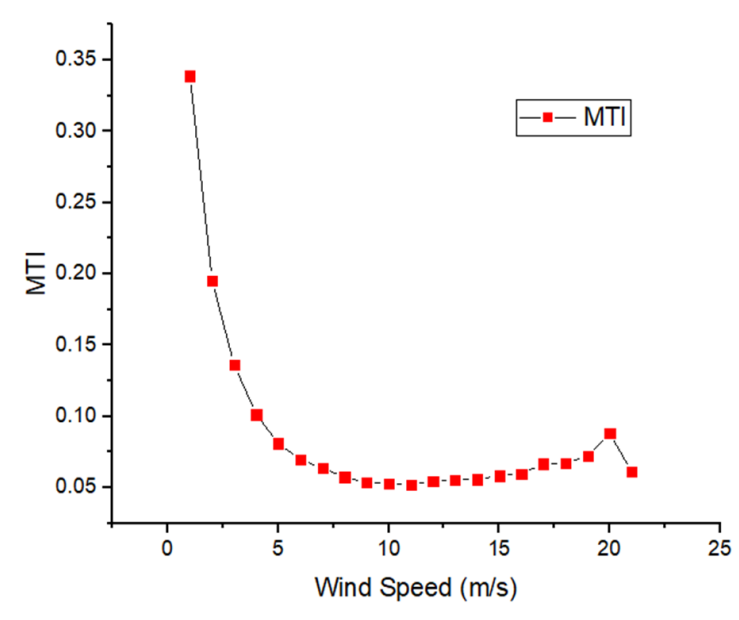

(b)

Figure 7. Gulf of Khambhat: (a) different wind altitudes; (b) turbulence intensity.

Table 5 shows the monthly-maximum mean wind speed in July $(10.13 \mathrm{~m} / \mathrm{s})$ and low mean wind speed in November $(4.81 \mathrm{~m} / \mathrm{s})$. Considering the $100 \mathrm{~m}$ measurements for analysis, the annual mean wind speed and maximum wind speed during June are observed as 7.59 and $22.99 \mathrm{~m} / \mathrm{s}$ respectively. The shear analysis power-law coefficient is perceived as 0.0782 based on the measured wind speeds at various altitudes. In comparison with the Kayathar onshore shear coefficient, the Gulf of Khambhat is less due to its offshore landscape by nature. The wind rose plot for seasonal periods is plotted and presented in Figure 8. The major wind directions during SW (Southwest) monsoon are observed in the SW-South direction and during the NE (Northeastern) monsoon on the North-NE direction. The annual and seasonal wind rose plots are shown in Figure 8. The maximum range of annual wind speed occurred in SSW and SW direction. Regarding seasonal changes, the winter season took the maximum wind that occurs in the North to NE direction.

Table 5. Annual and seasonal parameter of Gulf of Khambhat.

\begin{tabular}{cccccc}
\hline Param & Winter & Summer & SWM & NEM & Annual \\
\hline $\mathbf{V}_{\text {mean }}(\mathbf{m} / \mathbf{s})$ & 7.12 & 7.56 & 9.04 & 5.74 & 7.51 \\
$\mathbf{V}_{\text {std }}(\mathbf{m} / \mathbf{s})$ & 3.31 & 3.07 & 3.44 & 3.01 & 3.44 \\
$\mathbf{V}_{\text {max }}(\mathbf{m} / \mathbf{s})$ & 15.28 & 16.87 & 20.26 & 17.02 & 20.26 \\
MTI(m/s) & 0.06 & 0.07 & 0.07 & 0.10 & 0.08 \\
V $_{\text {Skew }}$ & 0.15 & 0.08 & 0.05 & 0.72 & 0.25 \\
V $_{\text {Kurt }}$ & -0.83 & -0.70 & -0.52 & 0.22 & 0.57 \\
\hline
\end{tabular}




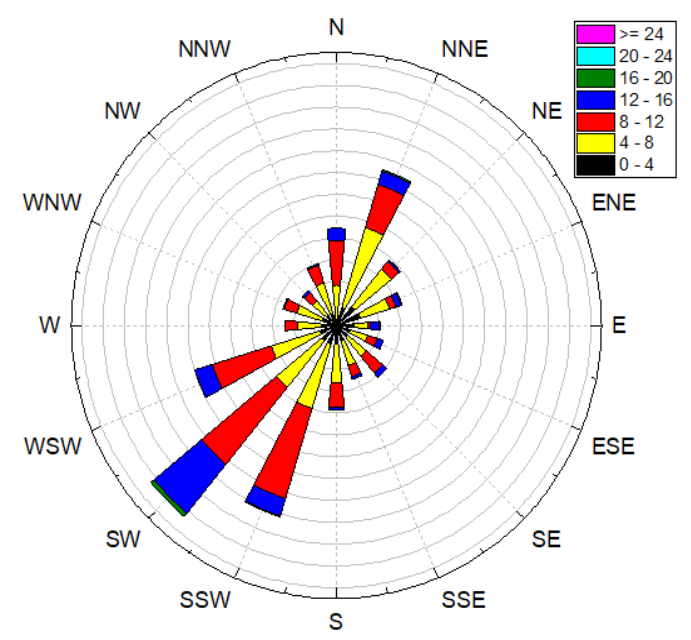

(a)

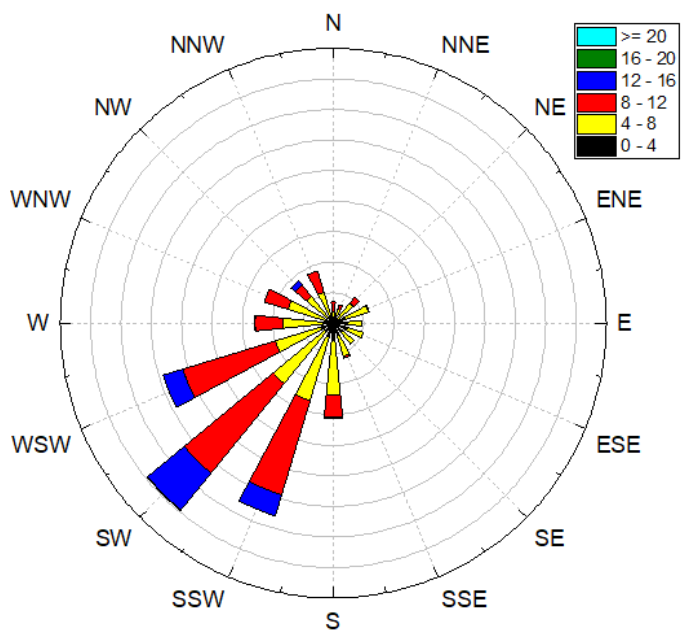

(c)

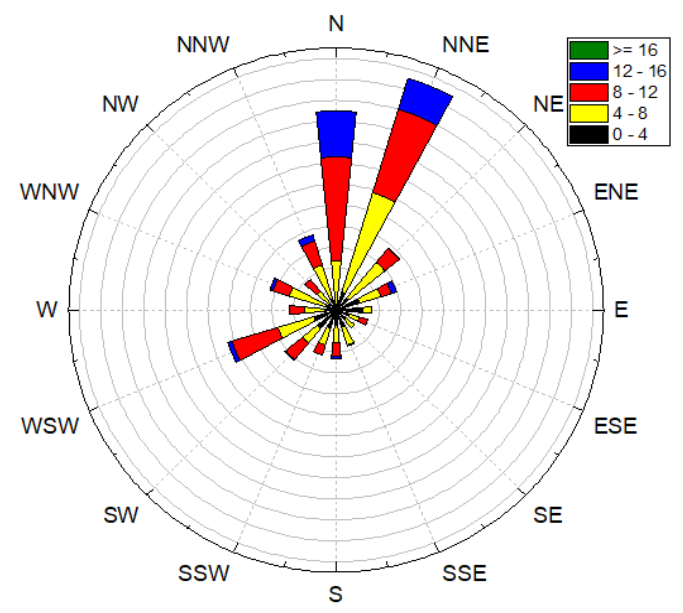

(b)

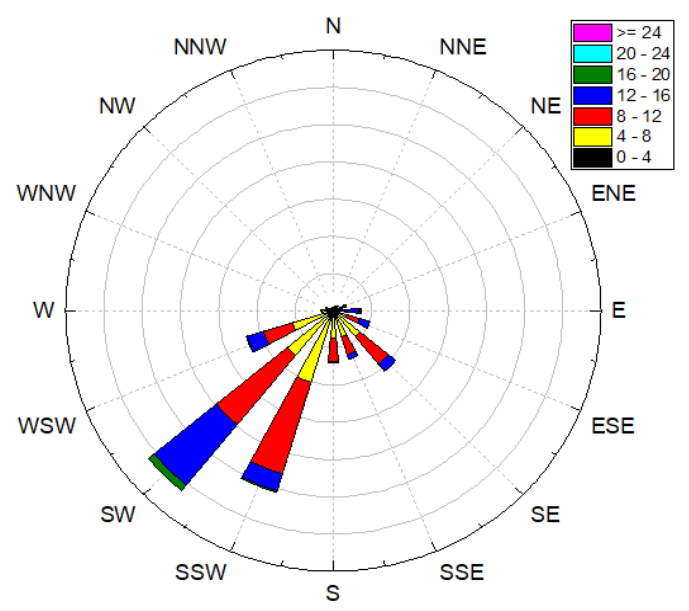

(d)

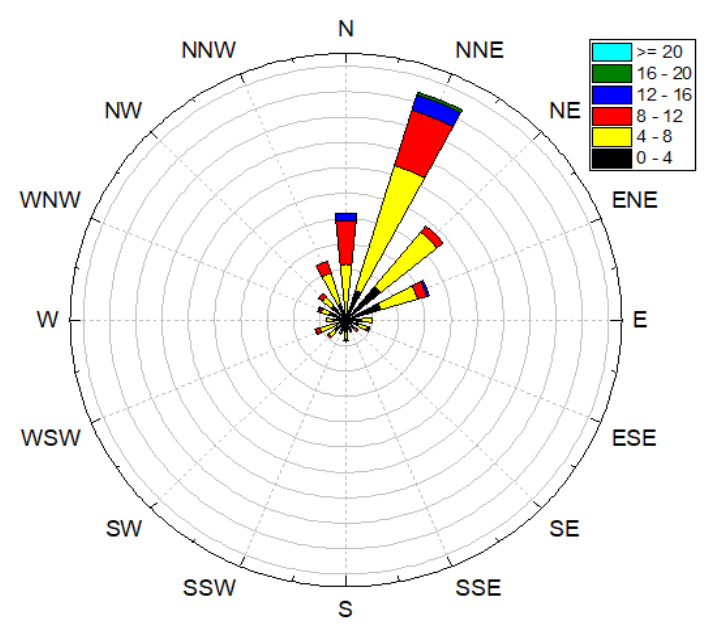

(e)

Figure 8. Gulf of Khambhat offshore wind rose: (a) annual; (b) winter; (c) summer; (d) SWM; (e) NEM.

Table 6 displays the maximum seasonal wind speed parameters of about $20.26 \mathrm{~m} / \mathrm{s}$ and maximum mean wind speed of $9.04 \mathrm{~m} / \mathrm{s}$ during the June to September (SWM) season. The standard deviation is 
stable throughout the year in all the seasons with an average value of $3.2 \mathrm{~m} / \mathrm{s}$. The minimum mean wind speed during NEM periods (October-December) is recorded as $5.74 \mathrm{~m} / \mathrm{s}$. Additionally, the annual wind speed of $7.511 \mathrm{~m} / \mathrm{s}$ and maximum wind speed of $20.263 \mathrm{~m} / \mathrm{s}$ is observed. The NEM period of the Gulf of Khambhat recorded the low wind speed of $5.74 \mathrm{~m} / \mathrm{s}$ and the remaining periods show the average range of about $7 \mathrm{~m} / \mathrm{s}$, i.e., winter and summer.

Table 6. Gulf of Khambhat monthly wind parameters.

\begin{tabular}{cccccccc}
\hline Month & $\mathbf{V}_{\text {mean }}(\mathbf{m} / \mathbf{s})$ & $\mathbf{V}_{\text {rmc }}(\mathbf{m} / \mathbf{s})$ & $\mathbf{V}_{\text {std }}(\mathbf{m} / \mathbf{s})$ & $\mathbf{V}_{\text {max }}(\mathbf{m} / \mathbf{s})$ & $\mathbf{V}_{\text {min }}(\mathbf{m} / \mathbf{s})$ & $\mathbf{V}_{\text {skew }}$ & $\mathbf{V}_{\text {kurt }}$ \\
\hline January & 7.61 & 9.06 & 3.64 & 15.34 & 0.43 & 0.02 & -1.06 \\
February & 6.52 & 7.64 & 2.91 & 15.89 & 0.3 & 0.11 & -0.65 \\
March & 6.62 & 7.62 & 2.71 & 15.93 & 0.4 & 0.30 & -0.37 \\
April & 7.25 & 8.36 & 3.04 & 16.42 & 0.35 & 0.08 & -0.65 \\
May & 9.01 & 9.97 & 3.18 & 17.27 & 0.49 & -0.40 & -0.43 \\
June & 9.51 & 10.63 & 3.46 & 22.99 & 0.37 & -0.007 & -0.43 \\
July & 10.13 & 11.18 & 3.54 & 18.74 & 0.54 & -0.57 & -0.26 \\
August & 8.86 & 10.07 & 3.38 & 20.39 & 1.1 & 0.50 & -0.04 \\
September & 7.56 & 8.47 & 2.79 & 15.25 & 0.5 & -0.06 & -0.66 \\
October & 5.40 & 6.84 & 2.90 & 17.98 & 0.42 & 1.07 & 1.35 \\
November & 4.81 & 5.97 & 2.51 & 19.39 & 0.43 & 0.60 & 0.70 \\
December & 6.65 & 8.02 & 3.22 & 17.37 & 0.2 & 0.43 & -0.55 \\
\hline
\end{tabular}

The month-based wind speed shown peak on July $(10.13 \mathrm{~m} / \mathrm{s})$ and maximum wind speed occurred during June $(22.99 \mathrm{~m} / \mathrm{s})$ due to SEM. The low wind speed occurred during October and November, i.e., 5.4 and $4.8 \mathrm{~m} / \mathrm{s}$ respectively, due to NEM. The skewness factor of the wind speed obtained a maximum value of 1.07 during October. The annual skewness is recorded as 0.25 . It indicates that the wind distribution is positive with a moderate skew, and its range falls between 0.5 to 1 . The annual kurtosis rate (0.57) indicates that the wind distribution is shorter; tails are thinner than the normal distribution.

The annual wind direction obtained a maximum value at the SW (Southwest) direction of about $15.8 \%$ with a mean wind speed of $9.8501 \mathrm{~m} / \mathrm{s}$. Further, SSW (South Southwest) and WSW (West Southwest) obtained about $15.8 \%$ and $8.7 \%$ respectively, due to SWM as shown in Table 7 . The next maximum wind direction occurred in the NNE (North Northeast) of about $11.07 \%$, with a mean wind speed of $7.0987 \mathrm{~m} / \mathrm{s}$ followed by North direction $(10.17 \%)$ with a mean wind speed of $7.83 \%$. The wind direction starts at N-NNE-NE during the winter season initially, and moves towards the South-Southwest direction during summer with the traces of the SWM season picking up. Later, the peaks have risen during the SWM with SW-S direction and finally through the NEM season in the $\mathrm{N}-\mathrm{NE}$ direction. The major wind directions are obtained in the S-SW and N-NE direction during the seasonal periods. The turbulence intensity for offshore LiDAR data is plotted in Figure $7 \mathrm{~b}$, and its mean value took place at $15 \mathrm{~m} / \mathrm{s}(5.9 \%)$. As per the IEC standard, it falls on the turbulence Ç category. On comparison with the onshore Kayathar station, the MTI value is low due to the offshore area. From the above discussed wind characteristics, the Gulf of Khambhat shows better results, with specifically steady wind speed and low turbulence intensity. These positive factors provide sustained wind generation and help the wind farm planners to invest in offshore wind power production in the region of Gulf of Khambhat. 
Table 7. Wind direction annual statistics of the Gulf of Khambhat.

\begin{tabular}{cccccccc}
\hline Sector & $\begin{array}{c}\text { Direction } \\
\text { Name }\end{array}$ & $\begin{array}{c}\text { Mean } \\
(\mathbf{m} / \mathbf{s})\end{array}$ & $\begin{array}{c}\text { Median } \\
(\mathbf{m} / \mathbf{s})\end{array}$ & Min (m/s) & Max (m/s) & $\begin{array}{c}\text { Std. Dev. } \\
(\mathbf{m} / \mathbf{s})\end{array}$ & $\begin{array}{c}\text { Wind Occ. } \\
(\%)\end{array}$ \\
\hline $348.75^{\circ}-11.25^{\circ}$ & N & 7.83 & 7.75 & 0.37 & 15.05 & 3.12 & 10.17 \\
$11.25^{\circ}-33.75^{\circ}$ & NNE & 7.09 & 6.73 & 0.4 & 17.98 & 3.13 & 11.07 \\
$33.75^{\circ}-56.25^{\circ}$ & NE & 5.73 & 5.09 & 0.42 & 18.12 & 3.02 & 5.82 \\
$56.25^{\circ}-78.75^{\circ}$ & ENE & 5.47 & 4.53 & 0.47 & 20.21 & 3.43 & 3.72 \\
$78.75^{\circ}-101.25^{\circ}$ & E & 6.48 & 4.79 & 0.41 & 22.99 & 4.51 & 2.92 \\
$101.25^{\circ}-123.75^{\circ}$ & ESE & 6.65 & 5.49 & 0.44 & 20.27 & 3.89 & 2.93 \\
$123.75^{\circ}-146.25^{\circ}$ & SE & 7.27 & 7.3 & 0.41 & 16.95 & 3.42 & 4.07 \\
$146.25^{\circ}-168.75^{\circ}$ & SSE & 6.35 & 5.66 & 0.43 & 15.74 & 3.29 & 3.53 \\
$168.75^{\circ}-191.25^{\circ}$ & S & 6.76 & 6.7 & 0.47 & 14.05 & 2.85 & 4.66 \\
$191.25^{\circ}-213.75^{\circ}$ & SSW & 8.44 & 8.73 & 0.3 & 18.17 & 2.89 & 13.05 \\
$213.75^{\circ}-236.25^{\circ}$ & SW & 9.80 & 10.06 & 0.48 & 20.39 & 3.48 & 15.80 \\
$236.25^{\circ}-258.75^{\circ}$ & WSW & 8.13 & 8.44 & 0.49 & 18.74 & 3.22 & 8.75 \\
$258.75^{\circ}-281.25^{\circ}$ & W & 6.22 & 5.93 & 0.35 & 14.06 & 2.89 & 3.24 \\
$281.25^{\circ}-303.75^{\circ}$ & WNW & 5.69 & 5.55 & 0.68 & 11.82 & 2.56 & 2.86 \\
$303.75^{\circ}-326.25^{\circ}$ & NW & 5.96 & 5.7 & 0.41 & 16.42 & 3.18 & 3.08 \\
$326.25^{\circ}-348.75^{\circ}$ & NNW & 6.50 & 6.63 & 0.61 & 13.84 & 2.90 & 4.25 \\
\hline
\end{tabular}

\subsubsection{Jafrabad (Gujarat-Nearshore)}

The wind data collected from mast anemometers with various altitudes (20-100 m) for the period of December 2018 to November 2019 is considered. The mean wind speed (MWS) data collected from mast measurements at various heights $(10$ to $100 \mathrm{~m})$ for the same period is presented in Figure 9 . The maximum mean wind speed is attained about $8.92 \mathrm{~m} / \mathrm{s}$ at $100 \mathrm{~m}$ in June and a low mean wind speed of $5.11 \mathrm{~m} / \mathrm{s}$ in November is perceived. Further, the comparison of mean wind speed gain is made while increasing the altitudes (June) at 20 and $100 \mathrm{~m}$ are $6.48 \mathrm{~m} / \mathrm{s}$, and $8.92 \mathrm{~m} / \mathrm{s}$, respectively. Wherein, the $100 \mathrm{~m}$ measurements are taken for analysis and the annual mean wind speed of $6.99 \mathrm{~m} / \mathrm{s}$ at $100 \mathrm{~m}$ is observed. The shear analysis power-law coefficient is observed as 0.0228 based on the measured wind speeds at various altitudes. On comparison with the Kayathar onshore shear coefficient, the Jafrabad nearshore is less due to its coastal area. The distance between the Jafrabad wind station and Gulf of Khambhat (offshore) is $25 \mathrm{~km}$. The wind speed behaves dynamically with different altitudes, and some steady wind speed patterns are observed at 100 and $80 \mathrm{~m}$. The wind turbine with the hub height of $80 \mathrm{~m}$ shows steady wind generation, and is suitable for efficient power production.

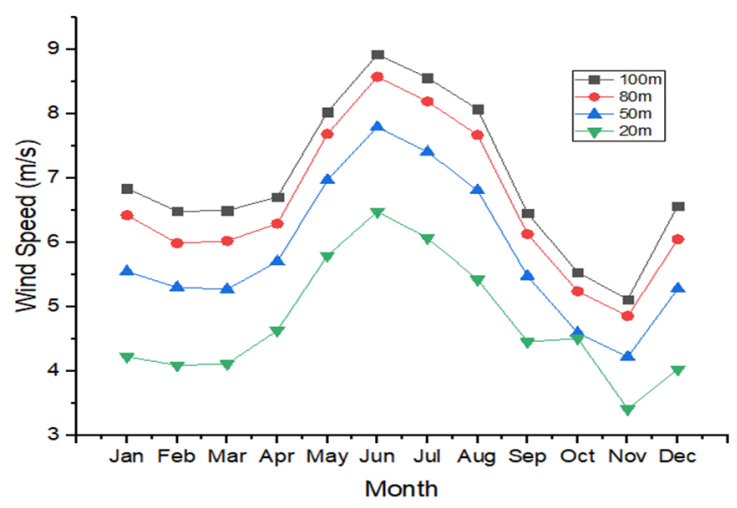

(a)

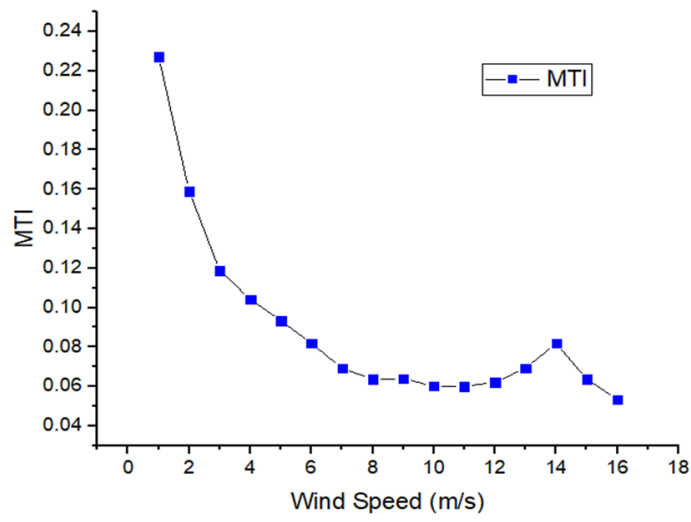

(b)

Figure 9. Jafrabad (a) wind pattern different altitude; (b) turbulence intensity.

The annual wind direction from the wind rose plots are shown in Figure 10. The maximum wind direction occurs in SW to West direction. Regarding the winter season and NEM, the wind direction 
goes toward the NNE to East direction. During the SWM season and summer monsoon periods, the majority of wind occurs in the SW to WNW direction.

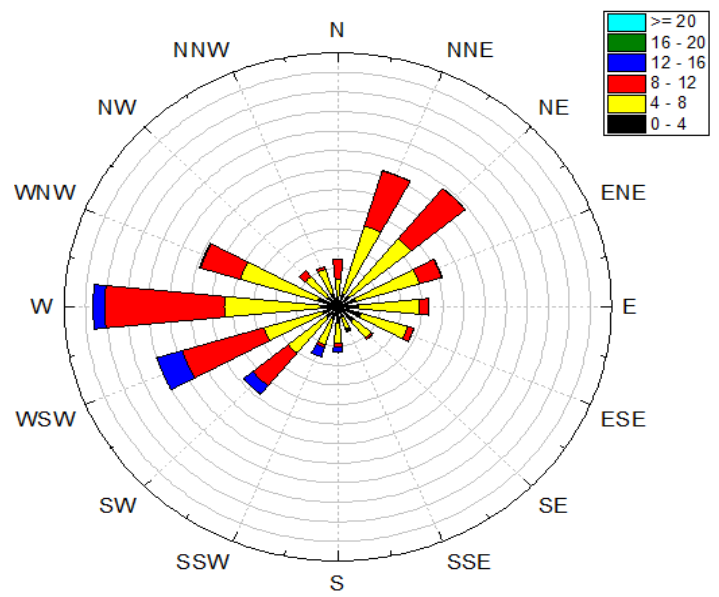

(a)

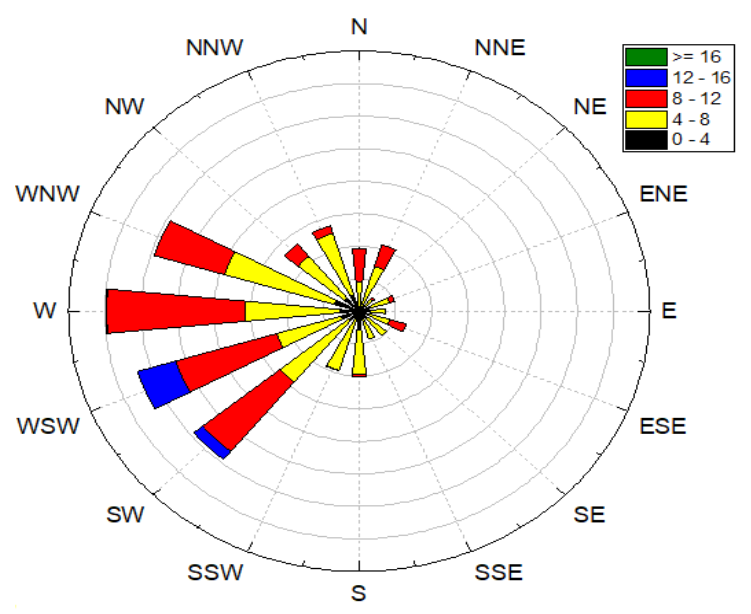

(c)

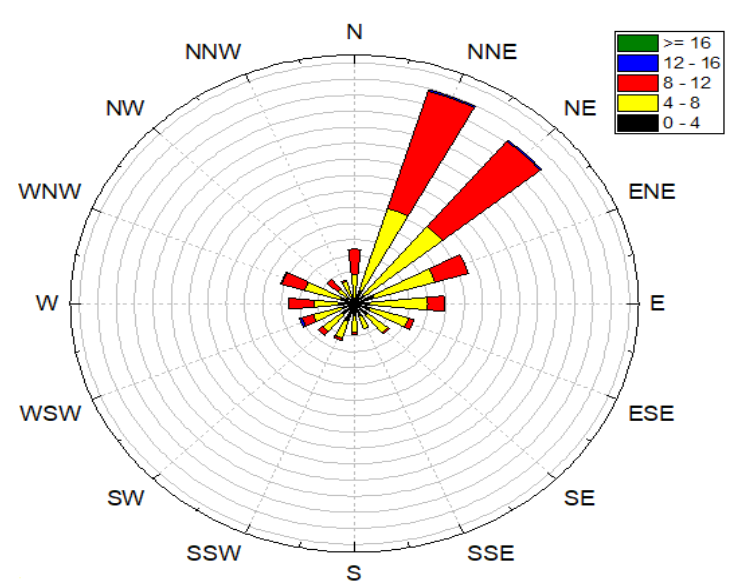

(b)

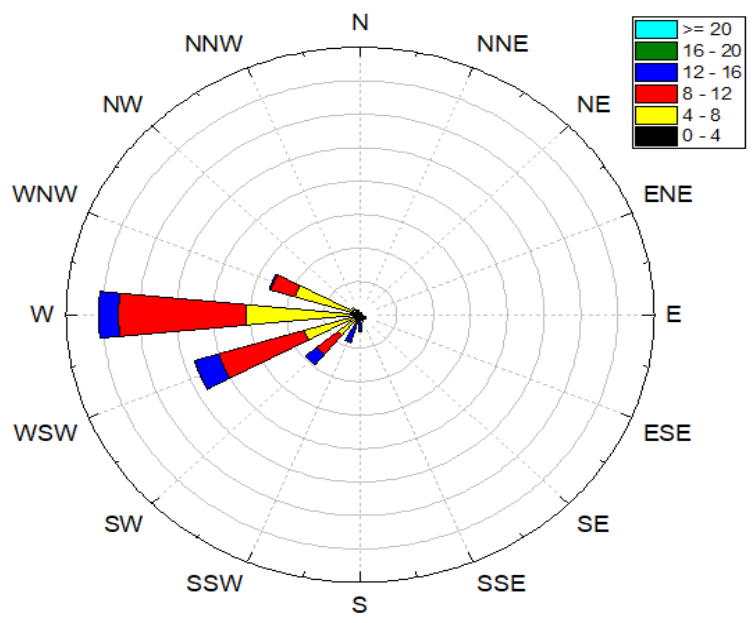

(d)

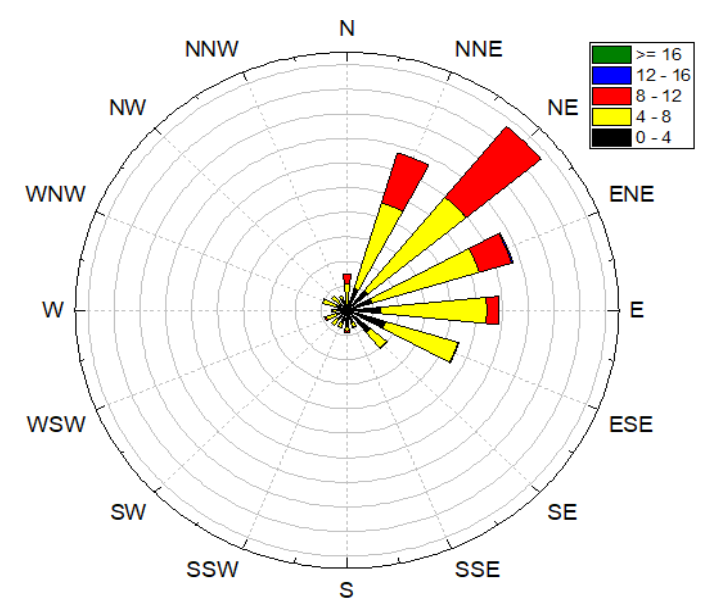

(e)

Figure 10. Wind rose: Jafrabad (a) annual; (b) winter; (c) summer; (d) SWM; (e) NEM. 
Tables 8 and 9 display the annual, seasonal, and monthly wind parameters. Table 10 shows the annual wind direction at the SW direction with maximum stake of $15.04 \%$ and mean wind speed of $7.991 \mathrm{~m} / \mathrm{s}$. Later, the WSW and WNW shares about $11.631 \%$ and $8.891 \%$ respectively, due to the South-West monsoon. The next maximum wind direction of $10.158 \%$ occurred in the NE with a mean wind speed of $7.335 \mathrm{~m} / \mathrm{s}$, followed by an NNE direction (9.42\%) with a mean wind speed of $7.217 \%$.

Table 8. Seasonal parameter-Jafrabad.

\begin{tabular}{cccccc}
\hline Wparm & Winter & Summer & SWM & NEM & Annual \\
\hline Vmean (m/s) & 6.67 & 7.08 & 8.01 & 5.74 & 6.99 \\
Vstd (m/s) & 2.58 & 2.63 & 2.97 & 2.43 & 2.83 \\
Vmax (m/s) & 13.38 & 14.75 & 17.47 & 13.72 & 17.47 \\
Skew & -0.008 & 0.09 & 0.27 & 0.30 & 0.29 \\
Kurtosis & 0.85 & -0.42 & 0.36 & 0.47 & 0.26 \\
\hline
\end{tabular}

Table 9. Monthly wind profile-Jafrabad.

\begin{tabular}{cccccccc}
\hline Month & $\mathbf{V}_{\text {mean }}(\mathbf{m} / \mathbf{s})$ & $\mathbf{V}_{\text {rmc }}(\mathbf{m} / \mathbf{s})$ & $\mathbf{V}_{\text {std }}(\mathbf{m} / \mathbf{s})$ & $\mathbf{V}_{\text {max }}(\mathbf{m} / \mathbf{s})$ & $\mathbf{V}_{\text {min }}(\mathbf{m} / \mathbf{s})$ & $\mathbf{V}_{\text {skew }}$ & $\mathbf{V}_{\text {kurt }}$ \\
\hline January & 6.84 & 7.76 & 2.68 & 14.49 & 0.42 & -0.04 & -0.85 \\
February & 6.48 & 7.38 & 2.58 & 13.70 & 0.37 & 0.03 & -0.74 \\
March & 6.49 & 7.24 & 2.31 & 13.13 & 0.52 & 0.10 & -0.47 \\
April & 6.70 & 7.60 & 2.62 & 15.0 & 0.31 & -0.02 & -0.42 \\
May & 8.02 & 8.93 & 2.88 & 15.56 & 0.51 & -0.14 & -0.47 \\
June & 8.92 & 10.11 & 3.41 & 19.09 & 0.36 & 0.28 & -0.62 \\
July & 8.56 & 9.41 & 2.90 & 17.34 & 0.53 & -0.43 & -0.38 \\
August & 8.07 & 8.88 & 2.61 & 17.79 & 1.80 & 0.55 & 0.30 \\
September & 6.45 & 7.37 & 2.54 & 14.05 & 0.47 & 0.46 & -0.14 \\
October & 5.53 & 6.38 & 2.28 & 13.78 & 0.28 & 0.41 & -0.002 \\
November & 5.11 & 6.01 & 2.28 & 19.36 & 0.24 & 0.31 & -0.06 \\
December & 6.57 & 7.50 & 2.63 & 13.17 & 0.54 & 0.07 & -0.87 \\
Annual & $\mathbf{6 . 9 9}$ & $\mathbf{8 . 0 2}$ & $\mathbf{2 . 8 3}$ & $\mathbf{1 7 . 4 7}$ & $\mathbf{0 . 5 4}$ & $\mathbf{0 . 2 9}$ & $\mathbf{- 0 . 2 6}$ \\
\hline
\end{tabular}

Table 10. Directional statistics-Jafrabad.

\begin{tabular}{ccccc}
\hline Sector & Direction Name & Mean $(\mathbf{m} / \mathbf{s})$ & Std. Dev. $(\mathbf{m} / \mathbf{s})$ & Wind Occ. $(\%)$ \\
\hline $348.75^{\circ}-11.25^{\circ}$ & N & 7.40 & 2.36 & 3.19 \\
$11.25^{\circ}-33.75^{\circ}$ & NNE & 7.21 & 2.23 & 9.42 \\
$33.75^{\circ}-56.25^{\circ}$ & NE & 7.35 & 2.41 & 10.15 \\
$56.25^{\circ}-78.75^{\circ}$ & ENE & 6.23 & 2.38 & 6.69 \\
$78.75^{\circ}-101.25^{\circ}$ & E & 5.39 & 2.02 & 5.59 \\
$101.25^{\circ}-123.75^{\circ}$ & ESE & 5.04 & 1.96 & 4.89 \\
$123.75^{\circ}-146.25^{\circ}$ & SE & 4.45 & 1.93 & 2.81 \\
$146.25^{\circ}-168.75^{\circ}$ & SSE & 4.97 & 3.27 & 1.74 \\
$168.75^{\circ}-191.25^{\circ}$ & S & 6.05 & 3.85 & 3.03 \\
$191.25^{\circ}-213.75^{\circ}$ & SSW & 6.71 & 3.96 & 3.47 \\
$213.75^{\circ}-236.25^{\circ}$ & SW & 7.81 & 3.07 & 7.50 \\
$236.25^{\circ}-258.75^{\circ}$ & WSW & 8.61 & 3.12 & 11.63 \\
$258.75^{\circ}-281.25^{\circ}$ & W & 7.99 & 2.57 & 15.04 \\
$281.25^{\circ}-303.75^{\circ}$ & WNW & 6.65 & 2.41 & 8.89 \\
$303.75^{\circ}-326.25^{\circ}$ & NW & 5.45 & 2.26 & 3.11 \\
$326.25^{\circ}-348.75^{\circ}$ & NNW & 5.14 & 1.86 & 2.77 \\
\hline
\end{tabular}

\subsection{Wind Distribution Fitting}

For estimating the wind energy potential, accurate wind distribution modeling is essential to extract wind power meritoriously. The performance of targeted location wind potential assessment 
hinges on the selection of the PDF to illustrate the computed wind speed behavior plotted in the frequency distribution.

The collected wind speed data to fit into ten numbers of wind distribution such as Weibull, Rayleigh, Birnbaum-Sandras (BS), gamma (GM), inverse Gaussian (IG), Rician (RI), lognormal (LN), Nakagami (NK), GEV and bimodal Weibull-Weibull (BM) distribution methods. The bimodal WW method is adopted, since the visual traces of probability distribution function have similarity in the bimodal with two peaks. The bimodal nature is predicted by numerical calculations of mean and standard deviation [33,34]. The goodness of fit and best-fitted wind distribution is ascertained with RMSE and $\mathrm{R}^{2}$ methods by comparing actual measured data with individual wind distribution methods through PDFs. In this work, three methods are adopted, namely the maximum likelihood method (MLM), expectation-maximization algorithm (EM) and moth flame optimization (MFO). The bimodal-Weibull-Weibull methods are used to estimate the parameters of wind speed distributions. The EM method consists of two steps, namely the expectation-step (E-step) and the maximization-step (M-step). The E-step computes the conditional expectation and the M-step maximizes the expectation. The parameters of the bimodal and multimodal distribution are estimated by an iterative procedure until convergence is reached. Additionally, the bimodal WW parameters (Appendix B) were estimated through the MFO with objective function by minimizing the error between estimated and observed PDF. The distribution of wind speed data (also known as wind frequency distribution) is presented by histogram plots which are a usual method of presenting wind data for a specific year. The histogram displays the percentage of time of occurrence of each wind speed ranges.

\subsubsection{Kayathar Station (Onshore)}

The annual wind speed observed at the $100 \mathrm{~m}$ hub height with estimated parameters using 10 distributions through probability distribution function (PDF) and cumulative probability distribution (CDF) plots are shown in Figure 11. The observed wind speed plotted into frequency distribution is fitting with other distributions to observe the difference in the fitting of each distribution with real histogram data.

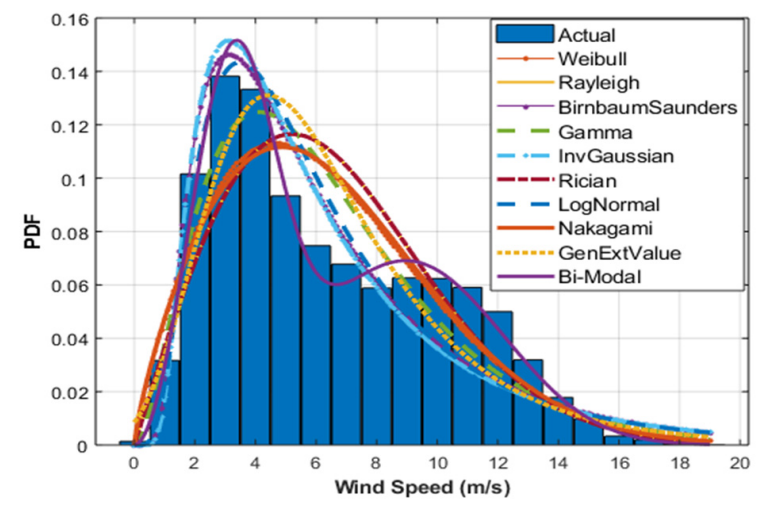

(a)

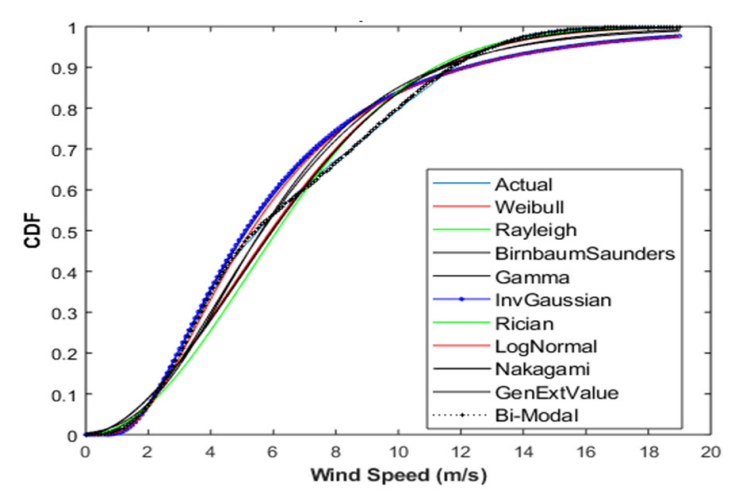

(b)

Figure 11. Annual wind behavior of Kayathar with ten wind distributions: (a) annual probability density functions (PDF); (b) annual cumulative probability distribution (CDF).

The wind distribution from the bimodal Weibull-Weibull method closely follows the peaks of observed histogram wind patterns. The other distribution plots seem to be under fitting and close fit to the observed histogram as per the pictorial observation. Figure 12 shows the seasonal wind speed pattern by estimated parameters with distribution functions and plotted with PDF functions. The visual examination of PDF-specifically the Rayleigh distribution-behaves distinctly from other distributions during winter, summer, and SEM monsoon periods. During winter, Rayleigh performs well owing to the incidence of low wind speed. 


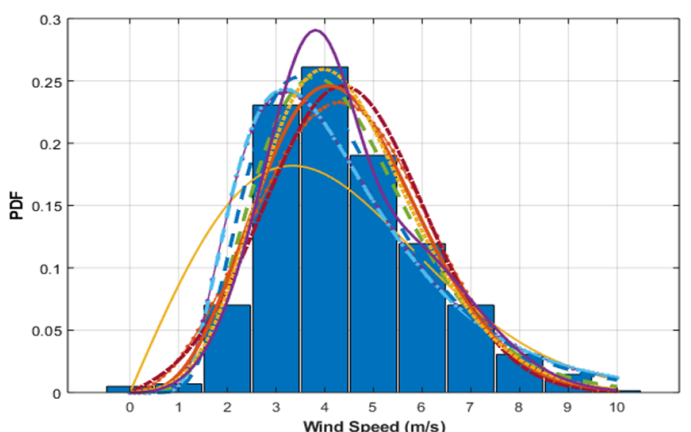

(a)

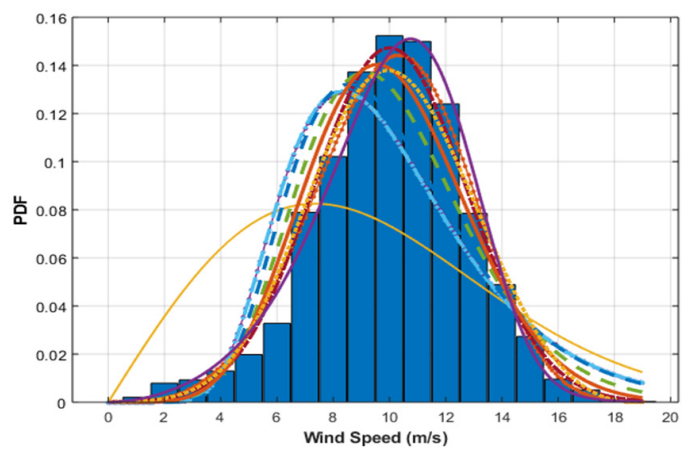

(c)

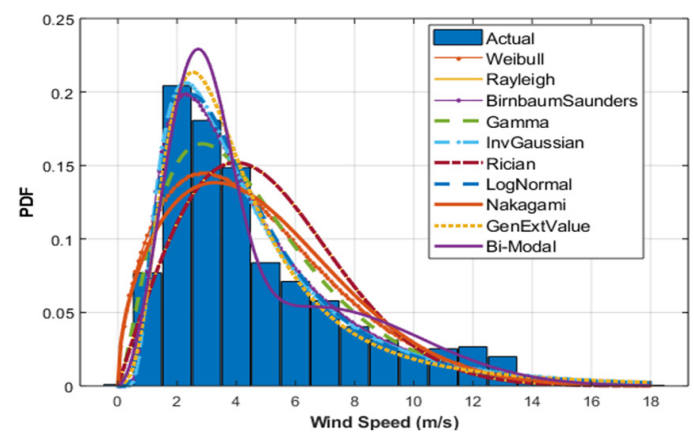

(b)

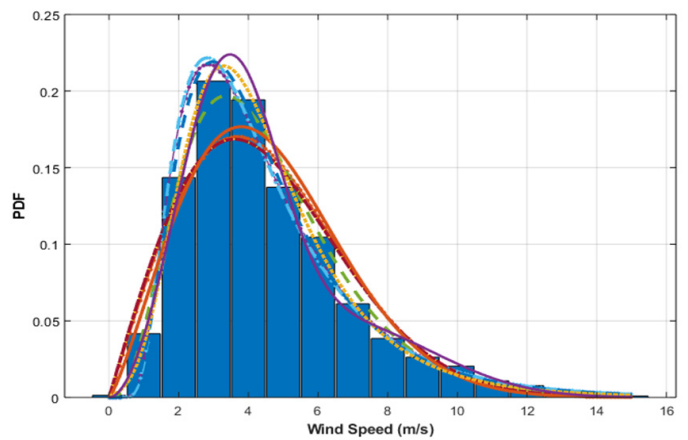

(d)

Figure 12. Seasonal plots PDF of Kayathar: (a) winter; (b) summer; (c) SWM; (d) NEM.

It is also observed that the Rayleigh distribution suffers from histogram fitting during the winter and Southwest Monsoon periods. The bimodal behavior observed during the summer season and the curve follows the histogram variations.

\subsubsection{Bi-Modal Behavior}

The bi-modal WW method was applied to observe the data in two parts with different weightage, as shown in Table 11. It is estimated using bimodal methods through the EM (expectation-maximization) algorithm and the values are plotted on each part along with weightage, mean speed, standard deviation, shape, and scale parameters. The bmc1 and bmc2 are the bimodality numerical check apart from visual analysis. Where bmc1 $=|\mu 2-\mu 1| /\left(2(\sigma 1 \times \sigma 2)^{(1 / 2)}\right)$ when bmc1 $>1$. Likewise, bmc2 == $\mid \mu 2$ $-\mu 1 / /\left(2^{*} \min (\sigma 1, \sigma 2)\right)$ when bmc $2>2$. ( $\mu 1$ and $\mu 2$ are means, and $\sigma 1$ and $\sigma 2$ are standard deviations of 2 parts of the bimodal model.

Table 11. Kayathar bimodal estimated parameters.

\begin{tabular}{|c|c|c|c|c|c|c|c|c|c|c|c|c|c|}
\hline Seasons & $\mathrm{V}_{\text {mean }}(\mathrm{m} / \mathrm{s})$ & mu1 & mu2 & sigma1 & sigma2 & w1 & w2 & k1bm & c1bm & $\mathrm{k} 2 \mathrm{bm}$ & $\mathrm{c} 2 \mathrm{bm}$ & bmc1 & bmc2 \\
\hline Annual & 6.38 & 3.36 & 8.96 & 1.27 & 2.98 & 0.45 & 0.54 & 2.87 & 3.76 & 3.29 & 9.99 & 1.43 & 3.05 \\
\hline Winter & 4.43 & 3.51 & 5.06 & 0.84 & 1.68 & 0.40 & 0.59 & 4.69 & 3.84 & 3.29 & 5.64 & 0.64 & -0.15 \\
\hline Summer & 4.69 & 2.74 & 7.28 & 1.05 & 3.08 & 0.57 & 0.42 & 2.82 & 3.08 & 2.54 & 8.21 & 1.25 & 2.43 \\
\hline SWM & 10.03 & 8.54 & 10.4 & 3.27 & 2.32 & 0.22 & 0.77 & 2.82 & 9.59 & 5.13 & 11.39 & 0.35 & -2.70 \\
\hline NEM & 4.51 & 3.45 & 6.71 & 1.29 & 2.51 & 0.67 & 0.32 & 2.89 & 3.87 & 2.90 & 7.52 & 0.90 & 0.66 \\
\hline
\end{tabular}

The wind distribution examination in the Kayathar region falls on multiple peaks and differs from normal bell-shaped histogram curves. The bimodal behavior is exclusively analyzed with the bimodal Weibull-Weibull method. Figure 13 shows the bimodal behavior of the annual and winter season. The annual season has more bimodality than winter through visual analysis, as given in Table 11, i.e., bmc 1 and bmc2 estimation. Wherein, winter comprises a lesser range of bmc1 and bmc 2 of 0.64 and -0.1511 respectively with the annual value of 1.43 and 3.05 for bmc1 and bmc2 respectively. 


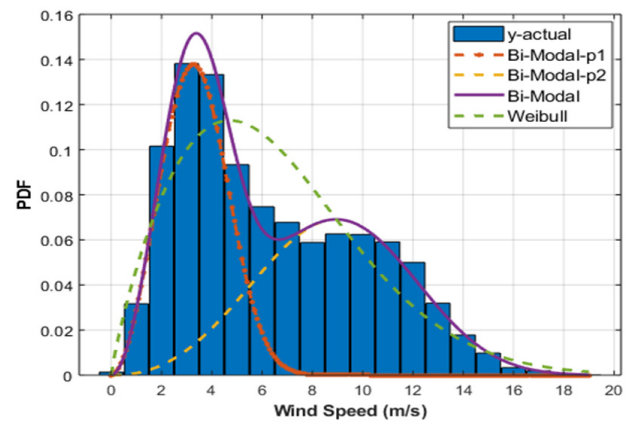

(a)

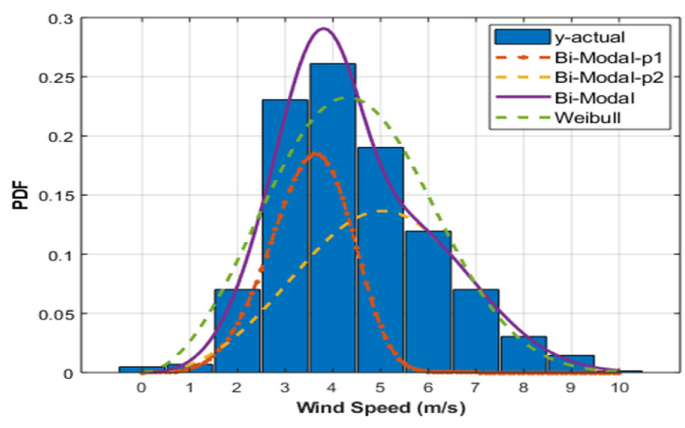

(b)

Figure 13. Kayathar: (a) bimodal annual plot; (b) winter bimodal plot.

Table 12 shows the yearly and seasonal parameters from the observed wind speed by ten wind distribution models with the parameter estimation from the maximum likelihood method. The MATLAB developed in-house software program codes are used for parameter estimation.

Table 12. Kayathar wind distribution estimated parameters.

\begin{tabular}{|c|c|c|c|c|c|c|}
\hline Dist & Parameter & Annual & Winter & Summer & SWM & NEM \\
\hline \multirow{5}{*}{ WB } & $\mathrm{V}_{\text {mean }}(\mathrm{m} / \mathrm{s})$ & 6.38 & 4.43 & 4.69 & 10.04 & 4.51 \\
\hline & k-shape & 7.21 & 4.96 & 5.28 & 11.03 & 5.11 \\
\hline & c-scale & 1.84 & 2.93 & 1.61 & 4.19 & 2.05 \\
\hline & Mean & 6.41 & 4.42 & 4.73 & 10.02 & 4.53 \\
\hline & Std & 3.61 & 1.63 & 2.99 & 2.70 & 2.32 \\
\hline \multirow[t]{3}{*}{$\mathrm{RY}$} & $\sigma$-scale & 5.20 & 3.33 & 3.99 & 7.35 & 3.60 \\
\hline & Mean & 6.52 & 4.17 & 5.00 & 9.21 & 4.51 \\
\hline & Std & 3.40 & 2.18 & 2.61 & 4.82 & 2.36 \\
\hline \multirow[t]{4}{*}{ NK } & $\mu$-shape & 0.88 & 2.00 & 0.75 & 3.24 & 1.13 \\
\hline & $\omega$-scale & 54.17 & 22.22 & 31.85 & 108.07 & 25.88 \\
\hline & Mean & 6.43 & 4.43 & 4.82 & 10.00 & 4.57 \\
\hline & Std & 3.57 & 1.60 & 2.92 & 2.83 & 2.24 \\
\hline \multirow[t]{4}{*}{ IG } & $\mu$-mean & 6.38 & 4.43 & 4.69 & 10.04 & 4.51 \\
\hline & $\lambda$-shape & 12.27 & 19.58 & 9.02 & 80.13 & 13.79 \\
\hline & Mean & 6.38 & 4.43 & 4.69 & 10.04 & 4.51 \\
\hline & Std & 4.60 & 2.11 & 3.38 & 3.55 & 2.58 \\
\hline \multirow[t]{4}{*}{ RI } & $\mathrm{b}$-location & 0.68 & 4.06 & 0.23 & 9.63 & 0.27 \\
\hline & a-scale & 5.18 & 1.69 & 3.99 & 2.76 & 3.59 \\
\hline & Mean & 6.52 & 4.43 & 5.00 & 10.04 & 4.51 \\
\hline & Std & 3.41 & 1.59 & 2.61 & 2.70 & 2.36 \\
\hline \multirow[t]{4}{*}{ BS } & $\beta$-scale & 5.16 & 3.99 & 3.81 & 9.46 & 3.91 \\
\hline & $\gamma$-shape & 0.68 & 0.46 & 0.68 & 0.35 & 0.55 \\
\hline & Mean & 6.37 & 4.42 & 4.70 & 10.03 & 4.51 \\
\hline & Std & 4.43 & 2.08 & 3.27 & 3.54 & 2.54 \\
\hline \multirow[t]{4}{*}{ GM } & $\theta$-scale & 2.82 & 6.94 & 2.54 & 11.00 & 3.91 \\
\hline & $\mathrm{k}$-shape & 2.26 & 0.63 & 1.85 & 0.91 & 1.15 \\
\hline & Mean & 6.38 & 4.43 & 4.70 & 10.04 & 4.51 \\
\hline & Std & 3.80 & 1.68 & 2.95 & 3.03 & 2.28 \\
\hline \multirow[t]{5}{*}{ GEV } & $\mu$-location & 0.05 & -0.13 & 0.31 & -0.28 & 0.07 \\
\hline & $\sigma$-scale & 2.81 & 1.43 & 1.80 & 2.79 & 1.70 \\
\hline & $\xi$-shape & 4.58 & 3.77 & 3.01 & 9.07 & 3.40 \\
\hline & Mean & 6.38 & 4.43 & 4.84 & 10.06 & 4.51 \\
\hline & Std & 3.92 & 1.59 & 4.59 & 2.78 & 2.42 \\
\hline \multirow[t]{4}{*}{$\mathrm{LN}$} & $\mu$-mean & 1.66 & 1.41 & 1.34 & 2.26 & 1.37 \\
\hline & $\sigma$-scale & 0.64 & 0.41 & 0.65 & 0.33 & 0.53 \\
\hline & Mean & 6.53 & 4.49 & 4.72 & 10.13 & 4.55 \\
\hline & Std & 0.64 & 0.41 & 0.65 & 0.33 & 0.53 \\
\hline
\end{tabular}


Table 13 displays the goodness of fit methods of RMSE and $\mathrm{R}^{2}$ between estimated wind distribution parameters and observed parameters by the ten distributions PDF. The annual wind distribution rate of the Kayathar region shows lower RMSE and $\mathrm{R}^{2}$ value of 0.004 and 0.9878 respectively. The seasonal wind distribution fitness such as winter (best fit by gamma method), summer (inverse gamma), SWM (Rician method) and winter season (GEV method) are observed. From the Kayathar wind distribution fitting observations, the bimodal Weibull-Weibull wind distribution is best suited, compared to other wind speed distributions on annual wind flow analyses.

Table 13. Kayathar wind distribution PDF fitness.

\begin{tabular}{|c|c|c|c|c|c|c|}
\hline \multicolumn{7}{|c|}{ Distribution Metrics } \\
\hline Season & Fitness & Annual & Winter & Summer & SWM & NEM \\
\hline $\mathrm{V}_{\text {mean }}$ & & 6.39 & 4.43 & 4.70 & 10.04 & 4.51 \\
\hline \multirow[t]{2}{*}{$\mathrm{BM}$} & RMSE & 0.00 & 0.01 & 0.01 & 0.01 & 0.01 \\
\hline & $R^{2}$ & 0.99 & 0.99 & 0.96 & 0.98 & 0.99 \\
\hline \multirow[t]{2}{*}{ WB } & RMSE & 0.02 & 0.02 & 0.02 & 0.01 & 0.02 \\
\hline & $\mathrm{R}^{2}$ & 0.82 & 0.93 & 0.87 & 0.99 & 0.94 \\
\hline \multirow[t]{2}{*}{ RY } & RMSE & 0.02 & 0.05 & 0.03 & 0.04 & 0.02 \\
\hline & $\mathrm{R}^{2}$ & 0.76 & 0.76 & 0.73 & 0.46 & 0.94 \\
\hline \multirow[t]{2}{*}{ NK } & RMSE & 0.02 & 0.02 & 0.03 & 0.01 & 0.02 \\
\hline & $R^{2}$ & 0.81 & 0.97 & 0.82 & 0.95 & 0.95 \\
\hline \multirow[t]{2}{*}{ IG } & RMSE & 0.02 & 0.03 & 0.01 & 0.03 & 0.01 \\
\hline & $\mathrm{R}^{2}$ & 0.91 & 0.90 & 0.98 & 0.78 & 0.97 \\
\hline \multirow[t]{2}{*}{ RI } & RMSE & 0.02 & 0.03 & 0.03 & 0.01 & 0.02 \\
\hline & $\mathrm{R}^{2}$ & 0.76 & 0.92 & 0.73 & 0.99 & 0.94 \\
\hline \multirow[t]{2}{*}{ BS } & RMSE & 0.01 & 0.03 & 0.01 & 0.03 & 0.01 \\
\hline & $\mathrm{R}^{2}$ & 0.91 & 0.90 & 0.98 & 0.78 & 0.98 \\
\hline \multirow[t]{2}{*}{ GM } & RMSE & 0.02 & 0.01 & 0.02 & 0.02 & 0.01 \\
\hline & $\mathrm{R}^{2}$ & 0.86 & 0.99 & 0.91 & 0.91 & 0.99 \\
\hline \multirow[t]{2}{*}{ GEV } & RMSE & 0.02 & 0.01 & 0.01 & 0.01 & 0.00 \\
\hline & $\mathrm{R}^{2}$ & 0.81 & 0.98 & 0.98 & 0.98 & 1.00 \\
\hline \multirow[t]{2}{*}{$\mathrm{LN}$} & RMSE & 0.02 & 0.02 & 0.01 & 0.02 & 0.01 \\
\hline & $R^{2}$ & 0.90 & 0.97 & 0.98 & 0.83 & 0.99 \\
\hline Good Fit & RMSE & $\mathrm{BM}$ & Gamma & $\mathrm{IG}$ & Rician & GEV \\
\hline Good Fit & $\mathrm{R}^{2}$ & $\mathrm{BM}$ & Gamma & $\mathrm{IG}$ & Rician & GEV \\
\hline
\end{tabular}

\subsubsection{Gulf of Khambat (Offshore) Wind Distribution}

The annual wind speed observed at $100 \mathrm{~m}$ with estimated parameters by 10 distributions through probability distribution function (PDF) and cumulative probability distribution (CDF) plots in the Gulf of Khambhat region is presented in Figure 14. 


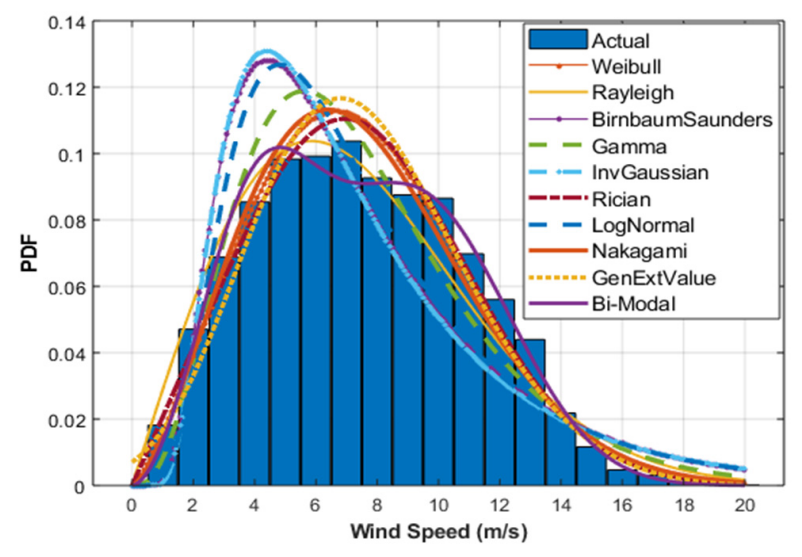

(a)

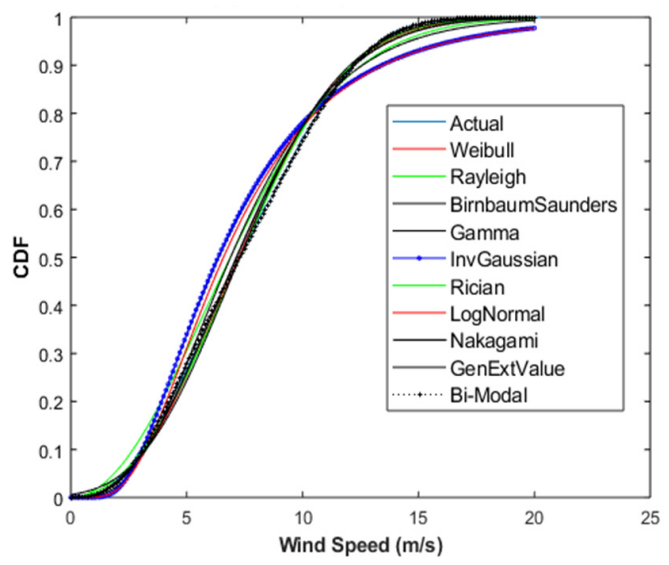

(b)

Figure 14. Gulf of Khambhat: (a) annual PDF; (b) annual CDF.

The Gulf of Khambhat wind distribution presented in a frequency distribution histogram plot is shown in the above Figure. Some bimodal traces and the bimodal distribution follows the peaks of a histogram, and most of the wind distributions seem to be slightly over fit. As per the observations, all the wind distributions follow the histogram if there are no bimodal traces. On bimodal traces, all distributions are slightly deviating except bimodal wind distributions.

Figure 15 shows the seasonal wind speed pattern by the estimated parameters using distribution functions and plotted with PDF functions. The Rician, Weibull and Nakagami seem to follow the histogram. Whereas, the bimodal distribution seems to be a close fit. The Rayleigh distribution shown in the orange line in the PDF plot during the Southwest monsoon deviates from the observed frequency histogram plot. The Rayleigh distribution looks to be fit on low wind speed seasons only. Table 14 shows the bi-modal WW method parameters. The bmc1 and bmc2 are the bimodality numerical check apart from visual analysis.

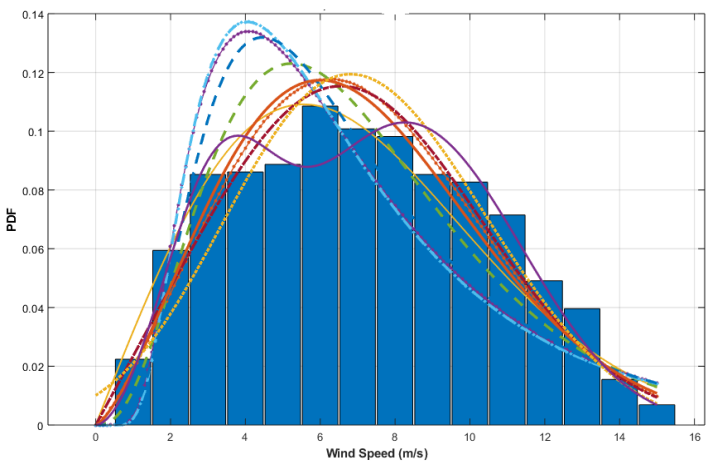

(a)

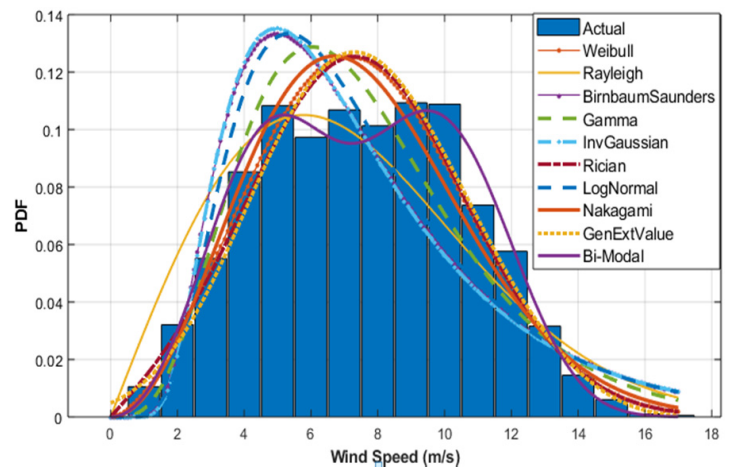

(b)

Figure 15. Cont. 


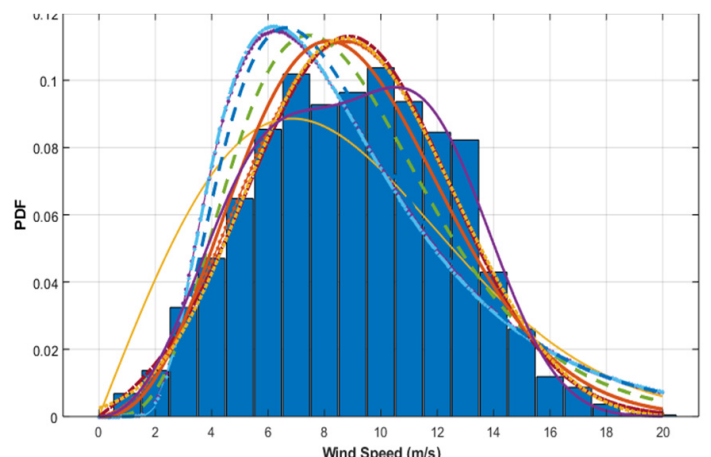

(c)

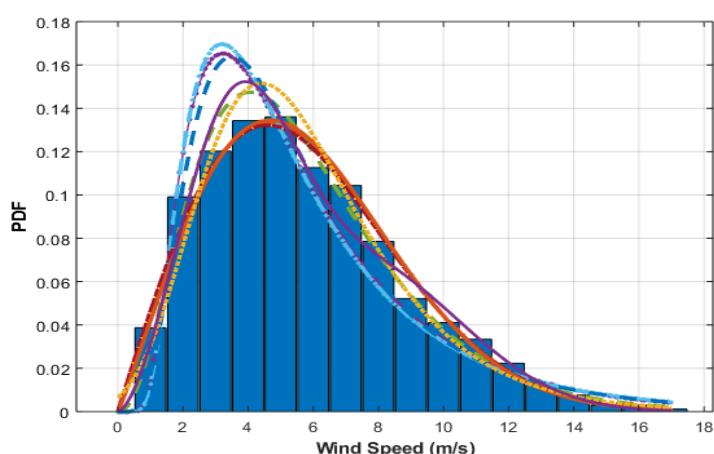

(d)

Figure 15. Gulf of Khambhat seasonal PDF: (a) winter; (b) summer; (c) SWM; (d) NEM.

Table 14. Gulf of Khambhat bimodal estimated parameters.

\begin{tabular}{ccccccccccccc}
\hline Season & mu1 & mu2 & sigma1 & sigma2 & w1 & w2 & k1bm & c1bm & k2bm & c2bm & bmc1 & bmc2 \\
\hline Ann & 4.18 & 9.01 & 1.66 & 2.95 & 0.31 & 0.69 & 2.72 & 4.70 & 3.36 & 10.04 & 1.09 & 1.51 \\
Win & 3.35 & 8.32 & 1.31 & 2.82 & 0.24 & 0.76 & 2.78 & 3.76 & 3.24 & 9.29 & 1.30 & 2.36 \\
Sum & 4.63 & 9.29 & 1.66 & 2.32 & 0.37 & 0.63 & 3.05 & 5.18 & 4.51 & 10.18 & 1.19 & 1.34 \\
SWM & 5.68 & 10.62 & 2.04 & 2.78 & 0.32 & 0.68 & 3.04 & 6.36 & 4.29 & 11.67 & 1.04 & 0.86 \\
NEM & 3.78 & 7.59 & 1.57 & 2.87 & 0.48 & 0.52 & 2.60 & 4.26 & 2.87 & 8.51 & 0.90 & 0.67 \\
\hline
\end{tabular}

The wind distribution analysis in the Gulf of Khambhat region falls on multiple peaks. Figure 15 shows the bimodal behavior of the annual and winter season. The annual season has less bimodality than winter through visual analysis. The estimated value of bmc1 and bmc2 are observed as 1.29 and 2.35 respectively. The annual value has a lower score of bmc1 and bmc 2 of about 1.09 and 1.50 respectively.

Table 15 shows the yearly and seasonal parameters from the observed wind speed by ten wind distribution models with the parameter estimation from the maximum likelihood method. Table 16 shows the goodness of fit methods of RMSE and $\mathrm{R}^{2}$ between estimated wind distribution parameters and observed parameters by ten distribution models. The annual wind distribution pattern follows the bimodal-WW wind distribution model with a lower rate of RMSE and $\mathrm{R}^{2}$ values.

Table 15. Gulf of Khambhat wind distribution estimated parameters.

\begin{tabular}{ccccccc}
\hline Dist & Param & Annual & Winter & Summer & SWM & NEM \\
\hline $\mathrm{V}_{\text {mean }}$ & & 7.51 & 7.13 & 7.56 & 9.05 & 5.75 \\
WB & k-shape & 8.48 & 8.05 & 8.51 & 10.15 & 6.50 \\
& c-scale & 2.33 & 2.30 & 2.68 & 2.87 & 2.02 \\
& Mean & 7.52 & 7.13 & 7.56 & 9.05 & 5.76 \\
\multirow{2}{*}{ RY } & Std & 3.43 & 3.28 & 3.05 & 3.42 & 2.98 \\
& $\sigma$-scale & 5.84 & 5.56 & 5.77 & 6.85 & 4.59 \\
& Mean & 7.32 & 6.97 & 7.23 & 8.58 & 5.75 \\
NK & Std & 3.83 & 3.64 & 3.78 & 4.48 & 3.01 \\
& $\mu$-shape & 1.24 & 1.20 & 1.53 & 1.72 & 1.05 \\
& $\omega-$ scale & 68.31 & 61.77 & 66.64 & 93.71 & 42.10 \\
& Mean & 7.49 & 7.10 & 7.53 & 9.01 & 5.78 \\
IG & Std & 3.49 & 3.37 & 3.15 & 3.54 & 2.95 \\
& $\mu$-mean & 7.51 & 7.13 & 7.56 & 9.05 & 5.75 \\
& $\lambda$-shape & 20.02 & 17.96 & 26.08 & 35.49 & 13.92 \\
& Mean & 7.51 & 7.13 & 7.56 & 9.05 & 5.75 \\
\end{tabular}


Table 15. Cont.

\begin{tabular}{|c|c|c|c|c|c|c|}
\hline Dist & Param & Annual & Winter & Summer & SWM & NEM \\
\hline \multirow[t]{4}{*}{ RI } & $\mathrm{b}$-location & 5.96 & 5.60 & 6.61 & 8.13 & 0.65 \\
\hline & a-scale & 4.05 & 3.90 & 3.39 & 3.71 & 4.57 \\
\hline & Mean & 7.51 & 7.13 & 7.56 & 9.04 & 5.75 \\
\hline & Std & 3.45 & 3.31 & 3.09 & 3.45 & 3.01 \\
\hline \multirow[t]{4}{*}{ BS } & $\beta$-scale & 6.39 & 6.01 & 6.64 & 8.06 & 4.82 \\
\hline & $\gamma$-shape & 0.59 & 0.60 & 0.52 & 0.49 & 0.61 \\
\hline & Mean & 7.49 & 7.11 & 7.55 & 9.03 & 5.73 \\
\hline & Std & 4.49 & 4.37 & 4.01 & 4.51 & 3.60 \\
\hline \multirow[t]{4}{*}{ GM } & $\theta$-scale & 3.96 & 3.77 & 4.96 & 5.63 & 3.42 \\
\hline & $k$-shape & 1.90 & 1.89 & 1.52 & 1.61 & 1.68 \\
\hline & Mean & 7.51 & 7.13 & 7.56 & 9.05 & 5.75 \\
\hline & Std & 3.78 & 3.67 & 3.40 & 3.81 & 3.11 \\
\hline \multirow[t]{5}{*}{ GEV } & $\mu$-location & -0.19 & -0.25 & -0.26 & -0.25 & -0.02 \\
\hline & $\sigma$-scale & 3.21 & 3.19 & 3.01 & 3.38 & 2.43 \\
\hline & $\xi$-shape & 6.15 & 5.91 & 6.44 & 7.77 & 4.37 \\
\hline & Mean & 7.49 & 7.10 & 7.55 & 9.04 & 5.73 \\
\hline & Std & 3.41 & 3.24 & 3.04 & 3.44 & 3.05 \\
\hline \multirow[t]{3}{*}{ LN } & $\mu-$ mean & 1.88 & 1.83 & 1.92 & 2.11 & 1.60 \\
\hline & $\sigma$-scale & 0.56 & 0.57 & 0.50 & 0.47 & 0.59 \\
\hline & Mean & 7.70 & 7.32 & 7.71 & 9.20 & 5.86 \\
\hline
\end{tabular}

Table 16. The goodness of fit values for the Gulf of Khambhat.

\begin{tabular}{ccccccc}
\hline Season & Fitness & Annual & Winter & Summer & SWM & NEM \\
\hline BM & RMSE & 0.00 & 0.01 & 0.01 & 0.01 & 0.01 \\
& $\mathrm{R}^{2}$ & 0.99 & 0.95 & 0.98 & 0.98 & 0.97 \\
WB & $\mathrm{RMSE}$ & 0.01 & 0.01 & 0.01 & 0.01 & 0.01 \\
& $\mathrm{R}^{2}$ & 0.97 & 0.93 & 0.95 & 0.96 & 0.99 \\
$\mathrm{RY}$ & $\mathrm{RMSE}$ & 0.01 & 0.01 & 0.02 & 0.02 & 0.01 \\
& $\mathrm{R}^{2}$ & 0.96 & 0.91 & 0.84 & 0.79 & 0.99 \\
$\mathrm{NK}$ & $\mathrm{RMSE}$ & 0.01 & 0.01 & 0.01 & 0.01 & 0.01 \\
& $\mathrm{R}^{2}$ & 0.97 & 0.92 & 0.93 & 0.94 & 0.98 \\
$\mathrm{IG}$ & $\mathrm{RMSE}$ & 0.02 & 0.03 & 0.02 & 0.02 & 0.02 \\
& $\mathrm{R}^{2}$ & 0.78 & 0.68 & 0.73 & 0.73 & 0.90 \\
$\mathrm{RI}$ & $\mathrm{RMSE}$ & 0.01 & 0.01 & 0.01 & 0.01 & 0.01 \\
& $\mathrm{R}^{2}$ & 0.98 & 0.94 & 0.94 & 0.96 & 0.99 \\
$\mathrm{BS}$ & $\mathrm{RMSE}$ & 0.02 & 0.03 & 0.02 & 0.02 & 0.02 \\
& $\mathrm{R}^{2}$ & 0.79 & 0.70 & 0.75 & 0.74 & 0.91 \\
Gamma & $\mathrm{RMSE}$ & 0.01 & 0.02 & 0.02 & 0.01 & 0.01 \\
& $\mathrm{R}^{2}$ & 0.92 & 0.85 & 0.87 & 0.89 & 0.99 \\
GEV & $\mathrm{RMSE}$ & 0.01 & 0.01 & 0.01 & 0.01 & 0.01 \\
& $\mathrm{R}^{2}$ & 0.96 & 0.90 & 0.94 & 0.96 & 0.97 \\
LN & $\mathrm{RMSE}$ & 0.02 & 0.02 & 0.02 & 0.02 & 0.01 \\
& $\mathrm{R}^{2}$ & 0.83 & 0.74 & 0.78 & 0.79 & 0.93 \\
Good Fit & $\mathrm{RMSE}$ & $\mathrm{BM}$ & $\mathrm{WB}$ & $\mathrm{BM}$ & $\mathrm{BM}$ & Rayleigh \\
& $\mathrm{R}^{2}$ & $\mathrm{BM}$ & $\mathrm{BM}$ & $\mathrm{BM}$ & $\mathrm{BM}$ & Rayleigh \\
\hline
\end{tabular}

By comparing the annual best fit, the bimodal WW distribution performed well compared with the other distributions as indicated with the $\mathrm{R}^{2}$ and RMSE values of 0.98 and 0.004 , respectively. During seasonal periods, the bimodal WW performed well on summer and SWM periods. The Weibull and $\mathrm{BM}$ share the best fit during the winter season, and the Rayleigh distribution performed well during the North East monsoon (NEM) period. 


\subsubsection{Jafrabad Station (Nearshore) Distribution Fitting}

Figure 16 shows the annual wind speed observed at the $100 \mathrm{~m}$ hub height with computed parameters by 10 distributions of PDF and CDF plots in the Jafrabad nearshore region. The wind distribution representation of the Jafrabad plot such as inverse Gaussian, gamma, and lognormal distribution looks to over fit the histogram. Whereas, the Weibull, Rician, Nakagami and bimodal distributions appear to fit the frequency distribution plot. The seasonal wind speed pattern of the estimated parameters by the distribution functions and plotted with PDF is shown in Figure 17. The bimodality is observed in the winter season of the Jafrabad plot with peaks of histogram and summer season. The Rayleigh shows the usual trend, which has diverged during the Southwest monsoon. It behaves worse during the high-wind period of the SEM. The other wind distributions, such as the Rician, Weibull and Nakagami, are responding well during the high-wind periods.

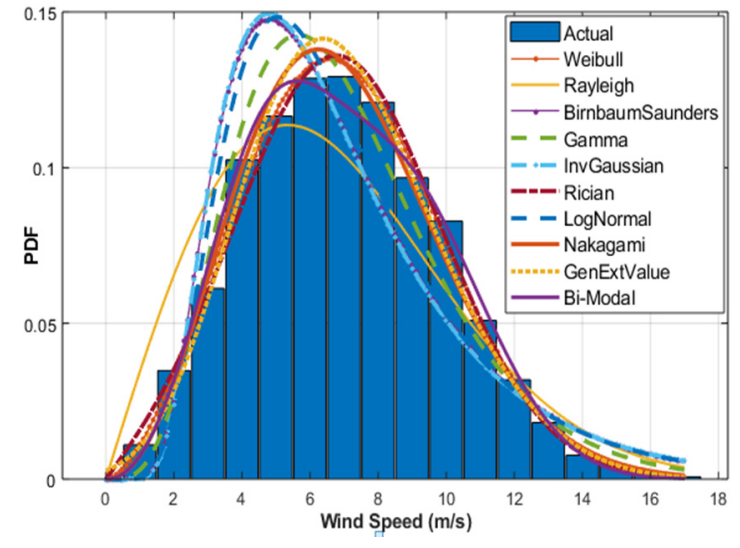

(a)

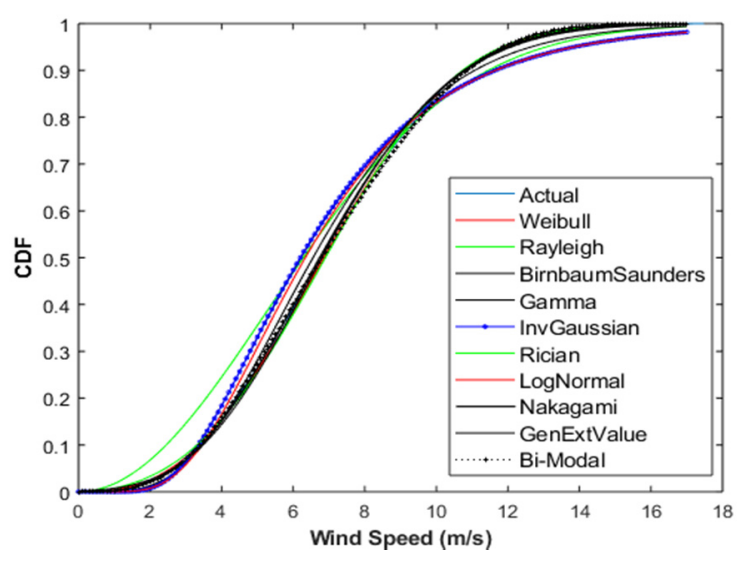

(b)

Figure 16. (a) Jafrabad annual PDF; (b) Jafrabad annual CDF.

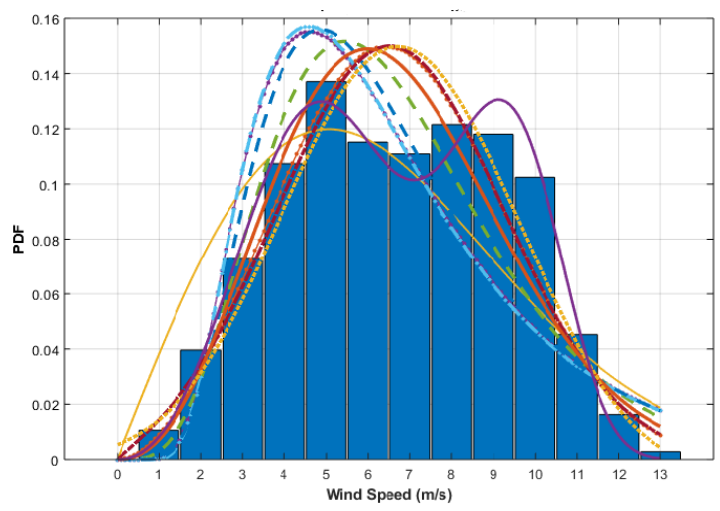

(a)

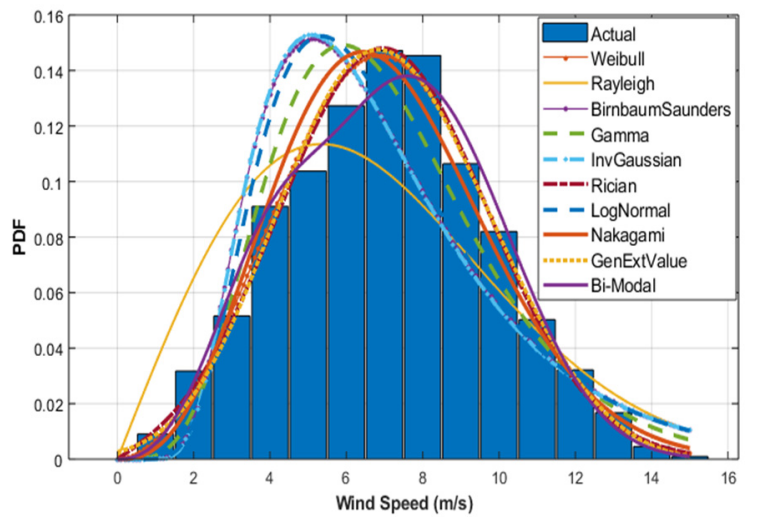

(b)

Figure 17. Cont. 


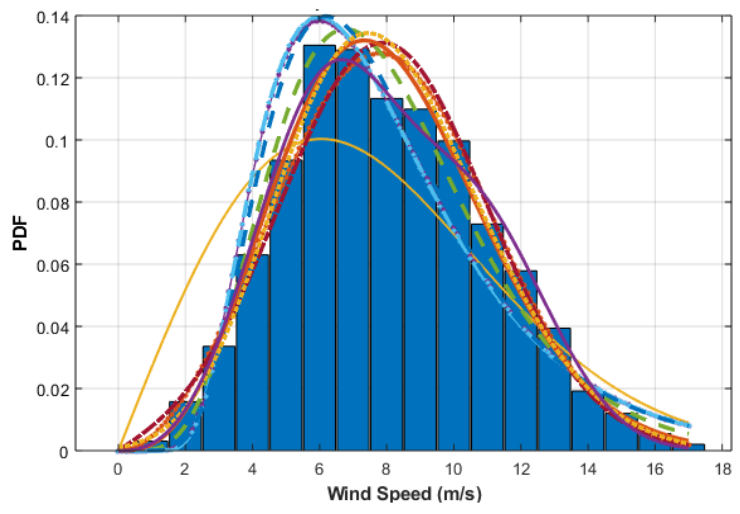

(c)

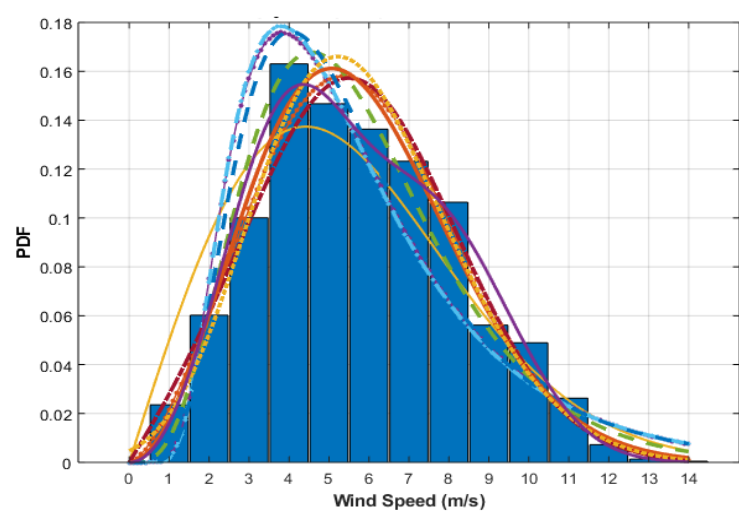

(d)

Figure 17. Jafrabad PDF: (a) winter; (b) summer; (c) SWM; (d) NEM.

Table 17 shows the bi-modal WW method parameters. The bmc1 and bmc2 are the bimodality numerical check, apart from visual analysis. There is no bimodality in comparison with other locations, due to the lower value of bmc1 and bmc 2 of about 0.860 and 0.328 , respectively. Figure 17 shows the bimodal behavior of winter season with the bmc1 and bmc2 scores of 1.321 and 1.088, respectively, with not much visual changes on bimodality during the summer season. Table 18 shows the yearly and seasonal estimated parameters from the observed wind speed by ten distribution models with the parameter estimation from the maximum likelihood method.

Table 17. Jafrabad bimodal estimated parameters.

\begin{tabular}{ccccccccccccc}
\hline Season & mu1 & mu2 & sigma1 & sigma2 & w1 & w2 & k1bm & $\mathbf{c 1 b m}$ & $\mathbf{k 2 b m}$ & c2bm & bmc1 & bmc2 \\
\hline Annual & 4.47 & 7.96 & 1.58 & 2.61 & 0.28 & 0.72 & 3.10 & 5.01 & 3.36 & 8.88 & 0.86 & 0.33 \\
Winter & 4.68 & 8.81 & 1.61 & 1.52 & 0.51 & 0.48 & 3.20 & 5.23 & 6.75 & 9.44 & 1.32 & 1.09 \\
Summer & 3.71 & 7.57 & 1.24 & 2.42 & 0.12 & 0.87 & 3.30 & 4.15 & 3.46 & 8.43 & 1.12 & 1.38 \\
SWM & 5.77 & 9.58 & 1.83 & 2.60 & 0.41 & 0.58 & 3.50 & 6.42 & 4.12 & 10.55 & 0.87 & 0.16 \\
NEM & 3.85 & 7.10 & 1.40 & 2.09 & 0.41 & 0.58 & 3.01 & 4.32 & 3.78 & 7.87 & 0.95 & 0.45 \\
\hline
\end{tabular}

Table 18. Jafrabad wind distribution estimated parameters.

\begin{tabular}{ccccccc}
\hline Dist. & Param & Annual & Winter & Summer & SW-Mon & NE-Mon \\
\hline \multirow{3}{*}{ WB } & Vmean & 6.99 & 6.67 & 7.08 & 8.02 & 5.75 \\
& k-shape & 7.87 & 7.50 & 7.94 & 8.99 & 6.48 \\
& c-scale & 2.66 & 2.84 & 2.94 & 2.93 & 2.54 \\
& Mean & 6.99 & 6.68 & 7.08 & 8.02 & 5.76 \\
RY & Std & 2.83 & 2.55 & 2.62 & 2.98 & 2.42 \\
& $\sigma$-scale & 5.34 & 5.06 & 5.34 & 6.05 & 4.42 \\
& Mean & 6.69 & 6.34 & 6.70 & 7.58 & 5.53 \\
NK & Std & 3.50 & 3.32 & 3.50 & 3.96 & 2.89 \\
& $\mu$-shape & 1.58 & 1.67 & 1.82 & 1.89 & 1.47 \\
& $\omega-$ scale & 56.93 & 51.21 & 57.13 & 73.11 & 38.98 \\
& Mean & 6.98 & 6.65 & 7.06 & 8.01 & 5.74 \\
IG & Std & 2.87 & 2.65 & 2.70 & 3.00 & 2.45 \\
& $\mu-$ mean & 6.99 & 6.67 & 7.08 & 8.02 & 5.75 \\
& $\lambda-$ shape & 26.86 & 25.99 & 31.60 & 40.51 & 20.27 \\
& Mean & 6.99 & 6.67 & 7.08 & 8.02 & 5.75 \\
RI & Std & 3.57 & 3.38 & 3.35 & 3.57 & 3.06 \\
& b-location & 6.11 & 5.96 & 6.42 & 7.27 & 4.90 \\
& a-scale & 3.13 & 2.81 & 2.83 & 3.18 & 2.74 \\
& Mean & 6.99 & 6.67 & 7.08 & 8.01 & 5.74 \\
& Std & 2.85 & 2.59 & 2.64 & 2.98 & 2.45 \\
\hline
\end{tabular}


Table 18. Cont.

\begin{tabular}{ccccccc}
\hline Dist. & Param & Annual & Winter & Summer & SW-Mon & NE-Mon \\
\hline BS & $\beta$-scale & 6.22 & 5.94 & 6.39 & 7.32 & 5.07 \\
& $\gamma$-shape & 0.50 & 0.49 & 0.46 & 0.43 & 0.52 \\
& Mean & 6.98 & 6.66 & 7.07 & 8.01 & 5.74 \\
& Std & 3.52 & 3.34 & 3.32 & 3.54 & 3.02 \\
GM & $\theta$-scale & 5.26 & 5.45 & 6.05 & 6.47 & 4.85 \\
& $k$-shape & 1.33 & 1.22 & 1.17 & 1.24 & 1.19 \\
& Mean & 6.99 & 6.67 & 7.08 & 8.02 & 5.75 \\
& Std & 3.05 & 2.86 & 2.88 & 3.15 & 2.61 \\
GEV & $\mu$-location & -0.18 & -0.31 & -0.25 & -0.19 & -0.18 \\
& $\sigma-$ scale & 2.65 & 2.59 & 2.58 & 2.79 & 2.25 \\
& $\xi$-shape & 5.86 & 5.79 & 6.11 & 6.85 & 4.78 \\
& Mean & 6.98 & 6.66 & 7.08 & 8.00 & 5.74 \\
& Std & 2.82 & 2.55 & 2.62 & 2.95 & 2.40 \\
& $\mu-$ mean & 1.85 & 1.80 & 1.87 & 2.00 & 1.64 \\
& $\sigma-$ scale & 0.48 & 0.47 & 0.44 & 0.42 & 0.50 \\
& Mean & 7.10 & 6.78 & 7.18 & 8.09 & 5.84 \\
\hline
\end{tabular}

It is observed that the bimodal WW performed well during the winter periods particularly on the SWM and NEM periods (Table 19). The value of $\mathrm{R}^{2}(0.989)$ shared the best fit during summer, whereas the Weibull shares the best fit with RMSE (0.006). By summarizing all the locations, the bimodal WW stands at the top, and the Jafrabad Weibull distribution ranked as the best fit. The annual PDF parameters estimated from the ten distributions are compared with the proposed optimization method using the moth flame optimization algorithm are in the subsequent section.

Table 19. Jafrabad goodness of fit estimated parameters.

\begin{tabular}{|c|c|c|c|c|c|c|}
\hline Season & Fitness & Annual & Winter & Summer & SWM & NEM \\
\hline \multirow{3}{*}{$\mathrm{BM}$} & & 6.99 & 6.67 & 7.08 & 8.02 & 5.75 \\
\hline & RMSE & 0.01 & 0.01 & 0.01 & 0.01 & 0.01 \\
\hline & $\mathrm{R}^{2}$ & 0.99 & 0.98 & 0.98 & 0.99 & 0.98 \\
\hline \multirow[t]{2}{*}{ WB } & RMSE & 0.00 & 0.02 & 0.01 & 0.01 & 0.01 \\
\hline & $\mathrm{R}^{2}$ & 1.00 & 0.89 & 0.99 & 0.98 & 0.97 \\
\hline \multirow[t]{2}{*}{$\mathrm{RY}$} & RMSE & 0.02 & 0.03 & 0.03 & 0.02 & 0.02 \\
\hline & $\mathrm{R}^{2}$ & 0.89 & 0.75 & 0.77 & 0.80 & 0.91 \\
\hline \multirow[t]{2}{*}{ NK } & RMSE & 0.01 & 0.02 & 0.01 & 0.01 & 0.01 \\
\hline & $\mathrm{R}^{2}$ & 0.99 & 0.87 & 0.97 & 0.99 & 0.98 \\
\hline \multirow[t]{2}{*}{ IG } & RMSE & 0.02 & 0.03 & 0.03 & 0.02 & 0.02 \\
\hline & $\mathrm{R}^{2}$ & 0.84 & 0.71 & 0.76 & 0.90 & 0.85 \\
\hline \multirow[t]{2}{*}{ RI } & RMSE & 0.01 & 0.02 & 0.01 & 0.01 & 0.01 \\
\hline & $\mathrm{R}^{2}$ & 0.99 & 0.88 & 0.99 & 0.97 & 0.96 \\
\hline \multirow[t]{2}{*}{ BS } & RMSE & 0.02 & 0.03 & 0.03 & 0.02 & 0.02 \\
\hline & $\mathrm{R}^{2}$ & 0.85 & 0.72 & 0.77 & 0.90 & 0.86 \\
\hline \multirow[t]{2}{*}{ GM } & RMSE & 0.01 & 0.02 & 0.02 & 0.01 & 0.01 \\
\hline & $\mathrm{R}^{2}$ & 0.96 & 0.83 & 0.91 & 0.97 & 0.96 \\
\hline \multirow[t]{2}{*}{ GEV } & RMSE & 0.01 & 0.02 & 0.01 & 0.01 & 0.01 \\
\hline & $\mathrm{R}^{2}$ & 0.99 & 0.89 & 0.99 & 0.98 & 0.97 \\
\hline \multirow[t]{2}{*}{ LN } & RMSE & 0.02 & 0.03 & 0.02 & 0.01 & 0.02 \\
\hline & $\mathrm{R}^{2}$ & 0.88 & 0.75 & 0.81 & 0.92 & 0.89 \\
\hline \multirow[t]{2}{*}{ Good Fit } & RMSE & Weibull & $\mathrm{BM}$ & Weibull & $\mathrm{BM}$ & $\mathrm{BM}$ \\
\hline & $\mathrm{R}^{2}$ & Weibull & $\mathrm{BM}$ & Rician & $\mathrm{BM}$ & $\mathrm{BM}$ \\
\hline
\end{tabular}




\subsection{Optimization Methods for Parameter Estimation}

Optimization Parameters Comparison

The parameters estimated from the wind distribution methods in the previous sections through unimodal and EM algorithm for bimodal (BM-EM) are compared with annual bimodal Weibull parameters through the moth flame optimization method. The estimation of the moth flame method parameter is presented in Table 20. The optimization parameter is projected through the MFO with the objective function for the bimodal Weibull distribution.

Table 20. BM-MFO wind distribution estimated parameters.

\begin{tabular}{ccccccccc}
\hline Method & Station & Mean & k1 & c1 & k2 & c2 & w1 & w2 \\
\hline BM-EM & Kayathar & 6.39 & 2.87 & 3.77 & 3.29 & 9.99 & 0.46 & 0.54 \\
BM-MFO & Kayathar & & 2.63 & 3.82 & 3.01 & 9.89 & 0.46 & 0.54 \\
BM-EM & GoK & \multirow{2}{*}{7.51} & 2.72 & 4.70 & 3.36 & 10.04 & 0.31 & 0.69 \\
BM-MFO & GoK & & 2.44 & 5.04 & 3.37 & 9.96 & 0.30 & 0.70 \\
BM-EM & Jafrabad & \multirow{2}{*}{6.99} & 3.10 & 5.01 & 3.36 & 8.88 & 0.28 & 0.72 \\
BM-MFO & Jafrabad & & 2.95 & 5.08 & 2.99 & 8.41 & 0.16 & 0.84 \\
\hline
\end{tabular}

The wind parameters from the MFO method, PDF fitness analysis with RMSE and $\mathrm{R}^{2}$ method, and the snapshot of WPD results are presented in Table 21. The MFO parameters are estimated in two stages by satisfying the PDF objective function firstly with minimum RMSE/R ${ }^{2}$ value. Then, the over fit and under fit of wind power density calculated from estimated parameters from optimization is tuned with MFO optimization again for higher accuracy. The observed results satisfy both the lower RMSE/ $\mathrm{R}^{2}$ value and the annual wind power density. It is accurately estimated through the MFO method. The results of MFO for Kayathar, Jafrabad, and the Gulf of Khambhat (GoK) outperform the bimodal parameters estimated through the EM algorithm and MFO stands top-graded in all the stations.

Table 21. Optimization PDF fitness.

\begin{tabular}{cllccc}
\hline Method & Station & RMSE & R2 & eWPD\% & WPD \\
\hline Pactual & Kayathar & & & & 334.17 \\
BM-EM & Kayathar & 0.005 & 0.99 & 0.08 & 333.89 \\
BM-MFO & Kayathar & 0.004 & 0.99 & 0.00 & 334.17 \\
Pactual & GoK & & & & 431.53 \\
BM-EM & GoK & 0.005 & 0.99 & 0.22 & 430.56 \\
BM-MFO & GoK & 0.004 & 0.99 & 0.00 & 431.53 \\
Pactual & Jafrabad & & & & 318.18 \\
BM-EM & Jafrabad & 0.005 & 0.99 & 0.45 & 316.76 \\
BM-MFO & Jafrabad & 0.003 & 1.00 & 0.68 & 318.18 \\
WB-Unimodal & Jafrabad & 0.003 & 1.00 & 0.68 & 316.03 \\
\hline
\end{tabular}

\subsection{Wind Power Density Analysis (WPD)}

The WPD value is the major factor for the wind energy potential assessment of a targeted location. It also helps to evaluate the economic feasibility to form a potential wind farm. The modelling of WPD outlines the distributions of wind energy at several wind speed and it is proportional to the cube of wind speed. Its value is represented in $\mathrm{W} / \mathrm{m}^{2}$ and depends on the wind location, air density, and wind speed. It is derived as follows:

$$
W P D=\frac{P}{A}=\frac{1}{2} \rho v^{3}
$$


where $P$ is the wind power measured in watts, $A$ stands for a swept area in $\mathrm{m}^{2}, \rho$ states the air density $\left(\rho=1.225 \mathrm{~kg} / \mathrm{m}^{3}\right)$, and $v$ represents the wind speed in $\mathrm{m} / \mathrm{s}$. Considering all these, the distribution of wind speed is taken into account and then WPD can be expressed as:

$$
\frac{P}{A}=\frac{1}{2} \rho \int_{0}^{\infty} v^{3} f(v) d v
$$

For evaluating the WPD of a particular distribution, the wind power density distribution function $f(v)$ can be expressed as:

$$
\frac{P}{A}=\frac{1}{2} \rho v^{3} f(v)
$$

The best fit of WPD is calculated as follows:

$$
e W P D=\left(\frac{(W P D o-W P D e s t)}{W P D o}\right) 100 \%
$$

where WPDo, the observed wind power density, WPDest is the estimated values from distribution fitting, and $e W P D$ is the error between observed and estimated values.

Comparison of Wind Power Density

The comparison of annual WPD with estimated MFO parameters and seasonable wind power density for the three locations are given in Tables 22 and 23 respectively.

Table 22. Annual WPD comparison with MFO and other methods.

\begin{tabular}{cccccccc}
\hline \multicolumn{2}{c}{$\begin{array}{c}\text { WPD Annual } \\
\text { Comparison }\end{array}$} & & GoK & Jafrabad & \multicolumn{3}{c}{ WPD Annual Fitness Comparison } \\
\cline { 1 - 1 } Dist. & $\begin{array}{c}\text { Kayathar } \\
\text { Annual }\end{array}$ & Annual & Annual & Distribution & $\begin{array}{c}\text { Kayathar } \\
\text { Annual }\end{array}$ & GoK Annual & $\begin{array}{c}\text { Jafrabad } \\
\text { Annual }\end{array}$ \\
\hline Actual & 334.17 & 431.53 & 318.18 & & & & \\
BM-MFO & 334.17 & 431.53 & 318.185 & BM-MFO & $5.42 \times 10^{-8}$ & $5.81 \times 10^{-10}$ & $-1.409 \times 10^{-5}$ \\
BM-EM & 333.89 & 430.54 & 316.76 & BM-EM & 0.08 & 0.23 & 0.45 \\
WB & 325.23 & 430.55 & 316.03 & WB & 2.68 & 0.23 & 0.68 \\
RY & 319.76 & 445.6 & 330.17 & RY & 4.31 & -3.26 & -3.77 \\
BS & 319.05 & 447.39 & 324.34 & BS & 4.53 & -3.67 & -1.93 \\
GM & 323.06 & 448.22 & 323.65 & GM & 3.32 & -3.87 & -1.72 \\
IG & 312.96 & 443.16 & 322.83 & IG & 6.35 & -2.69 & -1.46 \\
RI & 320 & 431.11 & 315.26 & RI & 4.24 & 0.1 & 0.92 \\
NK & 325.25 & 434.01 & 317.14 & NK & 2.67 & -0.58 & 0.33 \\
GEV & 310.55 & 423.73 & 314.85 & GEV & 7.07 & 1.81 & 1.05 \\
LN & 317.4 & 455.52 & 328.18 & LN & 5.02 & -5.56 & -3.14 \\
\hline
\end{tabular}

Table 23. Wind power density.

\begin{tabular}{ccccccccccccc}
\hline Dist. & $\begin{array}{c}\text { Kayathar } \\
\text { Winter }\end{array}$ & Summer & SWM & NEM & $\begin{array}{c}\text { GoK } \\
\text { Winter }\end{array}$ & Summer & SWM & NEM & $\begin{array}{c}\text { Jafrabad } \\
\text { Winter }\end{array}$ & Summer & SWM & NEM \\
\hline Actual & 76.45 & 170.80 & 751.97 & 111.58 & 370.79 & 399.83 & 653.26 & 225.29 & 266.13 & 310.66 & 450.83 & 183.59 \\
\hline Bimodal EM(WW) & 75.67 & 168.67 & 750.22 & 110.19 & 359.69 & 398.02 & 652.35 & 222.89 & 263.94 & 308.88 & 449.94 & 181.97 \\
\hline WB & 75.54 & 156.24 & 748.65 & 106.16 & 341.26 & 395.26 & 649.57 & 219.07 & 255.79 & 307.45 & 447.10 & 180.98 \\
\hline RY & 78.83 & 146.27 & 715.72 & 106.94 & 328.76 & 398.12 & 657.39 & 219.67 & 235.35 & 304.32 & 439.72 & 187.25 \\
\hline BS & 78.20 & 161.23 & 762.86 & 112.67 & 283.22 & 379.98 & 637.78 & 225.76 & 222.95 & 296.18 & 428.90 & 182.70 \\
\hline GM & 76.15 & 150.80 & 769.73 & 104.86 & 317.66 & 396.48 & 658.32 & 221.09 & 242.02 & 306.61 & 440.03 & 184.01 \\
\hline IG & 78.00 & 161.12 & 761.83 & 113.11 & 278.06 & 376.72 & 633.71 & 223.84 & 221.01 & 294.55 & 427.05 & 181.56 \\
\hline RI & 74.49 & 146.33 & 753.27 & 106.99 & 344.94 & 396.46 & 651.02 & 219.82 & 256.04 & 307.38 & 444.62 & 180.83 \\
\hline NK & 75.00 & 155.61 & 757.78 & 104.41 & 335.75 & 395.91 & 652.69 & 218.08 & 250.37 & 306.87 & 443.05 & 181.33 \\
\hline GEV & 74.77 & 153.03 & 766.27 & 106.14 & 349.27 & 392.36 & 650.64 & 214.73 & 259.20 & 307.47 & 443.06 & 178.76 \\
\hline LN & 78.76 & 156.70 & 774.63 & 112.23 & 289.81 & 387.29 & 650.40 & 226.53 & 227.56 & 300.51 & 432.14 & 184.80 \\
\hline
\end{tabular}


The different landscapes of three locations such as offshore, nearshore, and onshore are considered for the analysis. Wind power density is evaluated after carrying goodness of fit with RMSE and $\mathrm{R}^{2}$ using probability distribution methods. The goodness of fit indicates the wind power density and demonstrates the best distribution suits for the selected location.

Table 24 represent the wind power density calculated from different distributions along with measured value during seasonal periods for three selected locations. Additionally, the annual WPD shares (region wise) of Jafrabad, Gulf Khambhat, and Kayathar are shown in Figure 18. The percentage shares of the SW monsoon take the upper hand in all three sites compared to other seasonal shares. Moreover, Figure 19 shows the monthly wind power density statistics using monthly WPD analysis for Kayathar station. The bimodal method scores better during February, April, July, August, and September (five months), whereas GEV distribution scores best during March, October, November, and December (four months) followed by Weibull during May and June as the best fit. For monthly wind power density of Gulf of Khambhat, BM scores better except February, June, and November whereas Rician distribution scores best during February and November followed by Weibull during June. For Jafrabad region monthly WPD analysis, BM scores better except for in April, May, and August, whereas the Rician distribution scores best during April. The generalized extreme value (GEV) distribution scored better during May, and the Weibull during August was the best fit.

Table 24. Wind power density (WPD) error metrics.

\begin{tabular}{ccccccccccccc}
\hline & \multicolumn{3}{c}{ Kayathar } & \multicolumn{4}{c}{ Gulf of Khambhat } & \multicolumn{4}{c}{ Jafrabad } \\
\hline Season & Win & Sum & SWM & NEM & Win & Sum & SWM & NEM & Win & Sum & SWM & NEM \\
\hline BM-EM & 1.02 & 1.25 & 0.23 & 1.25 & 0.30 & 0.04 & 0.04 & -0.29 & 0.82 & 0.57 & 0.20 & 0.89 \\
WB & 1.19 & 8.53 & 0.44 & 4.86 & 7.96 & 0.56 & 0.56 & 2.76 & 3.88 & 1.03 & 0.83 & 1.43 \\
RY & -3.10 & 14.36 & 4.82 & 4.16 & 11.34 & -0.63 & -0.63 & 2.49 & 11.57 & 2.04 & 2.46 & -1.99 \\
BS & -2.30 & 5.60 & -1.45 & -0.97 & 23.62 & 2.37 & 2.37 & -0.21 & 16.22 & 4.66 & 4.87 & 0.49 \\
GM & 0.39 & 11.71 & -2.36 & 6.03 & 14.33 & -0.77 & -0.77 & 1.87 & 9.06 & 1.30 & 2.40 & -0.23 \\
IG & -2.00 & 5.67 & -1.31 & -1.37 & 25.01 & 2.99 & 2.99 & 0.64 & 16.95 & 5.18 & 5.27 & 1.10 \\
RI & 2.56 & 14.33 & -0.17 & 4.12 & 6.97 & 0.34 & 0.34 & 2.43 & 3.79 & 1.05 & 1.38 & 1.50 \\
NK & 1.90 & 8.89 & -0.77 & 6.43 & 9.45 & 0.09 & 0.09 & 3.20 & 5.92 & 1.22 & 1.73 & 1.23 \\
GEV & 2.20 & 10.40 & -1.90 & 4.87 & 5.80 & 0.40 & 0.40 & 4.69 & 2.60 & 1.03 & 1.72 & 2.63 \\
LN & -3.00 & 8.25 & -3.01 & -0.58 & 21.84 & 0.44 & 0.44 & -0.55 & 14.49 & 3.27 & 4.15 & -0.66 \\
GF & BM & BM & BM & BM & BM & BM & BM & IG & BM & BM & BM & BS \\
\hline
\end{tabular}

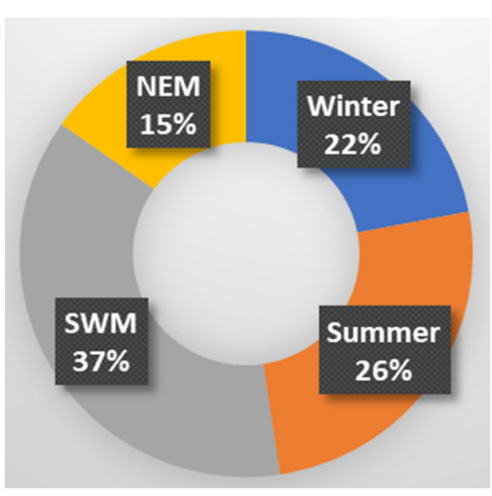

(a)

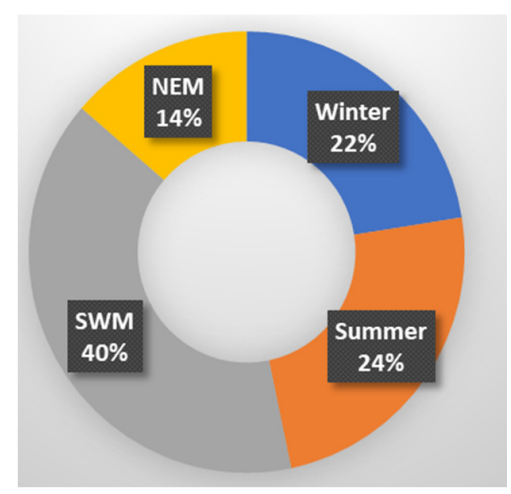

(b)

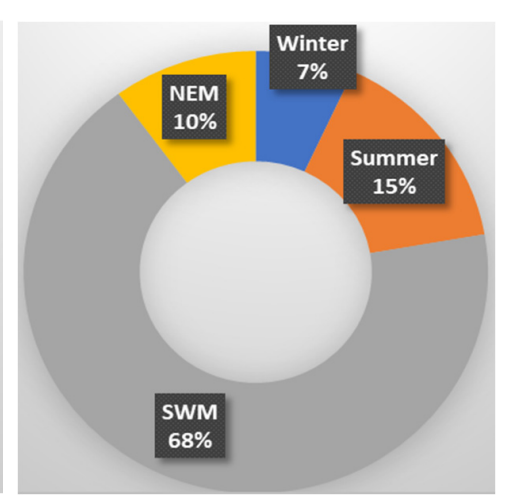

(c)

Figure 18. WPD Region annual share: (a) Jafrabad; (b) Gulf Khambhat; (c) Kayathar. 


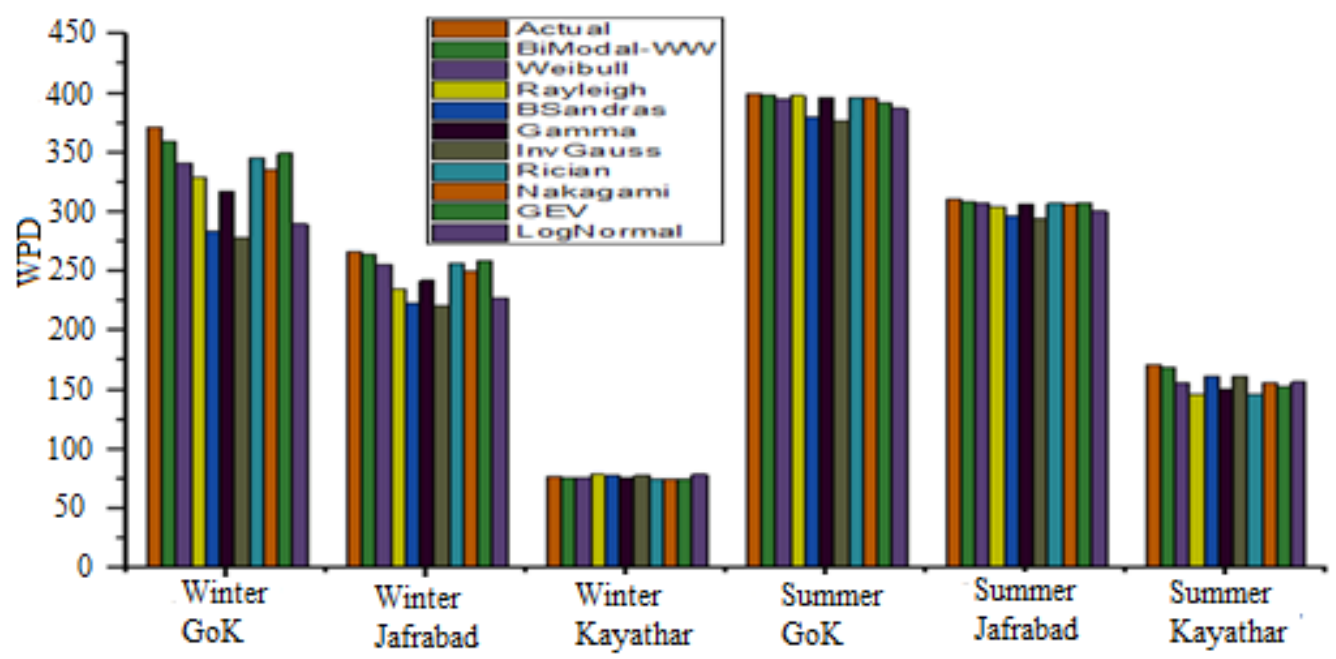

(a)

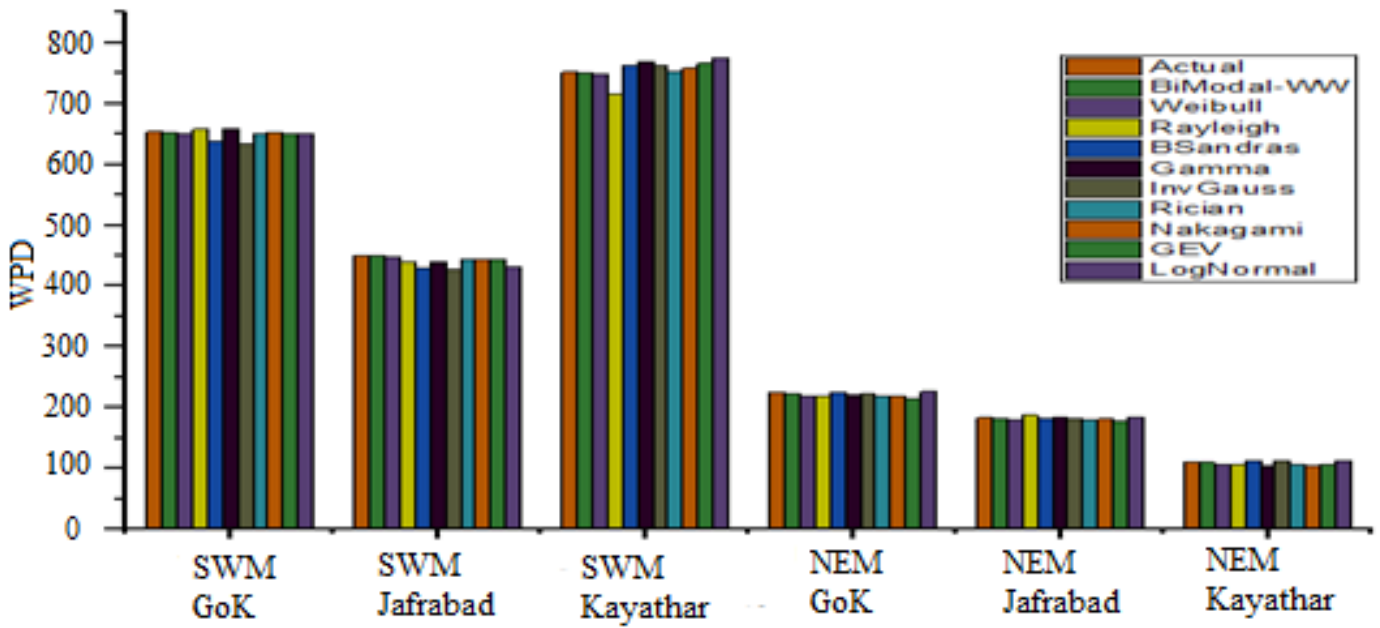

(b)

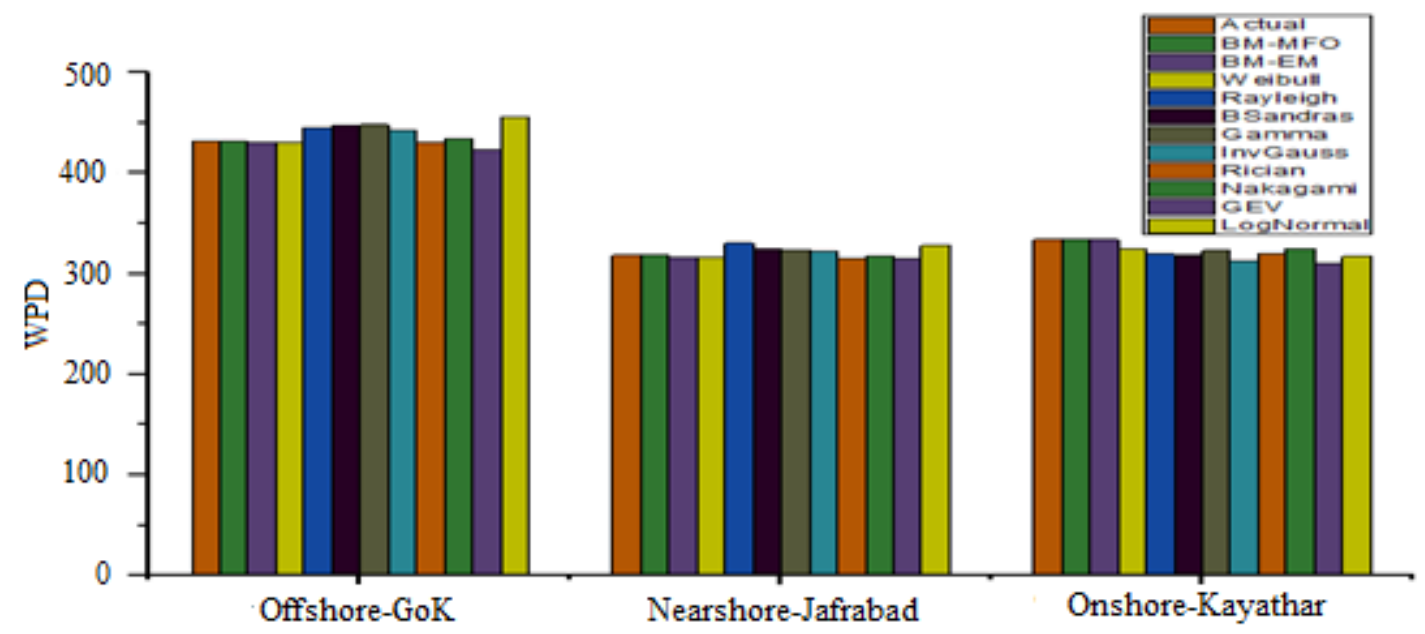

(c)

Figure 19. WPD region annual share: (a) seasonal WPD—winter and summer; (b) seasonal WPD—SWM and NEM; (c) annual WPD plot comparison.

Figure 19c represents the wind power density share in the different seasons by comparing each region. Gulf of Khambhat (offshore) shares about $37 \%$ of maximum wind power density during SWM 
and minimum during the NEM period with 15\%. The winter and summer have a steady share of $22 \%$ and $26 \%$ respectively. The Gulf of Khambhat (GoK) has the advantage of steady wind power density, due to the advantage of offshore characteristics which is free from wind obstruction comparing with landmass. Jafrabad shows a similar pattern of WPD with peak WPD during the SWM of $40 \%$ and minimum on the North East period from October to December (about 14\%). During winter and summer, WPD shares about $24 \%$ and $26 \%$ respectively. Kayathar displays wide marginal variations on WPD share with peaks during the SWM of about $68 \%$ and low WPD during North-East monsoon of $10 \%$ share. The winter stakes about $7 \%$ and summer share about $15 \%$ of the rest wind power density. Finally, the wind power class of Kayathar region falls on Class 2, Gulf of Khambhat falls on Class 3 and Jafrabad falls on Class 2 [35].

\subsection{Research Findings}

The wind energy potential assessments for selected locations of different landscape are evaluated using bimodal factors along with ten wind distribution methods and MFO optimization methods. The summary of the outcomes is represented in Table 25.

Table 25. Research statistics in onshore, nearshore, and offshore.

\begin{tabular}{|c|c|c|c|c|}
\hline S. No & Annual Parameter (@100 m) & $\begin{array}{l}\text { Kayathar } \\
\text { (Onshore) }\end{array}$ & $\begin{array}{c}\text { Gulf of Khambhat } \\
\text { (Offshore) }\end{array}$ & $\begin{array}{l}\text { Jafrabad } \\
\text { (Nearshore) }\end{array}$ \\
\hline 1 & Mean wind speed (m/s) & 6.38 & 7.51 & 6.99 \\
\hline 2 & Standard deviation $(\mathrm{m} / \mathrm{s})$ & 3.65 & 3.44 & 2.83 \\
\hline 3 & Max. wind speed (m/s) & 18.8 & 20.26 & 17.4 \\
\hline 4 & Skew & 0.55 & 0.25 & 0.29 \\
\hline 5 & Kurt & -0.70 & 0.57 & 0.26 \\
\hline 6 & MTI at $15(\mathrm{~m} / \mathrm{s})$ & $13.2 \%$ & $5.9 \%$ & $6.4 \%$ \\
\hline 7 & Shear power law index & 0.17 & 0.07 & 0.02 \\
\hline 8 & Mean cubic wind speed & 8.16 & 8.88 & 8.02 \\
\hline 9 & WPD (observed) W/m² & 334.17 & 431.53 & 318.18 \\
\hline 10 & $\begin{array}{l}\text { Turbulence category } \\
\text { Wind power class }\end{array}$ & $\begin{array}{l}\mathrm{B} \\
2\end{array}$ & $\begin{array}{l}\mathrm{C} \\
3\end{array}$ & $\begin{array}{l}\mathrm{C} \\
2\end{array}$ \\
\hline 11 & Wind distribution fit (Rank) & $\begin{array}{l}\text { BM-MFO } \\
\text { BM-EM } \\
\text { Nakagami }\end{array}$ & $\begin{array}{l}\text { BM-MFO } \\
\text { Rician } \\
\text { BM-EM } \\
\text { and Weibull }\end{array}$ & $\begin{array}{l}\text { BM-MFO } \\
\text { Nakagami } \\
\text { BM-EM }\end{array}$ \\
\hline 12 & WPD (Estimated) & 333.89 & 431.11 & 317.14 \\
\hline 13 & Best wind direction & $\begin{array}{c}\text { W-38\% } \\
\text { WSW-11\% } \\
\text { WNW-7.57\% } \\
\text { NE- } 6.51 \% \\
\text { NNE- } 6.50 \%\end{array}$ & $\begin{array}{c}\text { SW-15.8\% } \\
\text { SSW-13.05\% } \\
\text { NNE-11.07\% } \\
\text { N-10.17\% } \\
\text { WSW-8.75\% }\end{array}$ & $\begin{array}{c}\text { W-15.04\% } \\
\text { WSW-11.63\% } \\
\text { NE-10.158\% } \\
\text { NNE-9.421\% } \\
\text { WNW-8.891\% }\end{array}$ \\
\hline 14 & Wind power density share & $\begin{array}{c}\text { Winter-7\% } \\
\text { Summer-15\% } \\
\text { SWM-68\% } \\
\text { NEM-10\% }\end{array}$ & $\begin{array}{c}\text { Winter-22\% } \\
\text { Summer-24\% } \\
\text { SWM-40\% } \\
\text { NEM- }-14 \%\end{array}$ & $\begin{array}{c}\text { Winter-22\% } \\
\text { Summer-26\% } \\
\text { SWM-36\% } \\
\text { NEM-15\% }\end{array}$ \\
\hline
\end{tabular}

The research findings on three different landmasses onshore, offshore and nearshore are presented. The offshore location attained a mean wind speed of $7.51 \mathrm{~m} / \mathrm{s}$, with wind power density of $431 \mathrm{~m} / \mathrm{s}^{2}$ and low turbulence intensity of $5.9 \%$. It has the great advantage of exploring offshore wind energy extraction, by comparison with other onshore and nearshore wind stations. The proposed methodology (MFO-Bimodal Weibull-Weibull) performed well in all the three-wind location. The estimation of 
accurate wind distribution fit and wind power density are achieved using the moth flame optimization method (on estimating wind distribution parameters) in comparison with the maximum likelihood method. The selection of technologies for better wind resource assessment is the prime motive for ascertaining the accurate wind potential in targeted location. The commercially available wind analysis software should be tuned by incorporating the latest developments and observation of concepts from these types of research studies to cope the practical field conditions. This research study demonstrates the comparison of different wind distribution methods using different parameter estimation methods. It can be used to select the best wind distribution method from available methodologies. Though the proposed method shows numerous advantages over other methods, limitations such as number of iterations, number of moths, and measured quality of wind speed data are considered before adopting this method. Moreover, the measured data from field instruments are properly calibrated for high accuracy in results. The data collection during wind resource assessment and data loggers from instruments should be closely monitored for ensuring the continuance of data.

In nutshell, this research explored the multiple wind distributions and their behavior on different landscapes using bimodality influences. In India, Tamil Nadu and Gujarat stand at the top on wind energy generation. During data collection for this research, certain issues are observed in day to practice on wind energy management. The major hurdle is the low voltage ride through (LVRT) issue [36]. Because the power generating plants must continue to operate through short periods of low grid voltage, and should not get disconnected from the grid. As per the Indian Electricity Grid Code (IEGC), wind farms connected above $66 \mathrm{kV}$ need to stay connected in the grid. During system faults, it acts as a fault recovery by providing reactive power compensation to support the grid. In some of the old wind turbines with stall regulation types, the provision of putting add on LVRT is technically not possible. It is noted that about 11,510 such turbines were installed till April 2014 in India, which have to be replaced with new wind turbines to make a smooth grid operation. The active network management describes the control systems that manage the generation and load for specific purposes to implement in India to control the wind turbines during high grid frequency. However, the SCADA (supervisory control and data acquisition) integration and network communication have to be strengthened. During a higher rate of renewable energy injection in the grid, the control of renewable energy should be adopted to maintain the grid by modernizing the network and information technology systems. The wind resource assessment is based on field data measurements, history of data available in the archive, and satellite data. However, raising standards of data quality through big data analytics [37] will help to make the wind and solar resource assessment with high accuracy.

\section{Conclusions}

The wind speed characteristics and distribution patterns in the offshore, onshore, and nearshore in parts of India are compared at different timescales such as monthly, seasonal, and annual in detail to predict the wind behavior. The following conclusions are drawn based on the analysis:

- In the offshore coastal area of the Gulf of Khambhat, Gujarat, the turbulence intensity is at the low of 0.0782 due to low surface roughness, in comparison to the onshore Kayathar wind station. The prevailing wind direction for the Gulf of Khambhat is observed on the SW (15.8\%) and SSW $(13.05 \%)$ from the Southwest monsoon. The northeast monsoon fetches low wind and prevailing wind direction with a wind speed of about $11.07 \%$ (NNE) and North direction of $10.17 \%$ wind speed. The WPD density measured at $100 \mathrm{~m}$ of Gulf of Khambhat is highest with 431.53 watts $/ \mathrm{m}^{2}$, in comparison with Kayathar and Jafrabad. The annual mean wind speed is better at about $7.51 \mathrm{~m} / \mathrm{s}$.

- In the onshore area, the Kayathar region, the WPD obtained a maximum of $68 \%$ share during southwest monsoon which is highest compared with the Gulf of Khambhat and Jafrabad. During winter, it is perceived as $7 \%$, and the bimodality nature in the annual wind pattern is achieved a great value comparing with the other two regions. The wind power class for Kayathar and Jafrabad belongs to Class 2 categories while the Gulf of Khambhat falls under the Class 3 category. 
- In the nearshore area, the Jafrabad region, the mast is installed at $100 \mathrm{~m}$ in line of sight with LiDAR (installed at the offshore location) for correlation and validation. The distance between the two locations is roughly about $25 \mathrm{~km}$. However, the wind pattern has significant variations between the offshore and nearshore, with Jafrabad with a low mean speed of $6.99 \mathrm{~m} / \mathrm{s}$ in comparison with offshore measurements of $7.51 \mathrm{~m} / \mathrm{s}$.

- The influence of SW (South-west) and NEM (North east monsoon) taken for seasonal analysis. The SWM (South west monsoon) fetches more wind power generation than NE (North east).

- The conventional unimodal wind distribution models are overridden by the bimodal (Weibull-Weibull) method with the moth flame optimization method. Comparatively, the bimodal WW performed well, followed by the Nakagami, Rician, and Weibull distributions.

- This research outcome helps with investment in offshore wind farms in Gujarat, due to its higher power density obtained through the proposed method. Moreover, there would be a drop in pricing of offshore wind energy tariffs and land acquisition cost compared to onshore wind farm.

- The proposed MFO method can be extended to short term wind forecasting by optimizing the weight and bias parameters of the artificial neural network (ANN) method. The optimizing parameters of window size and neurons of long short-term memory (LSTM) would be adopted for accurate predictions.

In future, the concept of big data analysis will be adopted by integrating historical data and atmospheric environmental parameters in the targeted location for prediction of detailed wind resource assessment accurately.

Author Contributions: The authors K.R. (Krishnamoorthy R) and U.K. developed the main theme of the article, and performed the data collection, sampling and optimization; K.R. (Kannadasan Raju) and R.M.E. contributed equally to the final dissemination of the research investigation to form a full article; L.M.-P. provided the review and financial support. All authors have read and agreed to the published version of the manuscript.

Funding: This research received no external funding.

Conflicts of Interest: The authors declare no conflict of interest.

\section{Notations and Abbreviations}

$\begin{array}{ll}\text { AIC } & \text { Akaike information criterion } \\ \text { BIC } & \text { Bayesian information criterion } \\ \text { BM } & \text { Bimodal } \\ \text { BS } & \text { Birnbaum Sandras } \\ \text { CDF } & \text { Cumulative distribution function } \\ \text { E } & \text { East } \\ \text { EM } & \text { Expectation Maximization } \\ \text { ENE } & \text { East-Northeast } \\ \text { ESE } & \text { East-Southeast } \\ \text { EV } & \text { Extreme Value } \\ \text { EW } & \text { Exponentiated Weibull } \\ \text { GEV } & \text { Generalized Extreme Value } \\ \text { GW } & \text { Gamma Weibull } \\ \text { IG } & \text { Inverse Gaussian/Inverse Gamma } \\ \text { IW } & \text { Inverse Weibull } \\ \text { KS } & \text { Kolmogorov-Smirnov } \\ \text { LiDAR } & \text { Light detection and ranging } \\ \text { LN } & \text { Lognormal } \\ \text { MEP } & \text { Maximum entropy principle } \\ \text { MFO } & \text { Moth Flame Optimization } \\ \text { MLM } & \text { Maximum Likelihood Method } \\ \text { MNRE } & \text { Ministry of New and Renewable Energy }\end{array}$




$\begin{array}{ll}\text { MTI } & \text { Mean Turbulence Intensity } \\ \text { MWS } & \text { Mean wind speed } \\ \text { N } & \text { North } \\ \text { NE } & \text { Northeast } \\ \text { NEM } & \text { North-East Monsoon } \\ \text { NIWE } & \text { National Institute of Wind Energy } \\ \text { NK } & \text { Nakagami } \\ \text { NNE } & \text { North-Northeast } \\ \text { NNW } & \text { North-Northwest } \\ \text { NW } & \text { Northwest } \\ \text { NW } & \text { Normal Weibull } \\ \text { PDF } & \text { Probability density function } \\ \text { R } & \text { Correlation coefficient } \\ \text { RI } & \text { Rician } \\ \text { RMSE } & \text { Root mean square error } \\ \text { RY } & \text { Rayleigh } \\ \text { S } & \text { South } \\ \text { SE } & \text { Southeast } \\ \text { SEM } & \text { South East Monsoon } \\ \text { SODAR } & \text { Sonic detection and ranging } \\ \text { SSE } & \text { South-Southeast } \\ \text { SSW } & \text { South-Southwest } \\ \text { SW } & \text { Southwest } \\ \text { SWM } & \text { South West Monsoon } \\ \text { W } & \text { West } \\ \text { WB } & \text { Weibull } \\ \text { WNW } & \text { West-Northwest } \\ \text { WPD } & \text { Wind power density } \\ \text { WSW } & \text { West-Southwest } \\ \text { WW } & \text { Weibull-Weibull } \\ & \end{array}$

\section{Appendix A}

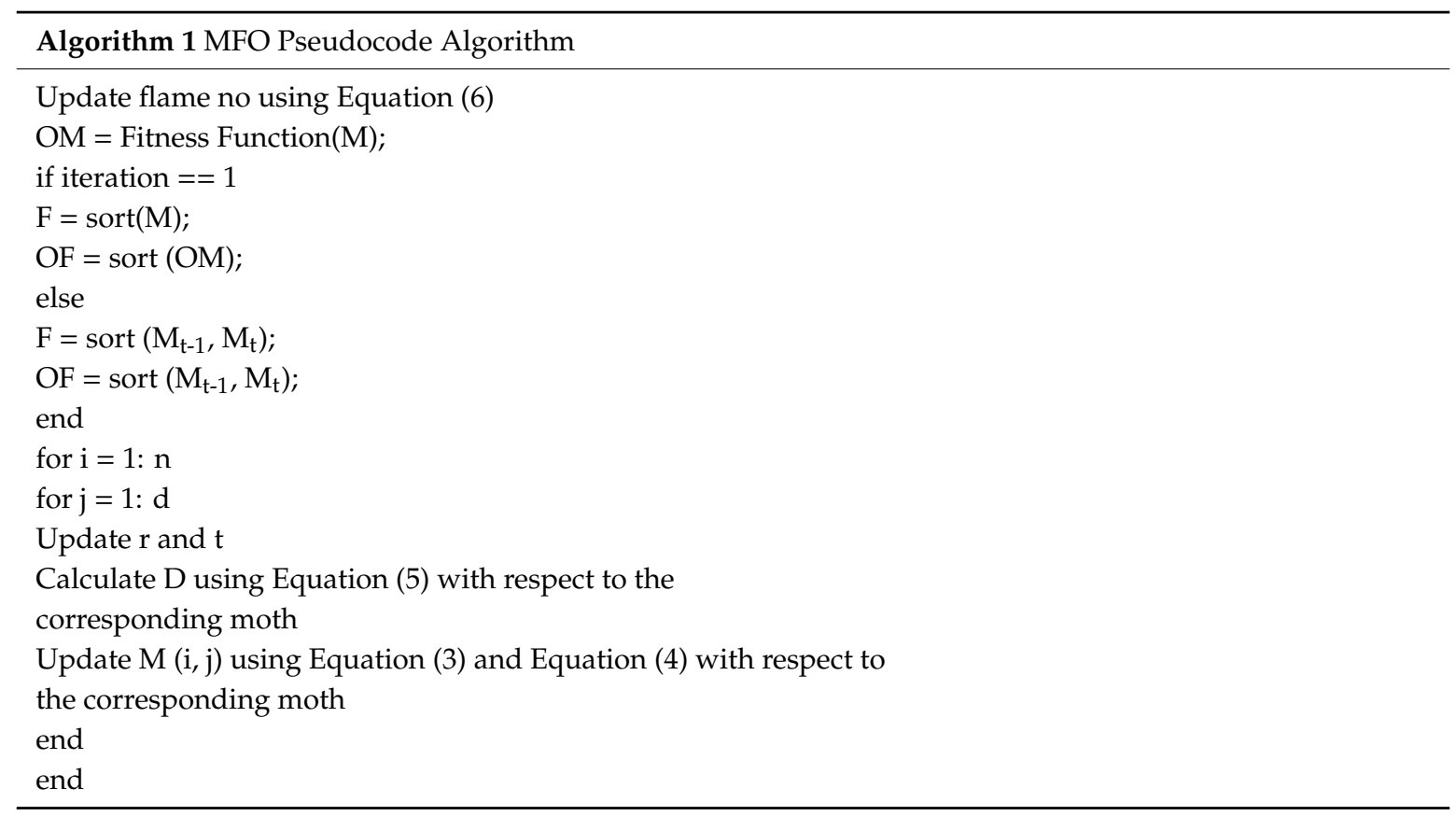




\section{Appendix B. Wind Distribution Parameters (PDFs and CDFs)}

The computation of PDF and CDF wind distribution parameters (k-shape and c-scale) using Weibull (WB) are carried out using Equation (A1) and Equation (A2) respectively.

$$
\begin{gathered}
f(v)=\left(\frac{k}{c}\right)\left(\frac{v}{c}\right)^{k-1} \exp \left(-\left(\frac{v}{c}\right)^{k}\right) \\
F(v)=1-\exp \left(-\left(\frac{v}{c}\right)^{k}\right)
\end{gathered}
$$

The computation of PDF and CDF wind distribution parameters ( $\sigma$-scale and $x$ - wind speed) using Rayleigh (RY) are carried out using Equation (A3) and Equation (A4) respectively.

$$
\begin{aligned}
& f(x)=\frac{x}{\sigma^{2}} e^{-x^{2} /\left(2 \sigma^{2}\right)} \\
& F(x)=1-e^{-x^{2} /\left(2 \sigma^{2}\right)}
\end{aligned}
$$

The computation of PDF and CDF wind distribution parameters ( $\mathrm{k}$ - shape, $\theta$ —scale and $\mathrm{v}$-wind speed) using Gamma (GA) are carried out using Equation (A5) and Equation (A6) respectively.

$$
\begin{gathered}
f(x)=\frac{1}{\Gamma(v) \theta^{k}} v^{k-1} e^{-\frac{v}{\theta}} \\
F(x)=\frac{1}{\Gamma(v)} \gamma\left(k, \frac{v}{\theta}\right)
\end{gathered}
$$

The computation of PDF and CDF wind distribution parameters ( $\mu$-mean, and $\sigma$-scale) using Lognormal (LN) are carried out using Equation (A7) and Equation (A8) respectively.

$$
\begin{gathered}
f(x)=\frac{1}{x \sigma \sqrt{2 \pi}} \exp \left(-\frac{\ln (x-\mu)^{2}}{2 \sigma^{2}}\right) \\
F F(x)=\varnothing\left(\frac{\ln (x)-\mu}{\sigma}\right)
\end{gathered}
$$

The computation of PDF and CDF wind distribution parameters ( $\lambda$-shape and $\mu$-mean) using Inverse Gaussian (IG) are carried out using Equation (A9) and Equation (A10) respectively.

$$
\begin{gathered}
f(x)=\left(\frac{\lambda}{2 \pi v^{2}}\right)^{\frac{1}{2}} e^{\left[\frac{-\lambda(v-\mu)^{2}}{2 \mu^{2} v}\right]} \\
\Phi\left(\sqrt{\frac{\lambda}{v}}\left(\frac{v}{\mu}-1\right)\right)+\exp \left(\frac{2 \lambda}{\mu}\right) \Phi\left(-\sqrt{\frac{\lambda}{v}}\left(\frac{v}{\mu}+1\right)\right)
\end{gathered}
$$

The computation of PDF and CDF wind distribution parameters ( $\mu$-location, $\sigma$-scale and $\xi$-shape) using Gen.Ext.Value (GEV) are carried out using Equation (A11) and Equation (A12) respectively.

$$
\begin{gathered}
f(x)=\frac{1}{\sigma} t(x)^{\xi+1} e^{-t(x),} \\
(x)=\left\{\begin{array}{c}
\left(1+\xi\left(\frac{x-\mu}{\sigma}\right)\right)^{-\frac{1}{\xi}} \text { if } \xi \neq 0 \\
e^{\frac{-(x-\mu)}{\sigma}} \text { if } \xi=0
\end{array}\right.
\end{gathered}
$$

The computation of PDF and CDF wind distribution parameters ( $\mu$-shape and $\omega-$ scale) using Nakagami (NK) are carried out using Equation (A13) and Equation (A14) respectively.

$$
f(x)=\left(\frac{\mu}{\omega}\right)^{\mu} \frac{1}{\Gamma(\mu)} v^{(2 \mu-1)} e^{-\frac{\mu v^{2}}{\omega}}
$$




$$
\mathrm{F}(\mathrm{x})=\frac{\gamma\left(\mu, \frac{\mu}{\omega} v^{2}\right)}{\Gamma(\mu)}
$$

The computation of PDF and CDF wind distribution parameters (a-scale and b-location) using Rician (RI) are carried out using Equation (A15) and Equation (A16) respectively.

$$
\begin{gathered}
f(x)=\frac{v}{a^{2}} e^{\frac{-\left(v^{2}+b^{2}\right)}{2 a^{2}}} I_{0}\left(\frac{b v}{a^{2}}\right)(a \geq 0, b \geq 0) \quad I_{\alpha}(z)=\sum_{k=0}^{\infty} \frac{\left(\frac{z}{2}\right)^{2 k+\alpha}}{k ! \Gamma(k+\alpha+1)} \\
F(x)=1-Q_{1}\left(\frac{b}{a}, \frac{v}{a}\right) \quad Q_{1}\left(\frac{b}{a}, \frac{v}{a}\right)=\int_{\frac{v}{a}}^{\infty} x e^{-\frac{x^{2}+\frac{b^{2}}{a^{2}}}{2}} I_{0}\left(\frac{b x}{a}\right) d x
\end{gathered}
$$

The computation of PDF and CDF wind distribution parameters ( $\mu$-location, $\gamma$-shape and $\beta$-scale) using Birnbaum -Sandras (BS) are carried out using Equation (A17) and Equation (A18) respectively.

$$
\begin{gathered}
(x)=\frac{\sqrt{\frac{x-\mu}{\beta}}+\sqrt{\frac{\beta}{x-\mu}}}{2 \gamma(x-\mu)} \phi\left(\frac{\sqrt{\frac{x-\mu}{\beta}}-\sqrt{\frac{\beta}{x-\mu}}}{\gamma}\right) x>\mu ; \gamma, \beta>0 \\
\Phi\left(\frac{\sqrt{x}-\sqrt{\frac{1}{x}}}{\gamma}\right) x>0 ; \gamma>0
\end{gathered}
$$

The computation of PDF and CDF wind distribution parameters (k1, k2-shapes, c1, c2-scales and w1, w2-weights) using Bimodal-WW (BM) are carried out using Equation (A19) and Equation (A20) respectively.

$$
\begin{gathered}
f(v)=w 1\left(\frac{k 1}{c 1}\right)\left(\frac{v}{c 1}\right)^{k 1-1} \exp \left(-\left(\frac{v}{c 1}\right)^{k 1}\right)+w 2\left(\frac{k 2}{c 2}\right)\left(\frac{v}{c 2}\right)^{k 2-1} \exp \left(-\left(\frac{v}{c 2}\right)^{k 2}\right) \\
F(v)=w 1\left(1-\exp \left(-\left(\frac{v}{c 1}\right)^{k 1}\right)\right)+w 2\left(1-\exp \left(-\left(\frac{v}{c 2}\right)^{k 2}\right)\right)
\end{gathered}
$$

\section{References}

1. Ministry of New and Renewable Energy (MNRE). India-Paris Agreement Commitments, the Government of India. MNRE Annual Report 2018-19; MNRE: New Dehli, India, 2019.

2. Rajvikram, M.E. Comprehensive Review on India's Growth in Renewable Energy Technologies in Comparison With Other Prominent Renewable Energy Based Countries. J. Sol. Energy Eng. 2019, 142, 030801.

3. Rajvikram, M.E. The Motivation for Renewable Energy and its Comparison with Other Energy Sources: A Review. Eur. J. Sustain. Dev. Res. 2019, 93, em0076.

4. Ministry of New and Renewable Energy (MNRE). Programme Scheme Wise Physical Progress in 2019-20 and Cumulative up to March 2020; MNRE: New Dehli, India, 2020.

5. Rajvikram, M.E.; Shafiullah, G.M.; Nallapaneni, M.K.; Sanjeevikumar, P. A State-of-the-Art Review on the Drive of Renewables in Gujarat, State of India: Present Situation, Barriers and Future Initiatives. Energies 2020, 13, 40 .

6. Rajvikram, M.E.; Shafiullah, G.M.; Sanjeevikumar, P.; Nallapaneni, M.K.; Annapurna, A.; Ajayragavan, M.V. A Comprehensive Review on Renewable Energy Development, Challenges, and Policies of Leading Indian States with an International Perspective. IEEE Access 2020, 8, 74432-74457.

7. Prabir, D. Offshore Wind Energy in India. MNRE Report April 2019; MNRE: New Dehli, India, 2019. Available online: https://mnre.gov.in/img/documents/uploads/2e423892727a456e93a684f38d8622f7.pdf (accessed on 1 April 2019).

8. Global Wind Energy Council. Global Wind Energy Report April 2019; Global Wind Energy Council: Brussels, Belgium, 2019.

9. Tim, O. Small Wind Site Assessment Guideline; National Renewable Energy Laboratory (NREL) USA Technical Report: Golden, CO, USA, 2015.

10. Kang, D.; Ko, K.; Huh, J. Comparative Study of Different Methods for Estimating Weibull Parameters: A Case Study on Jeju Island, South Korea. Energies 2018, 11, 356. [CrossRef] 
11. Pobočíková, I.; Sedliačková, Z.; Michalková, M. Application of four probability distributions for wind speed modeling. Procedia Eng. 2017, 192, 713-718. [CrossRef]

12. Yilmaz, V.; Heçeli, K.A. Statistical approach to estimate the wind speed distribution: The case of Gelibolu region. Doğuş Üniversitesi Dergisi 2008, 9, 122-132. [CrossRef]

13. Amaya-Martinez, P.A.; Saavedra-Montes, A.J.; Arango-Zuluaga, E.I. A statistical analysis of wind speed distribution models in the Aburrá Valley, Colombia. Ciencia Tecnologia y Futuro 2014, 5, 121-136. [CrossRef]

14. Mohamad, M.A.; Youssef, K.; Hüseyin, C. Assessment of wind energy potential as a power generation source: A case study of eight selected locations in Northern Cyprus. Energies 2018, 11, 2697.

15. Morgan, E.C.; Lackner, M.; Vogel, R.M.; Baise, L.G. Probability distribution for offshore wind speeds. Energy Convers. Manag. 2011, 52, 15-26. [CrossRef]

16. Gómez-Lázaro, E.; Bueso, M.C.; Kessler, M.; Martín-Martínez, S.; Zhang, J.; Hodge, B.M.; Molina-García, A. Probability Density Function Characterization for Aggregated Large-Scale Wind Power Based on Weibull Mixtures. Energies 2016, 9, 91. [CrossRef]

17. Tian, P.C. Estimation of wind energy potential using different probability density functions. Appl. Energy 2011, 88, 1848-1856.

18. Ravindra, K.; Srinivasa, R.R.; Narasimham, S.V.L.; Krishna, M.P. Mixture probability distribution functions to model wind speed distributions. Int. J. Energy Environ. Eng. 2012, 3, 27.

19. Ijjou, T.; Fatima, E.G.; Hassane, B.; Brahim, B. Wind speed distribution modelling for wind power estimation: Case of Agadir in Morocco. Wind Eng. 2019, 43, 190-200.

20. Jianxing, Y.; Yiqin, F.; Yang, Y.; Shibo, W.; Yuanda, W.; Minjie, Y.; Shuai, G.; Mu, L. Assessment of Offshore Wind Characteristics and Wind Energy Potential in Bohai Bay, China. Energies 2019, 12, 2879.

21. Mekalathur, B.H.K.; Saravanan, B.; Padmanaban, S.; Jens, B.H.N. Wind Energy Potential Assessment by Weibull Parameter Estimation Using Multiverse Optimization Method: A Case Study of Tirumala Region in India. Energies 2019, 12, 2158.

22. de Andrade, C.F.; dos Santos, L.F.; Macedo, M.V.S.; Rocha, P.A.C.; Gomes, F.F. Four heuristic optimization algorithms applied to wind energy: Determination of Weibull curve parameters for three Brazilian sites. Int. J. Energy Environ. Eng. 2019, 10, 1-12. [CrossRef]

23. Kasra, M.; Omid, A.; Jon, G.M. Use of Birnbaum-Saunders distribution for estimating wind speed and wind power probability distributions: A review. Energy Convers. Manag. 2017, 143, 109-122.

24. Jaramillo, O.A.; Borja, M.A. Bimodal versus Weibull wind speed distributions an analysis of wind energy potential in La Venta, Mexico. Wind Eng. 2004, 28, 225-234. [CrossRef]

25. Seshaiah, V.; Indhumathy, D. Analysis of Wind Speed at Sulur-A Bimodal Weibull and Weibull Distribution. Int. J. Latest Eng. Manag. Res. 2017, 2, 29-37.

26. Feng, J.L.; Hong, K.; Shyi, K.; Ying, H.; Tian, C. Study on Wind Characteristics Using Bimodal Mixture Weibull Distribution for Three Wind Sites in Taiwan. J. Appl. Sci. Eng. 2014, 17, 283-292.

27. Prem, K.C.; Siraj, A.; Vilas, W. Wind characteristics observation using Doppler-SODAR for wind energy applications. Resour.-Effic. Technol. 2017, 3, 495-505.

28. Wind Power Profile of Tamilnadu State. Indianwindpower.com Web Portal. Available online: http: //indianwindpower.com/pdf/Wind-Power-Profile-of-Tamilnadu-State.pdf (accessed on 21 June 2019).

29. Palaneeswari, T. Wind Power Development in Tamilnadu. Int. J. Res. Soc. Sci. 2018, 8, 661-673.

30. Wind Power Profile of Gujarat State. Indianwindpower.com Web Portal. Available online: http://www. indianwindpower.com/pdf/Gujarat-State-Wind-Power-Profile.pdf. (accessed on 16 April 2018).

31. Seyedali, M. Moth-flame optimization algorithm: A novel nature-inspired heuristic paradigm. Knowl.-Based Syst. 2015, 89, 228-249.

32. Jain, D. Skew and Kurtosis: 2 Important Statistics Terms You Need to Know in Data Science. Codeburst.io Web Portal. Available online: https://codeburst.io/2-important-statistics-terms-you-need-to-know-in-datascience-skewness-and-kurtosis-388fef94eeaa (accessed on 23 August 2018).

33. Hajo, H.; Sebastian, V. A likelihood ratio test for bimodality in two-component mixtures with application regional income distribution in EU. AStA Adv. Stat. Anal. 2008, 92, 57-69.

34. Javad, B. On the Modes of a Mixture of Two Normal Distributions. Technometrics 1970, 12, 131-139.

35. Oh, K.Y.; Kim, J.Y.; Lee, J.K.; Ryu, M.S.; Lee, J.S. An assessment of wind energy potential at the demonstration offshore wind farm in Korea. Energy 2012, 46, 555-563. [CrossRef] 
36. Thirumoorthy, A.D. LVRT Tamilnadu's Experience. Windpro Portal. Available online: http://www.windpro.org/Presentations-Forecasting-and-99+Grid-Availability/JAN-23-2018/session/ A.D.Thirumoorthy---LVRTTaminadu\T1 \textquoterightsExperience.pdf (accessed on 23 January 2018).

37. Munshi, A.A.; Yasser, A.R.M. Big data framework for analytics in smart grids. Electr. Power Syst. Res. 2017, 151, 369-380. [CrossRef] 